\title{
Estimated Bounds on Rock Permeability Changes from THM Processes
}

\author{
Patricia A. Berge \\ Herbert F. Wang \\ Stephen C. Blair
}

August 1998

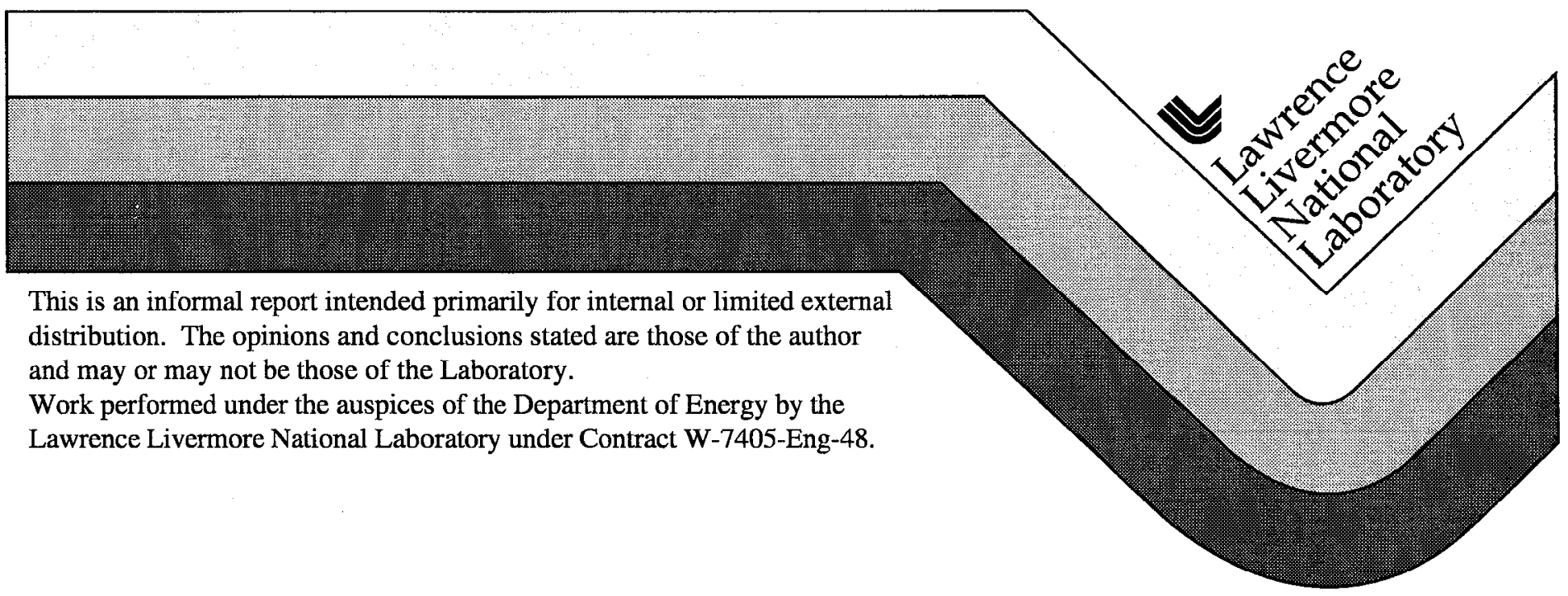




\section{DISCLAIMER}

This document was prepared as an account of work sponsored by an agency of the United States Government. Neither the United States Government nor the University of California nor any of their cmployees, makes any warranty, express or implied, or assumes any legal liability or responsibility for the accuracy, completeness, or usefulness of any information, apparatus, product, or process disclosed, or represents that its use would not infringe privately owned rights. Reference herein to any specific commercial product, process, or service by trade name, trademark, manufacturer, or otherwise, does not necessarily constitute or imply its endorsement, recommendation, or favoring by the United States Government or the University of California. The views and opinions of authors expressed herein do not necessarily state or reflect those of the United States Government or the University of California, and shall not be used for advertising or product endorsement purposes.

This report has been reproduced directly from the best available copy.

Available to DOE and DOE contractors from the

Office of Scientific and Technical Information

P.O. Box 62, Oak Ridge, TN 37831

Prices available from (615) 576-8401, FTS 626-8401

Available to the public from the

National Technical Information Service

U.S. Department of Commerce 5285 Port Royal Rd.

Springfield, VA 22161 


\title{
Estimated Bounds on Rock Permeability Changes from THM Processes
}

\author{
(SPLL35M4) \\ BA0000000-01717-5700-00005
}

by

Patricia A. Berge

Herbert F. Wang

Stephen C. Blair

August 1998

Lawrence Livermore National Laboratory

Livermore, California 



\section{Contents}

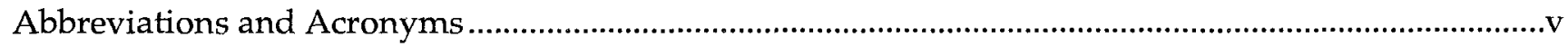

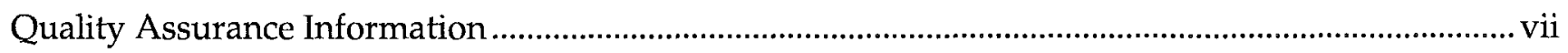

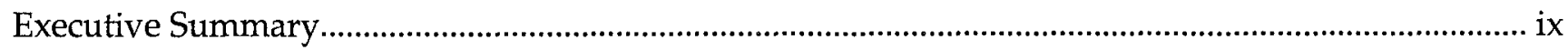

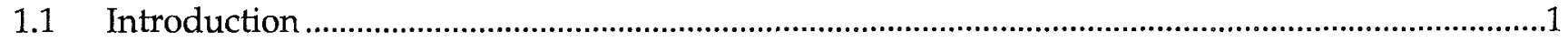

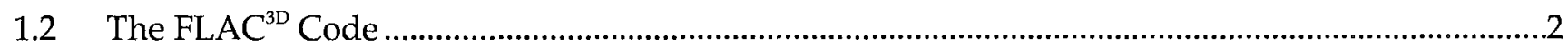

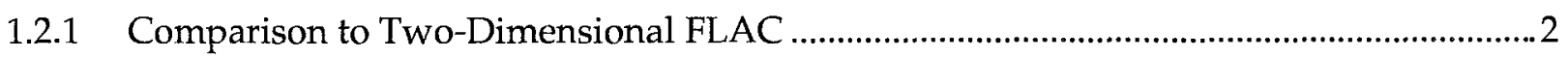

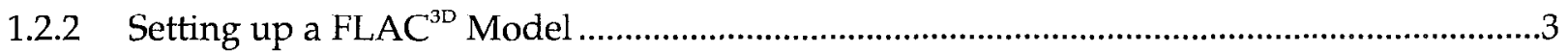

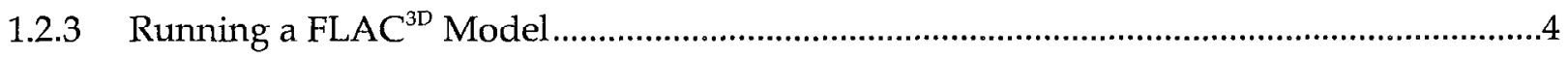

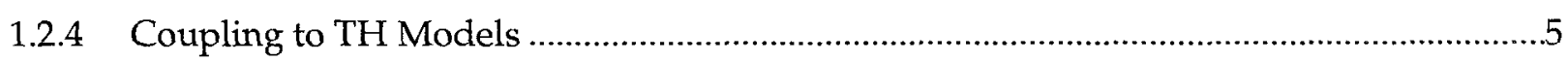

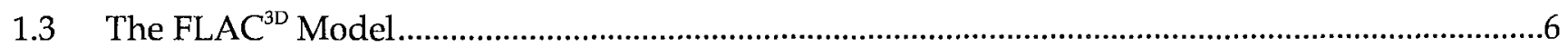

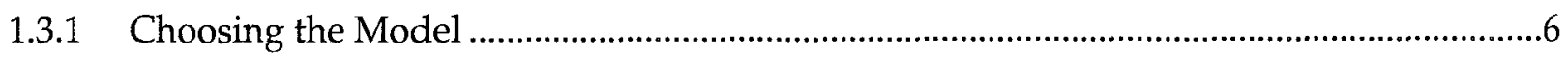

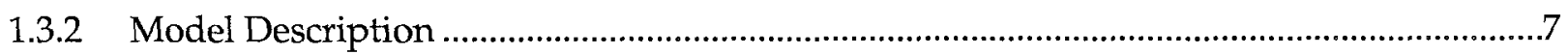

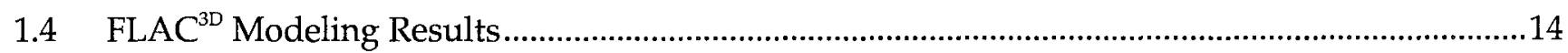

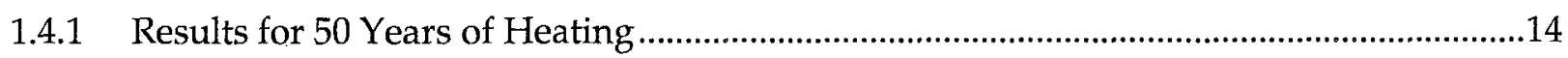

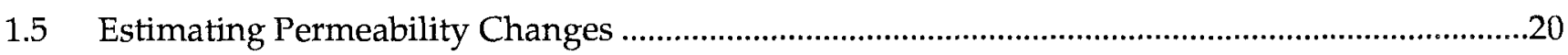

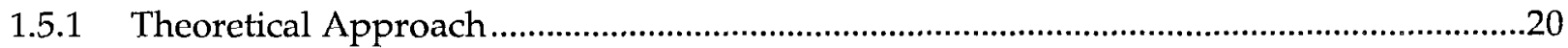

1.5.2 Results from Estimating Changes in Permeability .......................................................24

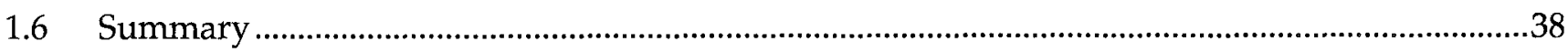

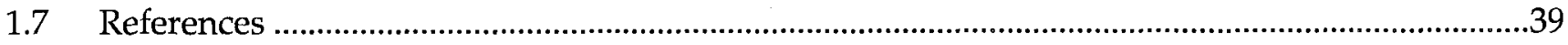

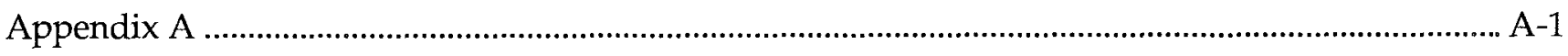

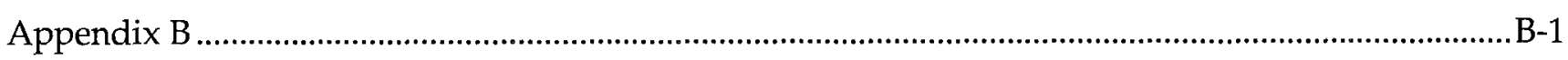

\section{Tables}

Table 1. Rock properties (DTN LL980805704243.023) .......................................................11

Table 2. Mechanical boundary conditions* (DTN LL980805704243.023).................................11

\section{Figures}

Figure 1. Model for 1.5 drifts in 3-D, grid viewed from $\mathrm{XZ}$ side ............................................

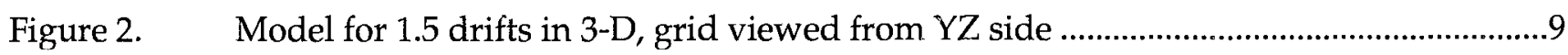


Figure 3. Model for 1.5 drifts in 3-D, model geometry; darkest regions indicate drift locations 10

Figure 4. Model for 1.5 drifts in 3-D, initial stress field for entire model ...................................12

Figure 5. Model for 1.5 drifts in 3-D, initial temperatures ........................................................ 13

Figure 6. Model for 1.5 drifts in 3-D, temperatures after 50 yr of heating ................................... 15

Figure 7. Model for 1.5 drifts in 3-D, stress field after $50 \mathrm{yr}$ of heating, for entire model............ 16

Figure 8. Model for 1.5 drifts in 3-D, stress field after 50 yr of heating, near model center ......... 17

Figure 9. Model for 1.5 drifts in 3-D, total displacement after $50 \mathrm{yr}$ of heating............................18

Figure 10. Illustration of geometry for vertical and horizontal fractures (light lines) cutting $X Z, Y Z$, and $X Y$ planes

Figure 11. Contours of the ratio of shear stress to frictional resistance for slip planes parallel to the $Y Z$ plane and cutting the $X Y$ plane (region about $10 \mathrm{~m}$ above drifts)

Figure 12. Contours of the ratio of shear stress to frictional resistance for slip planes parallel to the $Y Z$ plane and cutting the $X Y$ plane (region at the level of drifts) ..........25

Figure 13. Contours of the ratio of shear stress to frictional resistance for slip planes parallel to the $Y Z$ plane and cutting the $X Y$ plane (region about $10 \mathrm{~m}$ below drifts)

Figure 14. Contours of the ratio of shear stress to frictional resistance for slip planes parallel to the $X Z$ plane and cutting the $X Y$ plane (region about $10 \mathrm{~m}$ above drifts).

Figure 15. Contours of the ratio of shear stress to frictional resistance for slip planes parallel to the $\mathrm{XZ}$ plane and cutting the XY plane (region at the level of drifts). .28

Figure 16. Contours of the ratio of shear stress to frictional resistance for slip planes parallel to the $X Z$ plane and cutting the $X Y$ plane (region about $10 \mathrm{~m}$ below drifts).

Figure 17. Contours of the ratio of shear stress to frictional resistance for slip planes parallel to the $\mathrm{YZ}$ plane and cutting the $\mathrm{XZ}$ plane (region near middle of model) .......30

Figure 18. Contours of the ratio of shear stress to frictional resistance for slip planes parallel to the $X Y$ plane and cutting the $X Z$ plane (region near middle of model) .......31

Figure 19. Contours of the ratio of shear stress to frictional resistance for slip planes parallel to the $\mathrm{XZ}$ plane and cutting the $\mathrm{YZ}$ plane (region midway between drifts)

Figure 20. Contours of the ratio of shear stress to frictional resistance for slip planes parallel to the $\mathrm{XZ}$ plane and cutting the $\mathrm{YZ}$ plane (region near drift).

Figure 21. Contours of the ratio of shear stress to frictional resistance for slip planes parallel to the $X Y$ plane and cutting the $Y Z$ plane (region midway between drifts)

Figure 22. Contours of the ratio of shear stress to frictional resistance for slip planes parallel to the $X Y$ plane and cutting the $Y Z$ plane (region near drift). 35

Figure A1. Model for 1.5 drifts in 3-D, initial stress field near model center A-1

Figure A2. Model for 1.5 drifts in 3-D, initial horizontal stress component sxx, entire model (same as syy) 
Figure A3. Model for 1.5 drifts in 3-D, initial shear stress component syz ............................... A-3

Figure A4. Model for 1.5 drifts in 3-D, initial vertical stress component szz .............................. A-4.

Figure A5. Model for 1.5 drifts in 3-D, horizontal stress component sxx after

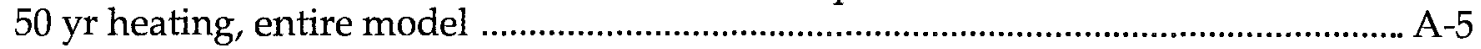

Figure A6. Model for 1.5 drifts in 3-D, horizontal stress component sxx after $50 \mathrm{yr}$ heating, region near middle of model ............................................................... A-6

Figure A7. Model for 1.5 drifts in 3-D, horizontal stress component sxx after 50 yr heating, region about $10 \mathrm{~m}$ above drifts.

Figure A8. Model for 1.5 drifts in 3-D, horizontal stress component sxx after $50 \mathrm{yr}$ heating, region near drifts

Figure A9. Model for 1.5 drifts in 3-D, horizontal stress component sxx after $50 \mathrm{yr}$ heating, region about $10 \mathrm{~m}$ below drifts.....

Figure A10. Model for 1.5 drifts in 3-D, shear stress component sxy after 50 yr heating, entire model.

Figure A11. Model for 1.5 drifts in 3-D, shear stress component sxy after 50 yr heating, region near middle of model.

Figure A12. Model for 1.5 drifts in 3-D, shear stress component sxy after 50 yr heating, region about $10 \mathrm{~m}$ above drifts.....

Figure A13. Model for 1.5 drifts in 3-D, shear stress component sxy after 50 yr heating, region near drifts

Figure A14. Model for 1.5 drifts in 3-D, shear stress component sxy after 50 yr heating, region about $10 \mathrm{~m}$ below drifts.

Figure A15. Model for 1.5 drifts in 3-D, shear stress component sxz after 50 yr heating, entire model.

Figure A16. Model for 1.5 drifts in 3-D, shear stress component sxz after 50 yr heating, region near middle of model.

Figure A17. Model for 1.5 drifts in 3-D, horizontal stress component syy after $50 \mathrm{yr}$ heating, entire model.

Figure A18. Model for 1.5 drifts in 3-D, horizontal stress component syy after 50 yr heating, region near middle of model.

Figure A19. Model for 1.5 drifts in 3-D, horizontal stress component syy after 50 yr heating, region about $10 \mathrm{~m}$ above drifts....

Figure A20. Model for 1.5 drifts in 3-D, horizontal stress component syy after 50 yr heating, region near drifts

Figure A21. Model for 1.5 drifts in 3-D, horizontal stress component syy after 50 yr heating, region about $10 \mathrm{~m}$ below drifts.

Figure A22. Model for 1.5 drifts in 3-D, horizontal stress component syy after 50 yr heating, region midway between drifts....

Figure A23. Model for 1.5 drifts in 3-D, horizontal stress component syy after 50 yr heating, region near drift.

Figure A24. Model for 1.5 drifts in 3-D, shear stress component syz after 50 yr heating, entire model. 
Figure A25. Model for 1.5 drifts in 3-D, shear stress component syz after 50 yr heating, middle of model.

Figure A26. Model for 1.5 drifts in 3-D, shear stress component syz after 50 yr heating, region midway between drifts.

Figure A27. Model for 1.5 drifts in 3-D, shear stress component syz after 50 yr heating, region near drift

Figure A28. Model for 1.5 drifts in 3-D, vertical stress component szz after 50 yr heating, entire model

Figure A29. Model for 1.5 drifts in 3-D, vertical stress component szz after 50 yr heating, region near middle of model

Figure A30. Model for 1.5 drifts in 3-D, vertical stress component szz after 50 yr heating, region midway between drifts

Figure B1. Model for .5 drift in 3-D, grid viewed from XZ direction

Figure B2. Model geometry for model using .5 drift in 3-D; darkest regions indicate drift location.

Figure B3. Fixed boundary condition locations for first case, using applied stresses at top and side boundaries

Figure B4. Fixed boundary condition locations for second case, no applied stresses at boundaries

Figure B5. Initial stress tensor for first case having applied stresses at top and side boundaries, view for entire model.

Figure B6. Initial stress tensor for first case having applied stresses at top and side boundaries, view for region near center of model

Figure B7. Initial stress tensor for second case having fixed boundaries, view for entire model

Figure B8. Initial stress tensor for second case having fixed boundaries, view for region near center of model

Figure B9. Model for .5 drift in 3-D, temperature field after $50 \mathrm{yr}$ of heating.

Figure B10. Stress tensor after $50 \mathrm{yr}$ of heating for first case having applied stresses at top and side boundaries, view for entire model.

Figure B11. Stress tensor after $50 \mathrm{yr}$ of heating for first case having applied stresses at top and side boundaries, view for region near center of model

Figure B12. Displacement vectors at each node of model after $50 \mathrm{yr}$ of heating for first case having applied stresses at top and side boundaries

Figure B13. Stress tensor after 50 yr of heating for second case having fixed boundaries, view for entire model

Figure B14. Stress tensor after $50 \mathrm{yr}$ of heating for second case having fixed boundaries, view for region near center of model

Figure B15. Displacement vectors at each node of model after $50 \mathrm{yr}$ of heating for second case having fixed boundaries

Figure B16. Model for .5 drift in 3-D, total displacement after 50 yr of heating for second case having fixed boundaries 


\section{Abbreviations and Acronyms}

2-D

two-dimensional

3-D

three-dimensional

DTN

data tracking number

ESF

Exploratory Studies Facility

FLAC

Fast Lagrangian Analysis of Continua

GUI

graphical user interface

NFE

near-field environment

NUFT

Nonisothermal Unsaturated-Saturated Flow and Transport

$\mathrm{TH}$ thermohydrologic

THM

thermohydromechanical

TM

thermomechanical

TSPA-VA Total System Performance Assessment-Viability Assessment

UZ unsaturated zone 



\section{Quality Assurance Information}

The following table addresses the acceptance criteria for the Level 4 deliverable Estimated Bounds on Rock Permeability from THM Processes. Table QA-1 is the required "roadmap" that indicates where the criteria are met in this report.

Table QA-1. "Roadmap" table identifying where the deliverable (SPLL35M4) acceptance criteria are met in Estimated Bounds on Rock Permeability from THM Processes

\begin{tabular}{|c|c|c|}
\hline Criteria Description & Section & Comment \\
\hline $\begin{array}{l}\text { Describe updated results of modeling of } \\
\text { processes projected to the near-field } \\
\text { environment (NFE). }\end{array}$ & 1.4 & \\
\hline $\begin{array}{l}\text { Describe model used, including criteria for model } \\
\text { selection. }\end{array}$ & 1.3 & \\
\hline $\begin{array}{l}\text { Describe experimental data used as input to the } \\
\text { model. }\end{array}$ & Table 1 & \\
\hline $\begin{array}{l}\text { Reach conclusions concerning the nature and } \\
\text { occurrence of significant changes in the } \\
\text { permeability in the NFE. }\end{array}$ & 1.5 .2 & \\
\hline $\begin{array}{l}\text { Identify and demonstrate an understanding of the } \\
\text { transient behavior of hydrologic, physical, and } \\
\text { mechanical properties of the near-field region } \\
\text { resulting from thermal-mechanical coupling }\end{array}$ & $\begin{array}{l}1.1 \text { through } \\
1.6\end{array}$ & \\
\hline $\begin{array}{l}\text { Develop and/or apply constitutive models and } \\
\text { numerical codes for analyzing time-dependent } \\
\text { geomechanical behavior of rock in the NFE. }\end{array}$ & $\begin{array}{l}1.1 \text { through } \\
1.6\end{array}$ & \\
\hline $\begin{array}{l}\text { Develop and implement techniques for coupling } \\
\text { of geomechanical and hydrologic codes to } \\
\text { enhance the analysis of field-testing activities.. }\end{array}$ & $\begin{array}{l}1.2 .2,1.2 .4 \\
1.3 .1,1.3 .2\end{array}$ & \\
\hline $\begin{array}{l}\text { Modeling studies will focus on simulation and } \\
\text { assessment of how thermomechanical processes } \\
\text { affect the spatial variability of rock permeability. }\end{array}$ & $\begin{array}{l}1.1 \text { through } \\
1.6\end{array}$ & See, in particular, Section 1.5.2. \\
\hline $\begin{array}{l}\text { Employ a three-dimensional (3-D) model to } \\
\text { evaluate the expected stress/displacement fields } \\
\text { over time. }\end{array}$ & $1.3,1.4$ & \\
\hline $\begin{array}{l}\text { Couple this model with thermohydrologic (TH) } \\
\text { modeling. }\end{array}$ & $\begin{array}{l}1.2 .2,1.2 .4 \\
1.3 .1,1.3 .2\end{array}$ & \\
\hline $\begin{array}{l}\text { Perform two-dimensional (2-D) analysis to guide } \\
\text { and supplement the 3-D simulations. }\end{array}$ & Appendix B & $\begin{array}{l}\text { Used 3-D analysis on simplified model } \\
\text { instead. See also Chapter } 3 \text { of the Near- } \\
\text { Field/Altered-Zone Models Report } \\
\text { (Hardin et al, 1998). }\end{array}$ \\
\hline
\end{tabular}




\begin{tabular}{|c|c|c|}
\hline Criteria Description & Section & Comment \\
\hline $\begin{array}{l}\text { Special attention will be paid to areas where high } \\
\text { shear stresses of displacements are anticipated. } \\
\text { In these areas, fracture patterns mapped in the } \\
\text { Exploratory Studies Facility (ESF) will be used, } \\
\text { along with laboratory and field data, to assess } \\
\text { permeability changes in these areas. }\end{array}$ & 1.5.1.3 & \\
\hline $\begin{array}{l}\text { Every effort will be made to ensure that qualified } \\
\text { data are used in this deliverable. }\end{array}$ & $\begin{array}{c}1.3 .1,1.3 .2 \\
1.5 .1 .3 \\
\end{array}$ & $\begin{array}{l}\text { Data are from Hardin et al. (1998) and } \\
\text { Albin et al. (1997) }\end{array}$ \\
\hline $\begin{array}{l}\text { Record accession numbers and automated } \\
\text { tracking numbers will be included, as appropriate, } \\
\text { for all data used or cited in this deliverable. }\end{array}$ & $\begin{array}{l}1.1 \text { through } \\
1.7\end{array}$ & $\begin{array}{l}\text { Accession numbers are provided in the } \\
\text { reference lists for sources for which they } \\
\text { are available. Data used are identified } \\
\text { with the data-tracking number (DTN) in } \\
\text { citation format within the text. }\end{array}$ \\
\hline
\end{tabular}




\section{Executive Summary}

In this report, we describe current results for modeling geomechanical behavior of the rock in the Near-Field Environment (NFE). The modeling focuses on estimating how thermomechanical (TM) processes affect the spatial variability of fracture permeability. Our results were obtained by a thermohydromechanical (THM) modeling procedure (wherein we use a temperature field computed by a thermohydrologic (TH) code as input for a TM code that finds thermal stresses). These results are needed for modeling changes in repositorylevel moisture movement and thermally induced seepage and for assessment of rock-fall and tunnel-collapse.

For our modeling, we used the TM three-dimensional (3-D) finite-difference code Fast Lagrangian Analysis of Continua 3D $\left(\mathrm{FLAC}^{3 \mathrm{D}}\right)$ to compute changes in stress and displacement in an elastic model subjected to temperature changes over time. Output from TH modeling, using the code Nonisothermal Unsaturated-Saturated Flow and Transport (NUFT), provided the temperature changes for input to FLAC ${ }^{3 \mathrm{D}}$. We then estimated how the stress changes could affect permeability.

Following a technique we developed in previous work for 2-D models, we determined which regions of the 3-D model would experience increases in permeability because of shear slip along fractures having particular orientations. Our technique estimates that the permeability increase would be approximately a factor of two for regions where shear slip could occur along parallel fractures. If slip occurred along two different fracture sets, the permeability could increase by a factor of at least four.

For this report, we chose to base our 3-D THM modeling on a coarser version of the 2-D model we ran for the work described in Chapter 4 of the Near-Field/Altered Zone Models Report (Hardin et al., 1998, Chapter 4). The grid and temperature field were based on those used by the $\mathrm{TH}$ code for $50 \mathrm{yr}$ of heating for the reference Case $1 \mathrm{TH}$ model calculated using Total System Performance Assessment-Viability Assessment (TSPA-VA) base-case properties, nominal infiltration, and a point-load repository design (Hardin et al., 1998, Chapter 3).

The model uses three drifts, centered at a depth of $385 \mathrm{~m}$ in a model extending from 337 $\mathrm{m}$ depth to $431.8 \mathrm{~m}$ depth; because the problem is symmetrical, only 1.5 drifts are actually modeled, and the plane at $X=0.0$ is a symmetry plane. The model, which has 3240 zones, represents the drifts and two tuff units, geological units Tptpll (TH unit tsw36, TM unit TSw2) and Tptpmn (TH unit tsw35, TM unit TSw2).

We began with the model at thermal and mechanical equilibrium and then ran FLAC ${ }^{3 \mathrm{D}}$ to compute stress and displacement changes resulting from temperature changes appropriate for $50 \mathrm{yr}$ of heating. The maximum temperature was about $420^{\circ} \mathrm{K}\left(147^{\circ} \mathrm{C}\right)$ in the center of a drift.

After $50 \mathrm{yr}$ of heating, the stress field rotated in the heater region so that the principal stress directions exhibited a lot of lateral heterogeneity between drifts and below the heaters. The asymmetrical temperature field with large temperature gradients above the heaters produced an asymmetrical stress field with large stress gradients above the heaters, and all the stresses increased significantly up to $20 \mathrm{MPa}$, compared to the initial values near 5 to 10 $\mathrm{MPa}$ in compression before heating. The horizontal stresses increased to about 15 to $20 \mathrm{MPa}$ in compression near the bottom of the model. 
High shear stresses of about $5 \mathrm{MPa}$ were found in the vertical plane midway between the drifts and in the horizontal plane containing the drifts. Note that the previous 2-D FLAC modeling could not compute shear stresses in these directions because these shear stresses are found in planes perpendicular to the plane of the 2-D model.

The displacement had a magnitude of several $\mathrm{cm}$ in the middle of the model, increasing near the top. Most $(5$ to $7 \mathrm{~cm}$ ) of the displacement was in the vertical direction. Horizontal displacements were 1 to $2 \mathrm{~cm}$ for most of the model.

Estimates of permeability changes were obtained by analyzing stresses, following a method we developed previously for 2-D models. Any stress field is considerably more complicated in 3-D than in 2-D. Two rotation angles are required for relating principle stress directions to fracture orientations. In general, the fractures of interest may lie anywhere within the model volume. Calculating and displaying the results for our 3-D model were much more complicated than for the 2-D case used in previous work.

Yet some simplification was possible because most of the fractures of interest in the NFE are likely to be horizontal or vertical. Three main fracture sets have been identified in the Exploratory Studies Facility (ESF):

- Set \#1 is a steeply dipping set of fractures striking east-west (EW).

- Set \#2 is a steeply dipping set of fractures striking north-south (NS).

- Set \#3 is a subhorizontal $(\mathrm{H})$ set of fractures striking east-west.

In our 3-D modeling for this report, we only considered vertical and horizontal fractures. We extended our 2-D method to a simplified 3-D case.

The results show consistently that NS fracture set \#2 is likely to exhibit slip due to thermal stresses, in many parts of the model, and EW fracture set \#1 may have slip in regions just above the drifts, but $\mathrm{H}$ fracture set \#3 is unlikely to have any thermally induced slip. Therefore, we conclude that widespread permeability enhancement is likely for fractures parallel to NS fracture set \#2, the vertical fractures that strike north-south, for regions above the drifts. In some regions just above the drifts, permeability may increase by a factor of at least four if slip also occurs along the vertical fractures in set \#1, the east-west fractures. Note that slip on NS fracture set +2 could not be modeled in the previous 2-D FLAC modeling because these fractures lie in the plane of the 2-D FLAC model rather than intersecting that plane. 


\subsection{Introduction}

This report describes current results for modeling geomechanical behavior of the rock in the Near-Field Environment (NFE). The modeling focuses on estimating how thermomechanical (TM) processes affect the spatial variability of fracture permeability. Our results were obtained by a thermohydromechanical (THM) modeling procedure (i.e., modeling coupled thermohydrologic [TH] and TM processes). These results are needed for modeling changes in repository-level moisture movement and thermally induced seepage and for assessment of rock-fall and tunnel-collapse.

Specifically, we used the TM three-dimensional (3-D) finite-difference code FLAC ${ }^{3 \mathrm{D}}$ version 2.0 (Itasca Consulting Group Inc. 1997) to compute changes in stress and displacement in an elastic model subjected to temperature changes over time. Output from TH modeling (Hardin et al., 1998, Chapter 3) using the code NUFT (Nitao 1993) provided the temperature changes for input to $\mathrm{FLAC}^{3 \mathrm{D}}$. We then estimated how the stress changes could affect permeability.

By using a model based on the work of Barton (Barton et al., 1997; 1995) and the MohrCoulomb criterion (Jaeger and Cook, 1976, p. 399), we determined which regions of the model would experience increases in permeability because of shear slip along fractures having particular orientations. As done in our previous work (Blair et al. 1997) incorporating a model developed by Brown (Brown, 1994; 1995; Brown and Bruhn, 1997), we estimated that the permeability would increase by approximately a factor of two for regions where shear slip could occur along parallel fractures. If slip occurred along two different fracture sets, the permeability could increase by a factor of at least four.

This report is divided into several sections:

- Section 0 on the FLAC ${ }^{3 \mathrm{D}}$ code (Itasca Consulting Group Inc. 1997) describes use and limitations of the code, including input requirements, initial and boundary conditions, output, inherent assumptions, run times, and a description of how temperature output from TH modeling is used as input to FLAC ${ }^{3 \mathrm{D}}$ for coupled THM modeling.

- Section 0 on the FLAC ${ }^{3 D}$ model provides a detailed description of the model used to simulate THM processes in the NFE, including an explanation of how the model was selected, rock properties and temperatures, TM initial and boundary conditions, and model geometry.

- Section 1.4 provides calculated changes in displacement and stress resulting from temperature changes.

- Section 1.5 presents our estimates for permeability changes from thermal stresses and includes subsections describing the theoretical approach and presenting and discussing the results.

- Section 1.6 of this report summarizes our findings.

Because presentation of 3-D modeling results involves too many figures to include within the main body of the report, Appendix A contains additional figures showing stress and displacement results. Appendix B presents results, for a simplified version of the model, of an analysis of the effects of using different types of mechanical boundary conditions. 


\subsection{The FLAC ${ }^{3 \mathrm{D}}$ Code}

\subsubsection{Comparison to Two-Dimensional FLAC}

The code FLAC ${ }^{3 \mathrm{D}}$ (Itasca Consulting Group Inc. 1997) is the 3-D version of FLAC (Itasca Consulting Group Inc. 1996), a finite difference code for Fast Lagrangian Analysis of Continua. This code calculates time-dependent changes in stress and displacement for rocks and sediments due to changes in temperature, mechanical loading, excavation, or various other TM processes encountered in rock mechanics and mining engineering. For the modeling described in this report, we ran FLAC ${ }^{3 \mathrm{~L}}$ version 2.0 (Itasca Consulting Group Inc. 1997) on an Ultra2 Unix workstation with cshell script files to control the runs. FLAC ${ }^{3 \mathrm{D}}$ uses the same type of input, command syntax, and run procedures as does the two-dimensional (2-D) FLAC code (Itasca Consulting Group Inc. 1996) that we used in previous modeling (Blair et al., 1995; 1997; Hardin et al., 1998, Chapter 4). The most significant differences between the 2-D and 3-D versions of FLAC are in the time required for a run, the number of zone elements needed to represent a given problem, and the number of plots generated to display results.

The 3-D modeling is at least an order of magnitude slower than 2-D modeling. Representing a given model in 3-D rather than in 2-D requires many more zone elements. For example, a $10 \mathrm{~m} \times 10 \mathrm{~m}$ model with $1 \mathrm{~m} \times 1 \mathrm{~m}$ zones in 2 -D contains 100 zone elements. The same model in 3-D contains 1000 zone elements. Yet the number of zones in the 3-D model could be reduced by using a coarser model having blocks that were $2 \mathrm{~m}$ on a side; in that case, the total number of zones would be 125 . The number of zones is reduced by an order of magnitude while the resolution is only reduced by a factor of two. This example illustrates why it is not always advisable to preserve the identical resolution when going from 2-D modeling to 3-D modeling. Although the 3-D modeling in this report is based on the 2-D modeling described in earlier work (Hardin et al., 1998, Chapter 4), we used a coarser grid here to keep the run time relatively shorl.

Increased run time in 3-D compared to 2-D is related to the larger number of zones and to the need to calculate three rather than two components for the displacement vector and six rather than three independent components for the stress tensor for each zone. The FLAC ${ }^{3 D}$ run time is proportional to $\mathrm{N}^{4 / 3}$ for a $3-\mathrm{D}$ model having $\mathrm{N}$ zones (Itasca Consulting Group Inc., 1997, p. 3-79). This power is $3 / 2$ for the 2-D version of FLAC (Itasca Consulting Group Inc., 1996, p. 3-123). Thus, increasing the number of zones in a 3-D model from 1000 zones to 2000 zones increases the run time by a factor of approximately 2.5 . Typical FLAC ${ }^{3 D}$ models with about 3000 zones require approximately 30 minutes to run on the Ultra 2 Unix workstation. Comparable 2-D models from our previous work (Blair et al., 1995; 1997; Hardin et al., 1998, Chapter 4) required only a few minutes to run.

In addition to requiring more run time than the 2-D modeling, 3-D modeling can produce many more plots to display the results. For each zone, displacement is calculated in the $X, Y$, and $Z$ directions rather than just in the $X$ and $Y$ directions. The independent components of the stress tensor include sxx, sxy, sxz, syy, syz, and szz rather than just sxx, sxy, and syy (Itasca Consulting Group Inc. 1997). For 2-D modeling, results are plotted in the XY plane. The 3-D results can be plotted in many other planes through the model volume. Although the capability of modeling 3-D problems with a 3-D code improves our understanding of TM response, analyzing 3-D results presents a logistical challenge. Interpretation of the results is 
more easily accomplished by using a graphical user interface (GUI) on a workstation to view results in the 3-D model space, rather than by looking at the results on the inherently 2-D medium of a printed page.

Because the current Unix version of FLAC ${ }^{3 \mathrm{D}}$ does not include a sophisticated GUI, for the modeling described in this report we plotted results in various planes through the $3-\mathrm{D}$ model. The number of plots soon became unwieldy, and we did not include all of them here. We have, however, included a selection of the more important ones in Appendix A to provide the interested reader with additional views of our results.

\subsubsection{Setting up a FLAC ${ }^{3 D}$ Model}

As in 2-D modeling with FLAC, setting up a TM model for FLAC ${ }^{3 D}$ requires defining a grid, setting mechanical and thermal initial and boundary conditions, choosing appropriate constitutive models, and assigning material properties to each zone in the grid.

The grid consists of a continuous set of connected 3-D zones in which zones can have various shapes such as blocks, wedges, cylinders, or pyramids (Itasca Consulting Group Inc., 1997, p. 5-53). Effects of faults or joints can be incorporated by using interfaces between different parts of the grid. Typically, models containing as many as 5000 elements reach a solution state in a few thousand steps (Itasca Consulting Group Inc., 1997, p. 2-41). Accurate results require using an adequate number of grid zones in regions of the model that experience high stress or strain gradients, avoiding large size changes for adjacent zones, and keeping zone aspect ratios close to unity (Itasca Consulting Group Inc., 1997, p. 3-9). Large contrasts in zone sizes will also increase the run time (Itasca Consulting Group Inc., 1997, p. 3-79). Zone aspect ratios of 5:1 or less are recommended (Itasca Consulting Group Inc., 1997, p. 3-79).

For our modeling, we generally used aspect ratios between 1:1 and 4:1 and limited the size contrast between adjacent zones to about a factor of four, based on guidelines developed for 2-D FLAC modeling (Itasca Consulting Group Inc., 1996, p. 3-6). To reduce edge effects, the grid must cover a volume that is significantly larger than the region of interest for the model, particularly if the elastic constitutive model is used (Itasca Consulting Group Inc., 1997, p. 3-38). We generally use a grid that is at least five times larger than the area of interest, again based on guidelines developed for 2-D FLAC modeling (Itasca Consulting Group Inc., 1996, p. 3-43).

Mechanical boundary conditions prescribe stresses or displacements for boundary zones. In our modeling, we generally use a fixed boundary at the bottom of the model and apply appropriate stresses to other boundaries. Fixing a boundary can cause stresses and displacements to be underestimated; stress boundary conditions have the opposite effect (Itasca Consulting Group Inc., 1997, p. 3-38). For thermal calculations, however, thermal stresses can become quite large if boundaries are fixed. We include a test of the effects of using different mechanical boundary conditions in Appendix B. (The test results are discussed later in this report.)

Mechanical initial conditions represent the initial displacements and stresses in each zone of the model. Usually initial displacements are zero, and in situ stress values (e.g., lithostatic stress for szz) are assigned for the initial stresses. Both boundary conditions and initial conditions can include stress gradients, and the effects of gravity can be included (Itasca Consulting Group Inc., 1997, p. 3-40). If gravity is not included, at least three points of the grid must be fixed in space (Itasca Consulting Group Inc., 1997, p. 3-82). 
Thermal boundary conditions for FLAC ${ }^{3 \mathrm{D}}$ generally represent either the temperature at the boundary or the component of the heat flux vector normal to the boundary (Itasca Consulting Group Inc., 1997, p. J-4). Boundaries can be convective or insulated as well, and boundaries are adiabatic by default (Itasca Consulting Group Inc., 1997, p. J-4). Initial temperatures can be assigned to represent the initial thermal conditions in the model.

Available constitutive models for mechanical behavior of $\mathrm{FLAC}^{3 \mathrm{D}}$ grid zones include a null model for stress-free zones such as excavations, an isotropic elastic model, two anisotropic elastic models, and six models for various kinds of plastic behavior (Itasca Consulting Group Inc., 1997, p. 3-54). Only two thermal-material models are available for FLAC $^{3 \mathrm{D}}$ : isotropic conduction and a null model (Itasca Consulting Group Inc., 1997, p. J-1). The thermal-material models may be combined with any of the mechanical constitutive models.

To simplify the modeling and to maximize stress estimates (e.g., Itasca Consulting Group nc., 1997, p. 3-38), we represented mechanical behavior by using the isotropic elastic constitutive law rather than one of the plasticity models. 'I'hus, we need only three material properties to describe the mechanical behavior in each zone (i.e., the bulk modulus, the shear modulus, and the density) (Itasca Consulting Group Inc., 1997, pp. 3-61 and 3-84). Note that large contrasts in bulk modulus in zone materials increase the run time (Itasca Consulting Group Inc., 1997, p. 3-79). The thermal properties required by the isotropic conduction model are the specific heat, the thermal conductivity, and the thermal expansion coefficient (Itasca Consulting Group Inc., 1997, p. J-19). Note that FLAC ${ }^{3 \mathrm{D}}$ uses the specific heat and thermal conductivity to find the thermal diffusivity, and the thermal expansion coefficient is used to compute thermal stresses. (The thermal diffusivity is not used in our modeling because we input a temperature field computed by the TH code NUFT instead of allowing FLAC ${ }^{3 \mathrm{D}}$ to compute the temperatures.)

\subsubsection{Running a FLAC ${ }^{3 D}$ Model}

After the grid, boundary conditions, and material properties have been set up, the model must be brought to initial mechanical equilibrium by running FLAC $^{3 \mathrm{D}}$ in the mechanical mode until the magnitude of the largest unbalanced force is small (e.g., the default is five orders of magnitude smaller) compared to the applied forces in the model (Itasca Consulting Group Inc., 1997, p. 3-80). This procedure typically requires several thousand steps (Itasca Consulting Group Inc., 1997, p. 2-41) for models having as many as 5000 zones. If the maximum unbalanced force is allowed to be three or four orders of magnitude smaller than the applied forces (i.e., $0.01 \%$ to $0.1 \%$ ), only about half as many steps are needed, and the run time is reduced by about half.

Next, FLAC ${ }^{3 D}$ is run in the thermal mode to assign initial temperatures and to apply the thermal boundary conditions. The model is brought to initial thermal equilibrium. (Typically this takes only a few-10 to 100 -thermal steps.) The model must again be brought to mechanical equilibrium after the initial temperatures are set. Typically this takes only a few hundred mechanical steps. Displacements can be initialized to zero when the model has reached mechanical equilibrium.

At this point, thermal or mechanical changes can be made (e.g., applying a new temperature field or excavating some zones), and FLAC ${ }^{3 \mathrm{D}}$ can be stepped to a new equilibrium while computing changes in stress and displacement caused by the thermal or mechanical changes. Several thousand mechanical steps may be required, and the run time may be fairly long. 
Note that the TM coupling is only one-way. Temperature changes cause thermal strains that influence the stress field, but the mechanical changes do not change the temperatures in the model (Itasca Consulting Group Inc., 1997, p. J-14).

The time scales are very different for the thermal and the mechanical processes. A mechanical time step is proportional to the ratio of the characteristic length for a zone edge (typically about $1 \mathrm{~m}$ for our models) to the sonic velocity in a zone (typically hundreds of $\mathrm{m} / \mathrm{s}$ for soils or a few $\mathrm{km} / \mathrm{s}$ for rocks), while a thermal time step is proportional to the ratio of the area of a typical zone face ( 1 to $10 \mathrm{~m}^{2}$ for our models) to the thermal diffusivity (typically $10^{-6} \mathrm{~m}^{2} / \mathrm{s}$ for rocks) (Itasca Consulting Group Inc., 1997, pp. J-13 through J-14). Thus, a thermal time step is at least five orders of magnitude larger than a mechanical time step. Mechanical effects can be assumed to occur instantly, in FLAC ${ }^{3 \mathrm{D}}$.

The main output from the FLAC ${ }^{3 \mathrm{D}}$ calculations includes the final temperature field, stress field, and displacements at all nodes in the model.

\subsubsection{Coupling to TH Models}

The FLAC ${ }^{3 D}$ code allows the application of point sources at grid nodes or the application of volume heat sources in zones (Itasca Consulting Group Inc., 1997, pp. J-16 and J-17) for TM modeling. Alternatively, heating can be modeled by assigning new temperatures to each zone and then running FLAC ${ }^{3 \mathrm{D}}$ in the mechanical mode to compute the resulting thermal stresses. We used this procedure in previous 2-D FLAC modeling (Hardin et al., 1998, Chapter 4) to take advantage of the sophisticated capabilities that the TH NUFT code (Nitao 1993) has for calculating temperature fields in the NFE. We can perform coupled THM modeling by using NUFT grids and temperature fields as input to FLAC ${ }^{3 \mathrm{D}}$. This is one-way coupling that can be extended if mechanical modeling results, such as our estimates for permeability changes, are later used as input for TH models.

The TH code NUFT is descried in detail by Nitao (1993; 1995). This code is an integrated suite of numerical models for flow and transport in porous media. It can model multiphase flow in both the vadose zone and the saturated zone, and heat transfer by mass advection, diffusion, and thermal conduction also can be modeled. Complex processes such as drying and rewetting are accommodated by the dynamic switching of primary variables that NUFT is capable of performing. The highly sophisticated temperature calculations from NUFT are preferred to using the simple thermal modeling of the mechanical code FLAC $^{3 \mathrm{D}}$ for computing the temperature. 


\subsection{The FLAC ${ }^{3 \mathrm{D}}$ Model}

\subsubsection{Choosing the Model}

We compared and discussed the capabilities of various geomechanics modeling codes in Berge et al. (Berge et al. 1997). The code ABAQUS (Hibbitt 1994) is another 3-D continuum code that we could have used for the modeling described in this report. We used FLAC ${ }^{3 D}$ rather than ABAQUS to simplify comparisons to our previous 2-D modeling with FLAC. ABAQUS is expected to provide results that do not differ greatly from those of FLAC ${ }^{3 D}$ (e.g., Blair et al. [1995]) because both are continuum codes. An alternative approach would be to use a discrete-element code such as 3DEC (Hart and Cundall 1992). A comparison of results from a discrete-element code would be useful but is beyond the scope of this report. (For an example of a 2-D modeling comparison, see Damjanac (1998).)

Our previous TM modeling of the NFE focused mainly on 2-D modeling (e.g., Blair et al., 1995; 1997; Hardin et al., 1998, Chapter 4). While developing the technique for coupling the TM modeling to TH modeling (Hardin et al., 1998, Chapter 4) using NUFT grids and temperature fields (Hardin et al., 1998, Chapter 3), we found that such modeling allows us to represent important features of the stress field that could not be modeled by FLAC alone. The asymmetrical temperature fields calculated by NUFT (Hardin et al., 1998, Chapter 3) can be used as input to FLAC (Hardin et al., 1998, Chapter 4), whereas the thermal sources in FLAC would only produce symmetrical temperature fields that oversimplify the NFE (e.g., Blair et al., 1997). This has significant implications for the computed stresses because the temperature gradient produces the thermal stress gradient. Therefore, clearly we need to use NUFT temperature fields as input for mechanical models where possible. This was one important criterion for choosing the 3-D model.

The main drawback for using NUFT temperature fields for mechanical models is that this procedure limits the FLAC grid to be a grid based on the NUFT grid. This is problematic if complicated gridding, such as representation of a circular drift within layered strata, is required in the model. The TH models use rectangular shapes for the drifts (Hardin et al., 1998, Chapter 3); in mechanical models, however, corners cause stress concentrations and produce artifacts within one or two drift diameters of the drift region (Blair et al. 1997). Circular drifts are more realistic (Hardin et al., 1998, Chapter 4) but require complicated gridding to avoid large changes in the sizes of adjacent grid zoncs. Most mechanical modeling codes include sophisticated grid generators to avoid problems with representing circular excavations in layered models (e.g., Itasca Consulting Group Inc., 1996; 1997). This is particularly important in complicated 3-D geometries, where drifts are cylinders that must be fit next to block-shaped zones without causing any zones to have high aspect ratios. Considering the trade-off between using the NUFT grid or using the FLAC ${ }^{3 \mathrm{D}}$ grid-generator at the expense of accurate temperatures, we chose to represent drifts as rectangular prisms within a model having block-shaped zones based on a NUFT grid. For future modeling, we may be able to overcome the gridding problem by developing a preprocessor for FLAC ${ }^{3 \mathrm{D}}$ to accommodate both NUFT output and FLAC ${ }^{3 \mathrm{D}}$ gridding.

We also needed to be able to use the technique that we developed for estimating permeability changes due to stress changes (Blair et al., 1997; Hardin et al., 1998, Chapter 4) and to extend this technique to three dimensions. The extension is not completely straightforward because it involves computing ratios of shear and normal stress components for fractures dipping at various angles. In two dimensions, the stress field only has three independent components, and all the fractures are normal to the plane of the model. In three 
dimensions, the stress field has six independent components, and the fractures can have any orientation within the volume of the model. Obviously, to extend our technique from two to three dimensions, we need to make some simplifying assumptions. These assumptions will be discussed in a later section of this report.

We wanted to base our 3-D modeling on a problem that we had already run in 2-D so we could simplify the procedure for interpreting our results and so we could assess the benefits of performing 3-D modeling. The main limitation for this criterion is that our previous models used several thousand zones in 2-D and typically had zone dimensions varying from 0.5 to $10 \mathrm{~m}$ (e.g., Blair et al., 1997). Although, in 2-D, such zone sizes do not present a problem for zone areas varying too much or zone aspect ratios becoming too high, adding a third dimension at the same resolution requires far too many zones (at least 10,000) and causes zone volumes to vary by 3 or 4 orders of magnitude. The accuracy is impacted if zone volumes vary too much or aspect ratios become too high. The best way to avoid these problems would be to use a coarser grid in the 3-D modeling than we used for the 2-D modeling, and to model a relatively simple problem that does not include any complicated geometry such as wing heaters (e.g., Blair et al., 1997) or interfaces representing fractures (e.g., Blair et al., 1995).

After considering all these points, we chose to base our 3-D modeling on a coarser version of the 2-D model we ran for the work described in Chapter 4 of the Near-Field/Altered Zone Models Report (Hardin et al., 1998, Chapter 4). We assumed that the model extended in a third dimension along the drift axis but had no variation in rock properties or temperatures in that direction, so that the 2-D grid and temperature field could be translated to 3-D in a straightforward manner. We would not expect to see variation in temperatures or rock properties along that third direction in a homogeneous 3-D model; thus we are taking advantage of the symmetry and using the 2-D temperature field to represent the temperatures in any cross section normal to the drift axis. The model is described in detail in the following section.

\subsubsection{Model Description}

The grid we used in our 3-D modeling was based on the NUFT grid used in previous 2-D 'IHM modeling (Hardin et al., 1998, Chapter 4), for the reference Case 1 TH model calculated using Total System Performance Assessment-Viability Assessment (TSPA-VA) base-case properties, nominal infiltration, and a point-load repository design (Hardin et al., 1998, Chapter 3). The 2-D grid had smaller zones with dimensions between 0.5 and $2.5 \mathrm{~m}$, except at the extreme edges of the model, for a total of 5775 zones in the 2-D FLAC model (Hardin et al., 1998, Chapter 4). The 2-D model extended from a depth of $300 \mathrm{~m}$ to $470 \mathrm{~m}$ and was $98 \mathrm{~m}$ wide, with a drift spacing of $28 \mathrm{~m}$ (Hardin et al., 1998, Chapter 4). The 2-D model contained 3.5 drifts and had a symmetry plane at $X=0.0$ (Hardin et al., 1998, Chapter 4). The drifts had circular cross sections in the 2-D model with $5.1 \mathrm{~m}$ diameters, and drifts were centered at a depth of $385 \mathrm{~m}$ (Hardin et al., 1998, Chapter 4).

Our 3-D grid, shown in Figure 1 and Figure 2, is coarser. It does not contain any zones smaller than $2 \mathrm{~m}$ across, and it represents the drifts as having 4-m-wide square rather than circular cross sections. The model uses three drifts; because the problem is symmetrical, only 1.5 drifts are actually modeled, and the plane at $X=0.0$ is a symmetry plane. The drifts are centered at a depth of $385 \mathrm{~m}$ in a model extending from $337 \mathrm{~m}$ depth ( $Z=94.8)$ to $431.8 \mathrm{~m}$ depth $(Z=0.0)$. The model extends from the symmetry axis out to $50.0 \mathrm{~m}$ in the $X$ direction. Drifts extend $96.0 \mathrm{~m}$ in the $Y$ direction. This model has 3240 zones with 15 in the $X$ direction, 12 in the $\mathrm{Y}$ direction, and 18 in the $\mathrm{Z}$ direction. All zones are $8 \mathrm{~m}$ across in the $\mathrm{Y}$ direction, and 
there is no lateral variation in properties, stresses, or temperatures in the $Y$ direction. The model does not extend as far in the $X$ and $Z$ directions as did the 2-D model; to keep the number of zones from becoming too large, it does not contain as many drifts. The region of interest is considered to be about $20 \mathrm{~m}$ wide; therefore, it is reasonable to have the model be about $100 \mathrm{~m}$ wide.

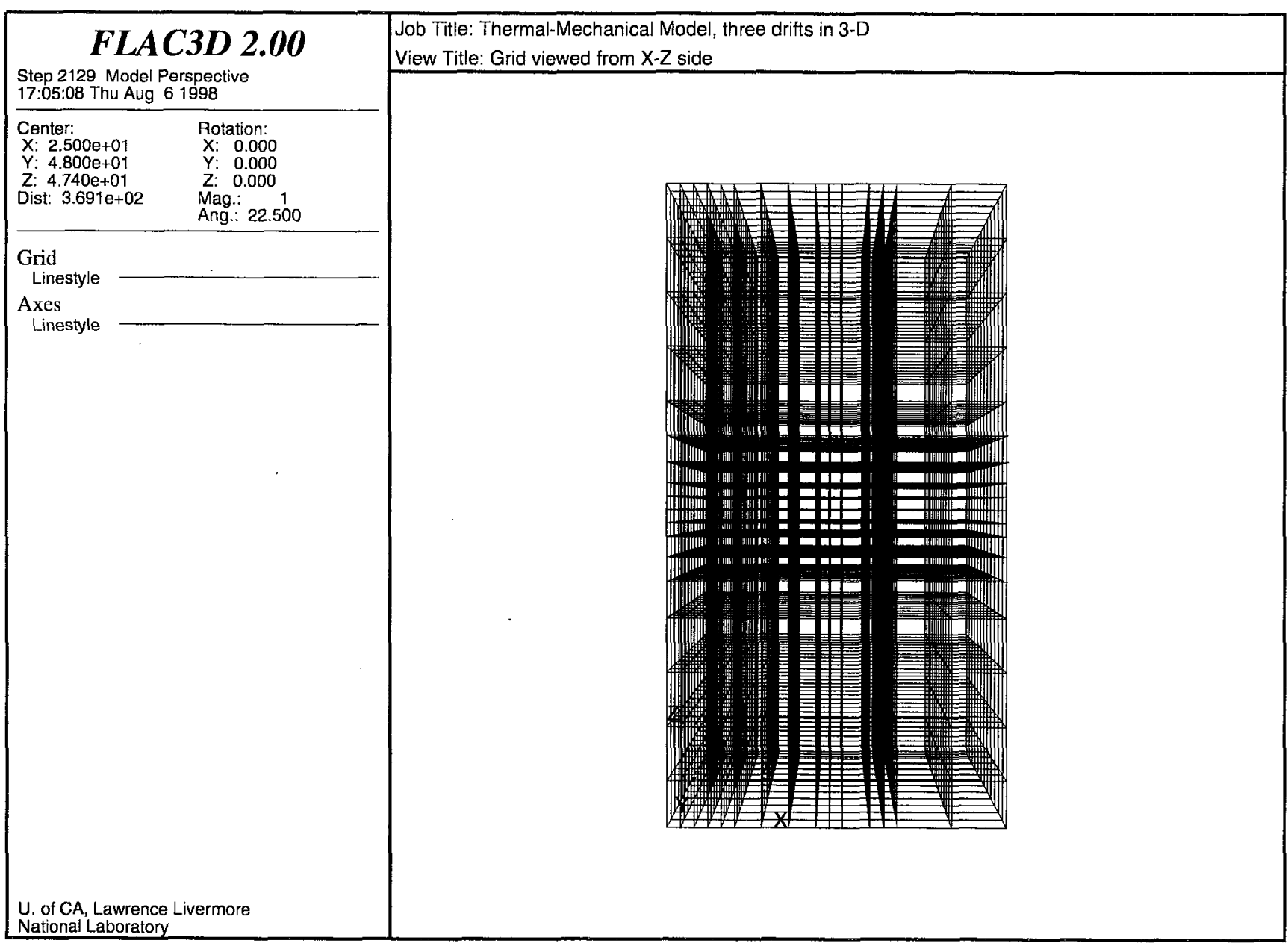

Figure 1. Model for 1.5 drifts in 3-D, grid viewed from $\mathrm{XZ}$ side (DTN LL980805604243.023) 


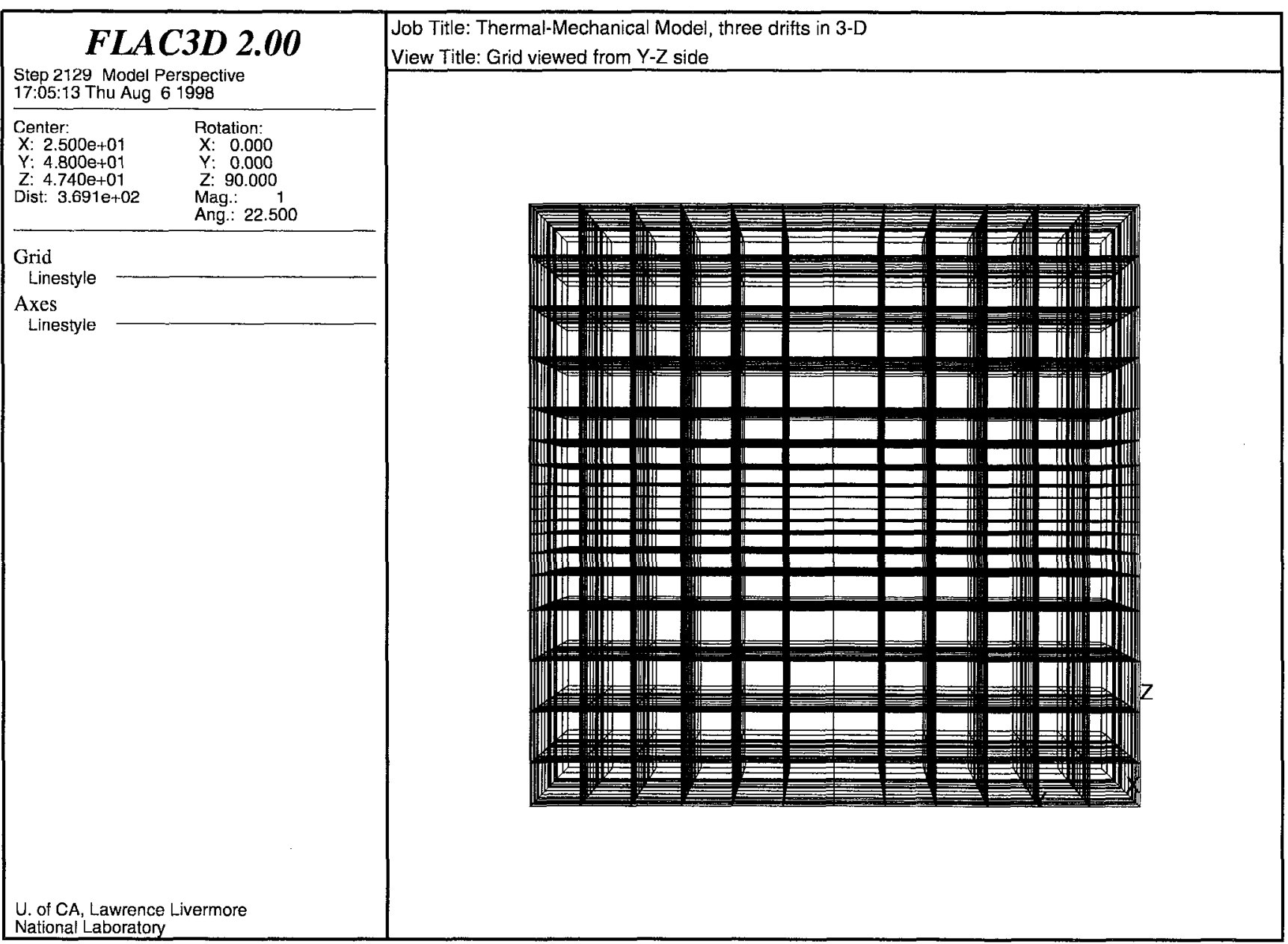

Figure 2. Model for 1.5 drifts in 3-D, grid viewed from YZ side (DTN LL980805604243.023)

The model geometry is shown in Figure 3. To maximize stresses and to reduce the number of required rock properties to the simplest case, the elastic-isotropic constilutive model was used in all zones. We represent two tuff units and the drifts in this model. There is a contact between the two tuff units at a depth of $395.6 \mathrm{~m}(\mathrm{Z}=36.2 \mathrm{~m})$. The two geological units are Tptpll (TH unit tsw36, TM unit TSw2) and Tptpmn (TH unit tsw35, TM unit TSw2) (Hardin et al. 1998). The model properties used for the tuff were the same as those used in the 2-D modeling (Hardin et al., 1998, Chapter 4) and are consistent with the unsaturated zone (UZ) site-scale model (Bodvarsson and Bandurraga 1996; Bodvarsson et al. 1997).

The values listed for the bulk and shear moduli for the tuff units in Table 1 were calculated from available Young's modulus and Poisson's ratio data (Bodvarsson and Bandurraga 1996; Bodvarsson et al. 1997). The Poisson's ratios are reported to be about 0.21 , with standard deviations of as much as 0.06 . The Young's moduli have very large standard deviations and thus have a greater effect on values for bulk and shear moduli. The moduli values listed in Table 1 have uncertainties of approximately \pm 3 to 4 GPa because of the large uncertainties in Young's modulus. Using different values for the bulk and shear moduli would not greatly affect our main results in this report. The results are much more sensitive to the thermal expansion coefficient, which is known to vary with temperature by a factor of 3 or 4 (Bodvarsson and Bandurraga 1996; Bodvarsson et al. 1997). For this report, we used a 
thermal expansion coefficient appropriate for temperatures of about $25^{\circ} \mathrm{C}\left(298^{\circ} \mathrm{K}\right)$ to $175^{\circ} \mathrm{C}$ $\left(448^{\circ} \mathrm{K}\right)$ (Bodvarsson and Bandurraga 1996; Bodvarsson et al. 1997). Future modeling will include parameter sensitivity studies for the thermal expansion coefficient.

For the drift, we simplified the properties by assuming that the entire drift contained unconsolidated rock fragments with bulk and shear moduli values about half as large as those used for tuff and having a slightly lower density. The thermal properties used for the drift material were the same as those used for the tuff unit containing the drifts. All the model properties are presented in Table 1 . Note that the thermal conductivity and specific heat are not actually used in the FLAC ${ }^{3 \mathrm{D}}$ modeling because the temperature field is computed by the NUFT code (Hardin et al., 1998, Chapter 3 ) instead of by FLAC ${ }^{3 \mathrm{D}}$. The values for thermal conductivity and specific heat listed in Table 1 were those used by NUFT for tsw35 and tsw36. Only the thermal expansion coefficient is used, and the value set for the drifts is the same as that used for the tuffs so that there is no discontinuity across drift boundaries. This and the relatively small contrast in mechanical properties were intended to minimize stress concentrations caused by using square rather than circular cross sections for the drifts.

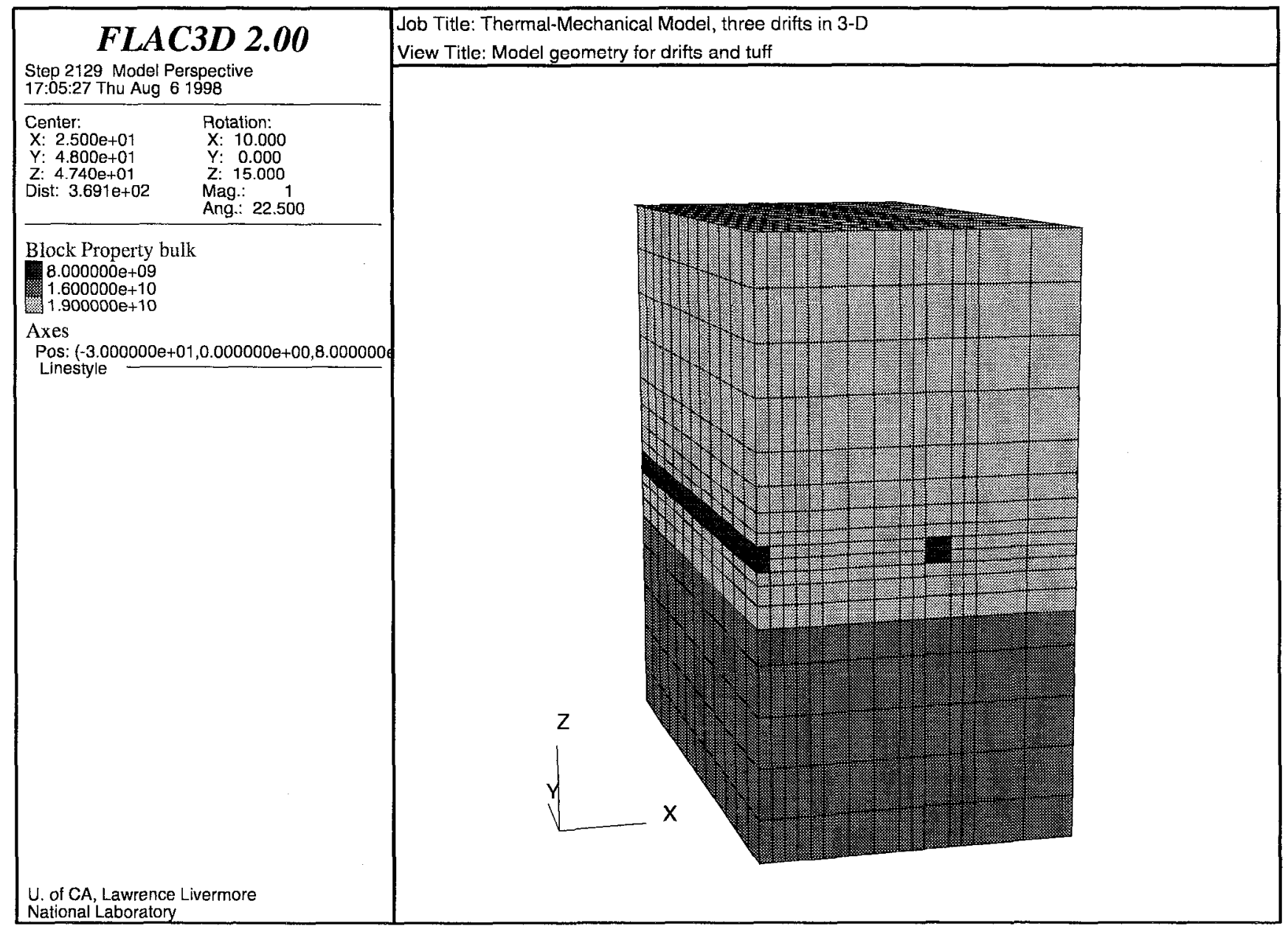

Figure 3. Model for 1.5 drifts in 3-D, model geometry; darkest regions indicate drift locations (DTN LL980805604243.023) 
Table 1. Rock properties (DTN LL980805704243.023)

\begin{tabular}{|l|c|c|c|c|c|c|}
\hline Unit & $\begin{array}{c}\text { Bulk } \\
\text { Modulus } \\
(\mathbf{G P a})\end{array}$ & $\begin{array}{c}\text { Shear } \\
\text { Modulus } \\
(\mathbf{G P a})\end{array}$ & $\begin{array}{c}\text { Density } \\
\left(\mathbf{k g} / \mathbf{m}^{\mathbf{3}}\right)\end{array}$ & $\begin{array}{c}\text { Thermal } \\
\text { Conductivity } \\
\left(\mathbf{w} / \mathbf{m}-{ }^{\circ} \mathbf{K}\right)\end{array}$ & $\begin{array}{c}\text { Specific Heat } \\
\left(\mathbf{J} / \mathbf{k g}-{ }^{\circ} \mathbf{K}\right)\end{array}$ & $\begin{array}{c}\text { Thermal Expansion } \\
\text { Coefficient }^{\left({ }^{\circ} \mathbf{K}\right)^{-1}}\end{array}$ \\
\hline \hline Tptpmn & 19. & 14. & 2300. & 1.2 & 900. & $10 . \times 10^{-6}$ \\
\hline Tptpll & 16. & 11. & 2300. & 1.4 & 870. & $10 . \times 10^{-6}$ \\
\hline Drifts & 8. & 6. & 2000. & 1.2 & 900. & $10 . \times 10^{-6}$ \\
\hline
\end{tabular}

For the mechanical initial and boundary conditions, we fixed the bottom of the model in all directions and fixed the symmetry plane in the $X$ direction. We applied a lithostatic szz stress to the top of the model and applied horizontal stresses sxx and syy about half as large to the sides of the model. This corresponds to an assumption of a Poisson's ratio of 1/3, which may be slightly high, but is not expected to affect our results significantly and is certainly correct to the first order. We used a gravitational gradient for all applied stresses and set initial stresses in all zones to be in equilibrium with these applied stresses. The mechanical boundary and initial conditions are summarized in Table 2 . These stress values are in agreement with those used in our previous 2-D modeling (Hardin et al., 1998, Chapter 4) and also are consistent with available in situ stress data (Stock et al., 1984; 1985). The initial stress field used for our model is shown in Figure 4. Additional views of the 3-D initial stress field are included in Appendix A. Note that initial shear stresses are very small: less than 0.01 $\mathrm{MPa}$ (syz plot in Appendix A).

Table 2. Mechanical boundary conditions* (DTN LL980805704243.023)

\begin{tabular}{|c|c|}
\hline Boundary Location & Condition \\
\hline$X=0.0 \mathrm{~m}$ & Symmetry plane, fixed in $\mathrm{X}$ direction \\
\hline$X=50.0 \mathrm{~m}$ & $\begin{array}{l}\text { sxx }=4.85 \mathrm{MPa} \text { in compression applied near top of model, with vertical gradient } \\
\text { of } 0.0115 \mathrm{MPa} / \mathrm{m}\end{array}$ \\
\hline$Y=0.0 \mathrm{~m}$ & $\begin{array}{l}\text { syy }=4.85 \mathrm{MPa} \text { in compression applied near top of model, with vertical gradient } \\
\text { of } 0.0115 \mathrm{MPa} / \mathrm{m}\end{array}$ \\
\hline$Y=96.0 \mathrm{~m}$ & $\begin{array}{l}\text { syy }=4.85 \mathrm{MPa} \text { in compression applied near top of model, with vertical gradient } \\
\text { of } 0.0115 \mathrm{MPa} / \mathrm{m}\end{array}$ \\
\hline $\mathrm{Z}=0.0 \mathrm{~m}$ & Fixed in $X, Y, Z$ at bottom of model (431.8 $\mathrm{m}$ depth) \\
\hline$Z=94.8 \mathrm{~m}$ & $\mathrm{szz}=7.6 \mathrm{MPa}$ in compression applied at top of model (337.0 m depth) \\
\hline
\end{tabular}




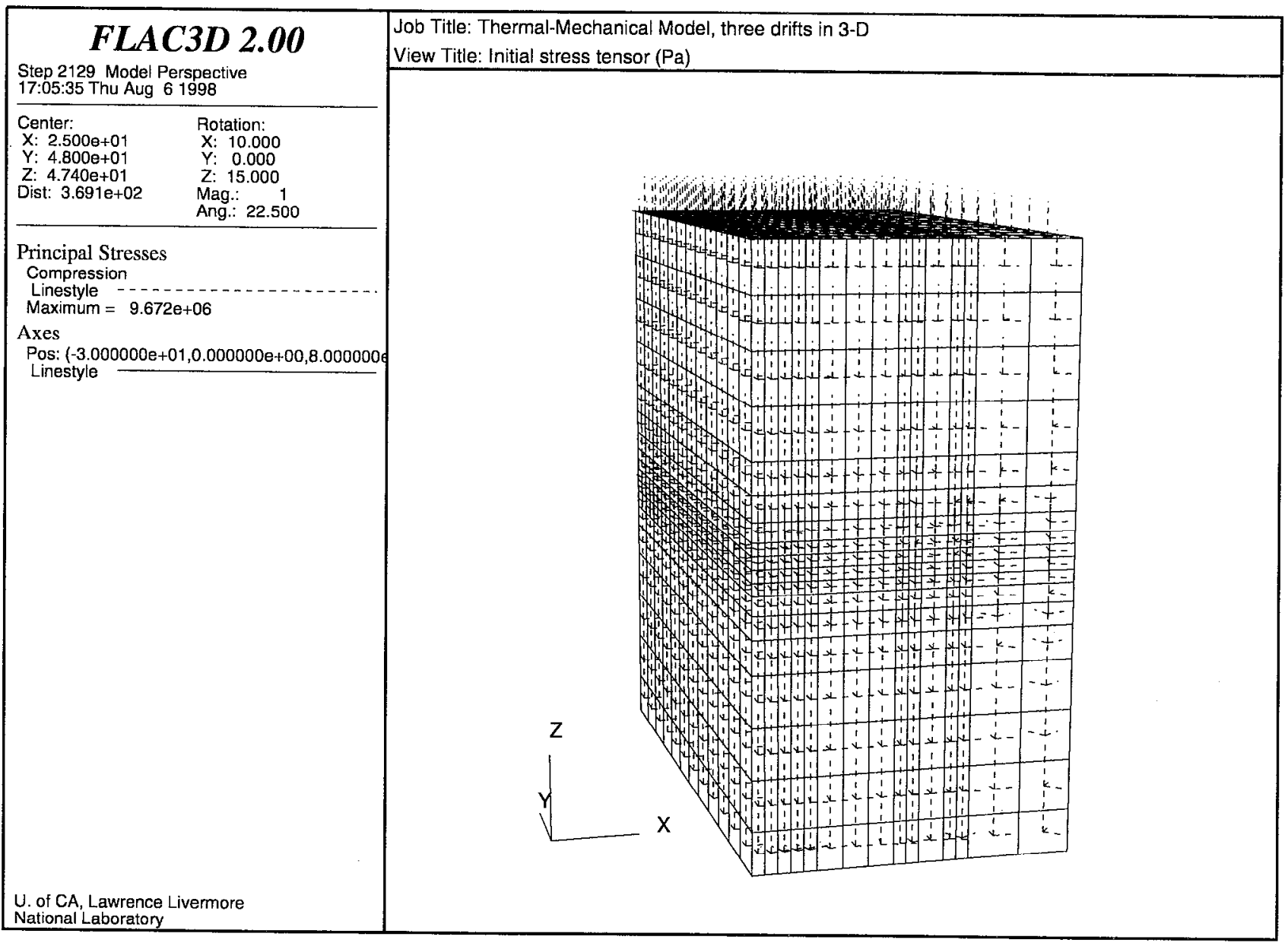

Figure 4. Model for 1.5 drifts in 3-D, initial stress field for entire model (DTN LL980805604243.023)

We allowed all the exterior boundaries of the model to be adiabatic, including the symmetry plane boundary at $X=0$. We used an initial temperature field with values of approximately $298^{\circ} \mathrm{K}\left(25^{\circ} \mathrm{C}\right)$ at the top of the model and about $299^{\circ} \mathrm{K}\left(26^{\circ} \mathrm{C}\right)$ at the bottom of the model, in agreement with temperatures used in our 2-D modeling (Hardin et al., 1998, Chapter 4). These temperatures came from the initial temperatures used in NUFT modeling (Hardin et al., 1998, Chapter 3), which set the surface temperature at $15.8^{\circ} \mathrm{C}$ and used a temperature of $34.6^{\circ} \mathrm{C}$ at a depth of $728.7 \mathrm{~m}$ at the water table. Figure 5 shows our initial temperature field. 


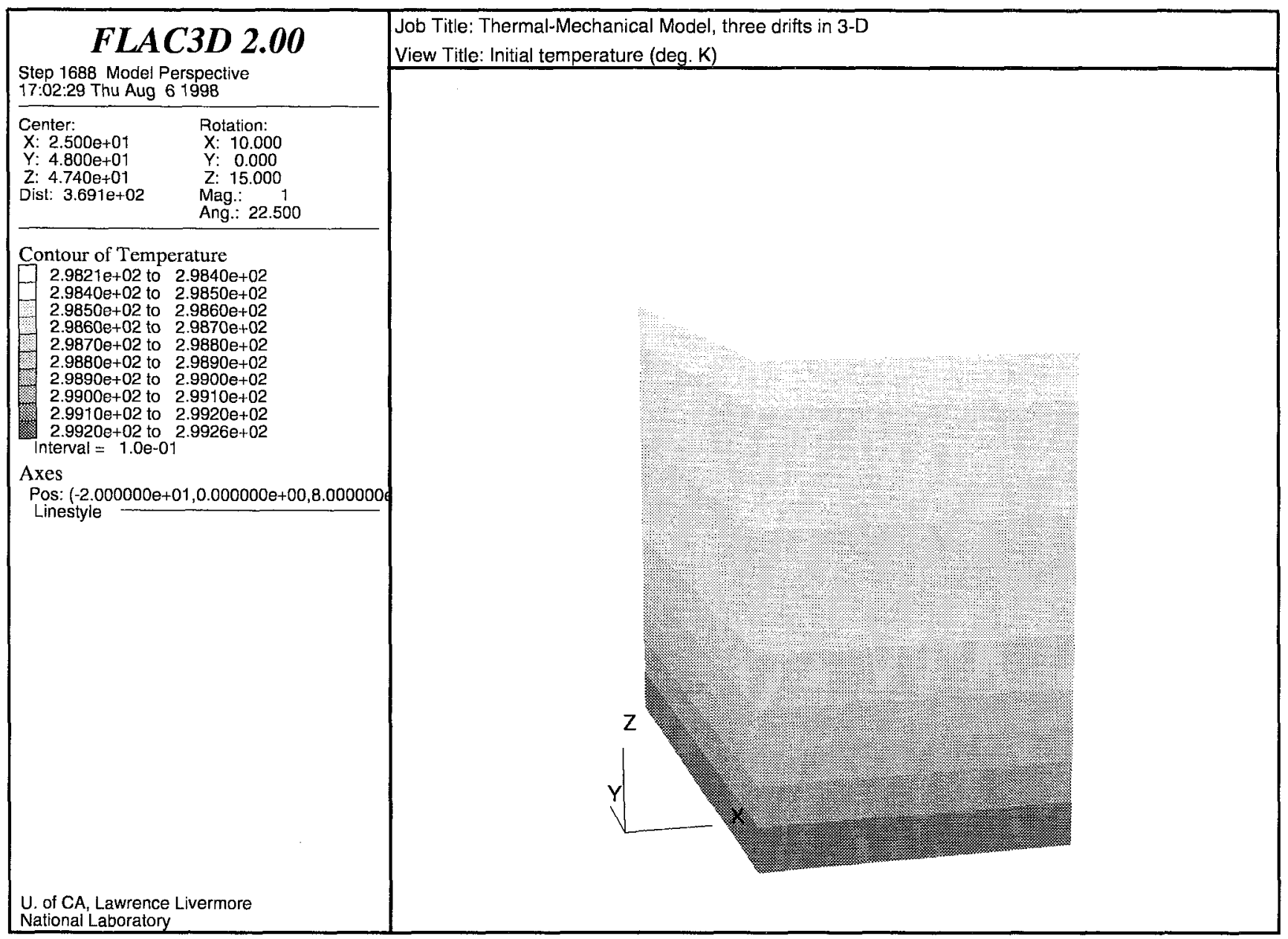

Figure 5. Model for 1.5 drifts in 3-D, initial temperatures (DTN LL980805604243.023)

We began our THM modeling by setting up the grid and assigning material properties and initial and boundary conditions, and then brought the model to initial mechanical equilibrium. This required about 1700 steps and about 6 minutes of computer time on the Ultra 2. We then read in the initial temperature field and ran $F_{L A C}{ }^{3 \mathrm{D}}$ in the thermal mode for 30 steps (a few seconds) to bring the model to initial thermal equilibrium. We again ran the model in the mechanical mode to bring it to mechanical equilibrium, which required about 400 steps and about 1 minute of computer time. We initialized the displacements to zero in all zones once the model was in mechanical and thermal equilibrium. 


\subsection{FLAC FD $^{3 \mathrm{D}}$ Modeling Results}

\subsubsection{Results for 50 Years of Heating}

We began with the model at thermal and mechanical equilibrium and then ran $\mathrm{FLAC}^{3 \mathrm{D}}$ in the thermal mode and read in temperatures appropriate for $50 \mathrm{yr}$ of heating. The temperature field is shown in Figure 6. The maximum temperature is about $420^{\circ} \mathrm{K}\left(147^{\circ} \mathrm{C}\right)$ in the center of a drift. This temperature field is based on that calculated by NUFT for the reference Case 1 TH model calculated using TSPA-VA base-case properties, nominal infiltration, and a pointload repository design (Hardin et al., 1998, Chapter 3). We used the NUFT temperature field in our 2-D FLAC modeling (Hardin et al., 1998, Chapter 4). Because our 3-D grid is coarser than that used by NUFT and the 2-D FLAC modeling, the temperature field is not as smooth for the 3-D model. Yet the key features of the temperature field are apparent in Figure 6. Note the asymmetrical isotherms and the steep thermal gradient above the drifts. These key features could not be represented using FLAC ${ }^{3 D}$ instead of NUFT to compute the temperature field. Note that, in this report, we did not calculate results for other heating times (e.g., $100 \mathrm{yr}$, $1000 \mathrm{yr}$ ). Most of the high stress gradients form early because the temperature gradients are highest between 0 and 50 yr (Hardin et al., 1998, Chapter 4).

The asymmetrical temperature field computed by NUFT shows the dry-out zone that is expected to develop in the NFE early in the time period modeled (I Iardin et al. 1998), Chapter 3). Under unheated conditions, pores in the rock in the NFE contain liquid water, air, and water vapor. Porosity of the Topopah Spring tuff at the repository horizon is about 10\%, and water saturation for the pores is about $90 \%$ (Hardin et al. 1998), p. 3-3). The pores provide the fluid-storage capacity of the rock, but permeability and fluid-transport are controlled by connected fractures in the host rock. Both liquid and gas phases may flow through fractures. Under ambient conditions, the gas phase filling about $10 \%$ of the pore space in the host rock is made up of approximately $98.5 \%$ air and $1.5 \%$ water vapor (Hardin et al. 1998, p. 3-4).

Decay heat from a waste package is transferred to the drift and host rock by radiation, conduction, and convection. These processes lead to boiling in the rock matrix and to matrixto-fracture vapor transport followed by vapor flow in fractures and condensation in fractures in regions beyond the dry-out zone where temperatures are lower. The vapor flow in the fractures is directed radially outward form the waste package, but condensate drainage through fractures beyond the dry-out zone is controlled by gravity. This results in an asymmetrical temperature field having a steeper thermal gradient above the drift than below the drift (Hardin et al. 1998), p. 3A-2, Figure 3-2). Details of the NUFT temperature calculations are in Chapter 3 of the Near-Field/Altered-Zone Models Report (Hardin et al. 1998). The asymmetrical temperature field leads to an asymmetrical stress field. 


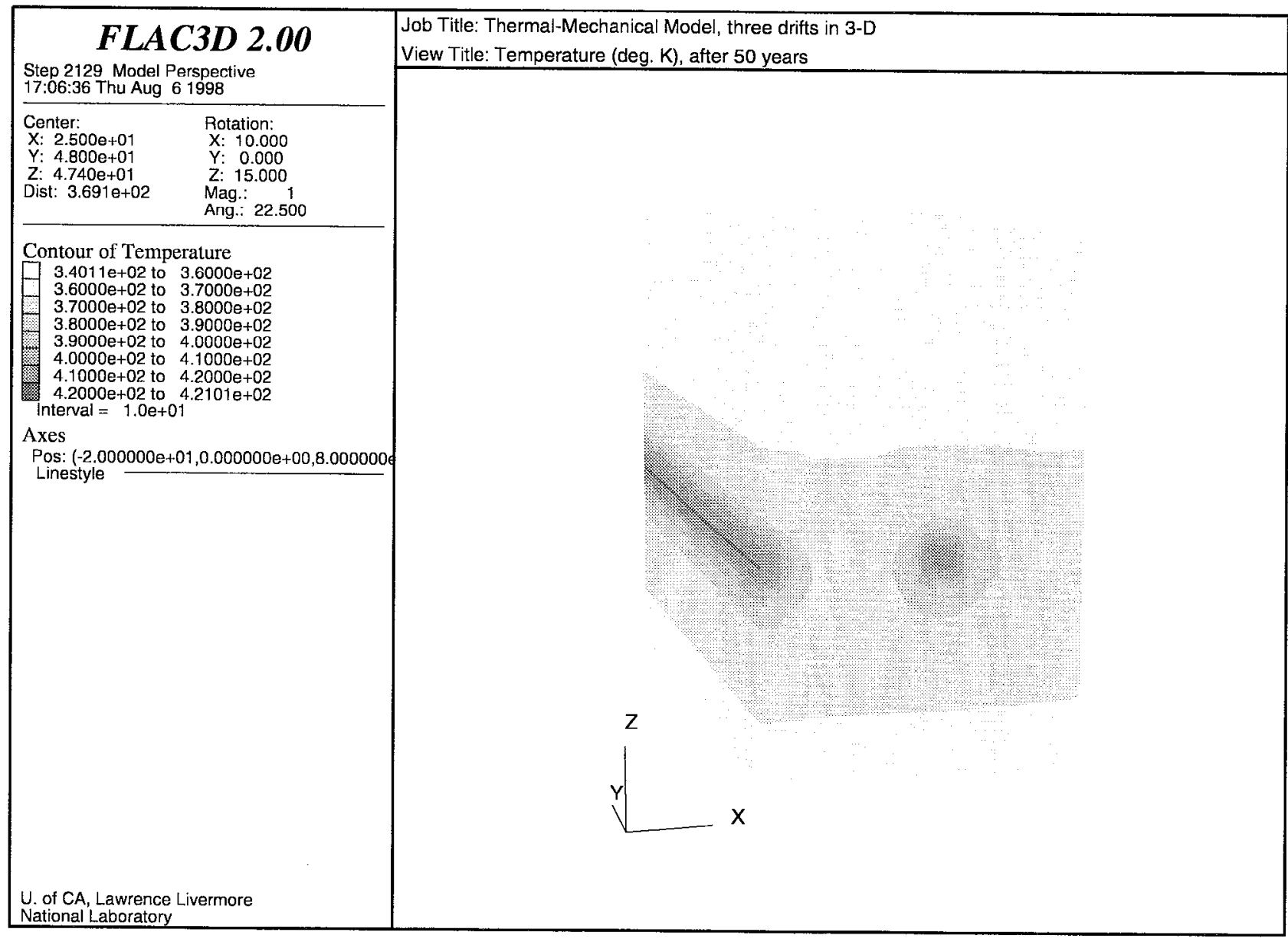

Figure 6. Model for 1.5 drifts in 3-D, temperatures after 50 yr of heating (DTN LL980805604243.023)

Temperature field adapted from field calculated during previous NUFT TH modeling

We computed thermal stresses and displacements resulting from $50 \mathrm{yr}$ of heating by running FLAC ${ }^{3 \mathrm{D}}$ in the mechanical mode and bringing the model to mechanical equilibrium. Attaining equilibrium required about 5300 steps and took approximately 25 minutes of computer time on the Ultra 2.

The new stress field after $50 \mathrm{yr}$ of heating is shown in Figure 7 and Figure 8. Additional views of the stress components in the 3-D model are included in Appendix A. Note how the stress field has rotated in the heater region so that the principal stress directions exhibit a lot of lateral heterogeneity (in the $\mathrm{X}$ direction) below the heaters. The asymmetrical temperature field with large temperature gradients above the heaters produced an asymmetrical stress field with large stress gradients above the heaters (szz plots, Appendix A), and all the stresses have increased significantly compared to the initial values near 5 to $10 \mathrm{MPa}$ in compression before heating. 


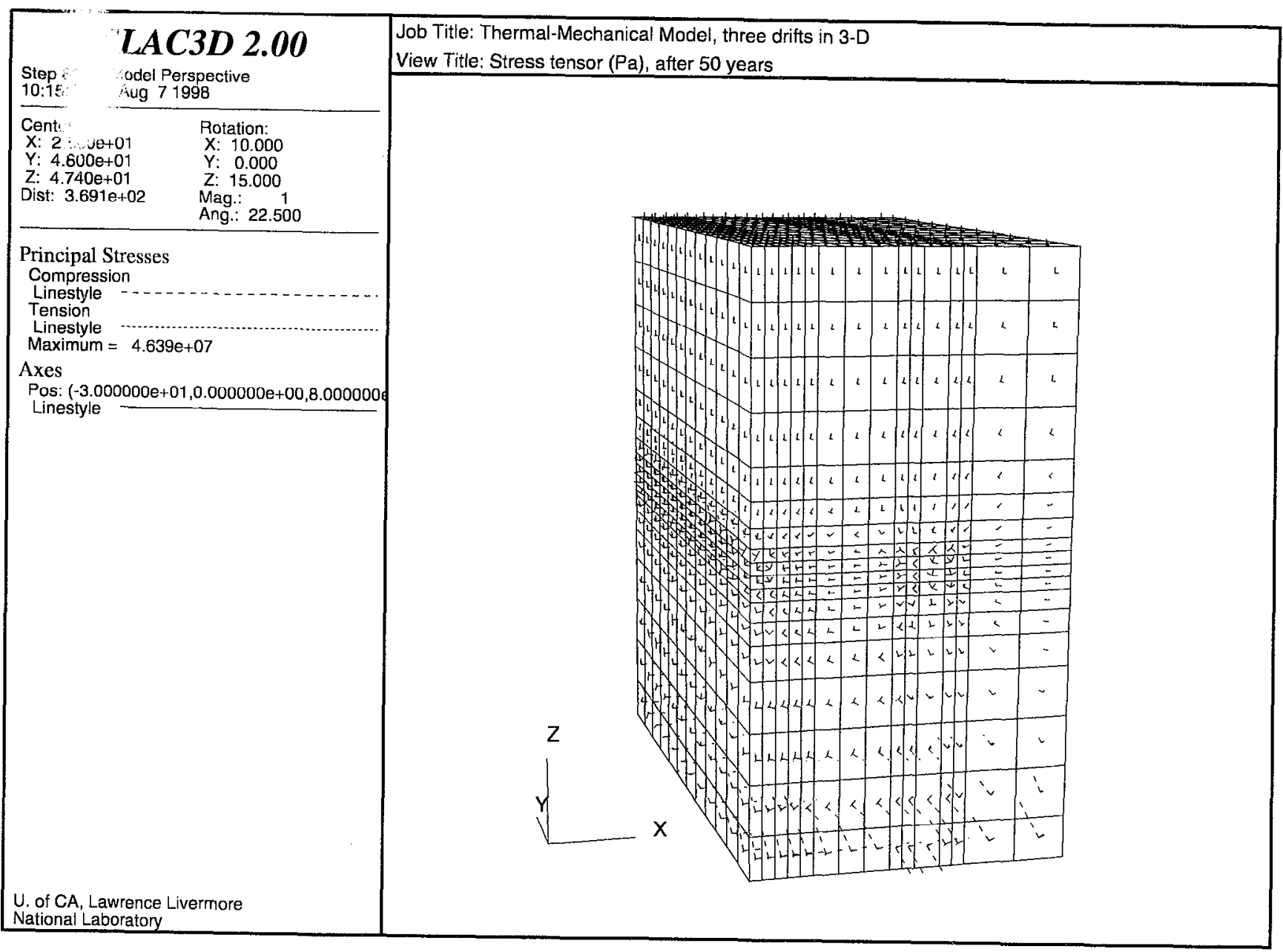

Figure 7. Model for 1.5 drifts in 3-D, stress field after 50 yr of heating, for entire model (DTN LL980805604243.023) 


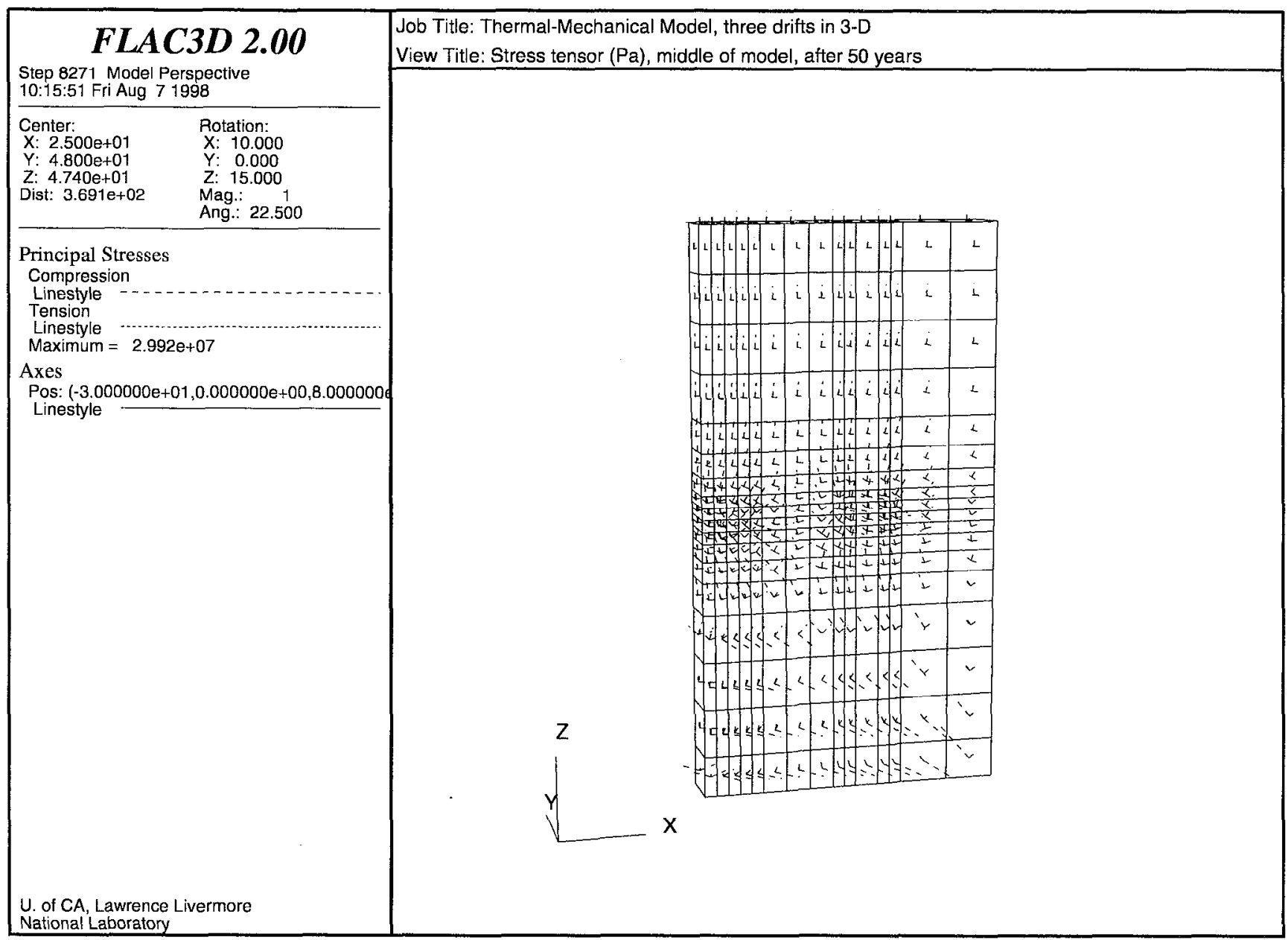

Figure 8. Model for 1.5 drifts in 3-D, stress field after $50 \mathrm{yr}$ of heating, near model center (DTN LL980805604243.023)

The horizontal stresses have increased to about 15 to $20 \mathrm{MPa}$ in compression near the bottom of the model (sxx and syy plots, Appendix A). Horizontal stresses in the X direction have dropped at the top of the model and in the region midway between the drifts, to values as low as $1 \mathrm{MPa}$ in compression (sxx plots, Appendix A). Values are much higher for horizontal stresses in the $Y$ direction and for all horizontal stresses near the heaters, about 10 $\mathrm{MPa}$ in the region next to the drifts about 2 drift diameters away.

The sxy and sxz shear stresses are relatively small, about $2 \mathrm{MPa}$, in most parts of the model (sxy and sxz plots in Appendix A). Some artifacts are seen in the blocks at the lower corners of the model where these shear stresses are high due to edge effects. High syz shear stresses are found in the plane midway between the drifts where syz values reach about 5 $\mathrm{MPa}$, and in the $\mathrm{YZ}$ planes containing the drifts (syz plots, Appendix A). Note that the previous 2-D FLAC modeling could not compute shear stresses in this direction because the YZ plane is perpendicular to the plane of the 2-D model (Hardin et al., 1998, Chapter 4).

Vertical stresses are high (10 to $20 \mathrm{MPa}$ ) near the top and bottom of the model (szz plots, Appendix A). The region between drifts has high vertical stress gradients. Some artifacts, due to edge effects, can be seen in the vertical stresses for the outermost blocks in the model. 
The total displacement after $50 \mathrm{yr}$ of heating is shown in Figure 9. Additional plots in Appendix A show horizontal and vertical displacement components. The displacement has a magnitude of several $\mathrm{cm}$ in the middle of the model, increasing near the top. Most of the displacement is in the $Z$ direction. $X$ and $Y$ displacements are 1 to $2 \mathrm{~cm}$ for most of the model, and the $Z$ displacement is 5 to $7 \mathrm{~cm}$.

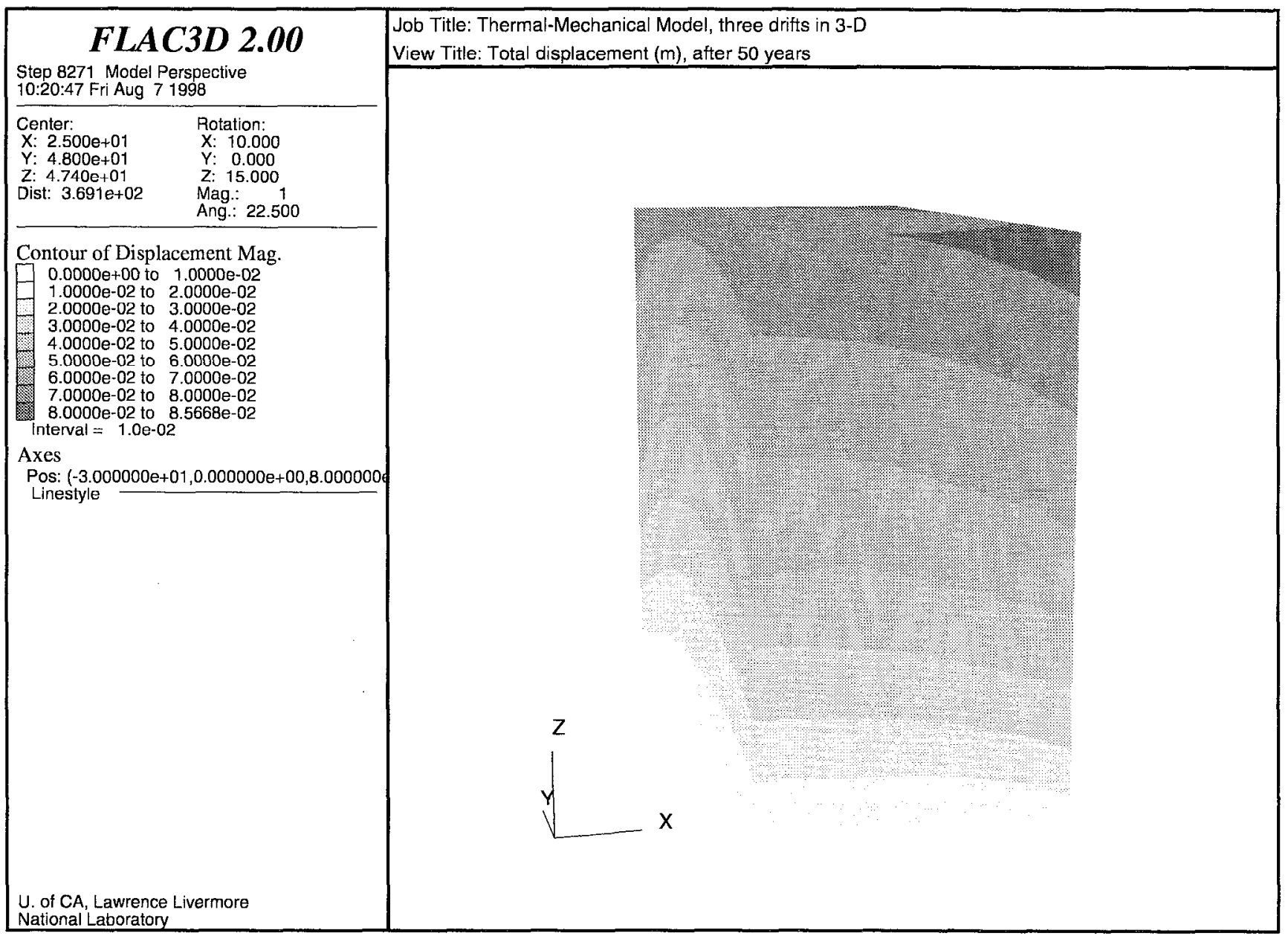

Figure 9. Model for 1.5 drifts in 3-D, total displacement after $50 \mathrm{yr}$ of heating (DTN LL980805604243.023)

These displacement and stress results from 3-D modeling are in agreement with those found using the 2-D FLAC code (Hardin et al., 1998, Chapter 4). Using the coarser grid does not significantly change the results from those found for 2-D modeling with a fine grid. The additional insight gained by having the ability to compute the stress field in 3-D (e.g., computing the high syz shear stresses) is much more significant than the small loss of resolution resulting from using a coarser grid.

The displacement and stress results are somewhat sensitive to the mechanical boundary conditions. We tested these effects by comparing fixed and applied stress mechanical boundary conditions for a simplified version of the 3-D model having only one-half a drift instead of one and one-half drifts. These results are shown in Appendix B. Although the initial stress field is virtually the same for either case, after 50 yr of heating, using fixed boundaries causes the compressive stresses to be about twice as large and the displacements 
to be an order of magnitude smaller than for the other case. These results suggest that future modeling should use boundaries that are much further away from the region of interest in the model so that boundary effects are minimized. To find minimum and maximum estimates for displacements, future modeling must also compare results for fixed and applied stress boundary conditions . 


\subsection{Estimating Permeability Changes}

\subsubsection{Theoretical Approach}

The proposed repository host rock is a fractured, densely welded, ash-flow tuff. The rock has low matrix permeability, and the bulk permeability is mainly associated with fractures. Any changes in rock mass permeability from TM effects can be attributed to changes in the fractures because changes to matrix permeability in response to stress and temperature are small (Hardin and Chesnut 1997).

Laboratory studies (Bandis et al. 1983; Barton et al. 1985) have shown that greater impact often results from shear deformation of fractures rather than from normal deformation. Fractures may be more deformable in shear under certain stress conditions, in which case the magnitude of changes in fracture aperture is greater than it is for perpendicular (normal) deformation. With greater deformation, there is increased likelihood of permanent displacement, which could produce durable changes in fracture permeability. This may be especially true for stress-unloading conditions during repository cool-down. Permanent changes in hydrologic properties or flow paths can result from normal deformation, but they tend to be smaller than those caused by shear displacements. This has been observed in field studies (e.g., Wilder, 1987).

Several investigators have shown that increasing stress across fractures causes a reduction in fracture aperture, and, to a first approximation, flow in a fracture is related to the cube of the fracture aperture (Raven and Gale 1985). Heating the rock generally increases stress and thereby reduces the fracture aperture. Excavation of drifts and resulting redistribution of stresses nearby may increase permeability near the drifts (e.g., Ouyang and Elsworth 1993). Studies have also shown that fracture shear displacement can significantly increase fracture permeability and that the magnitude of the change may readily exceed that due to normal displacement (Barton et al. 1985). Finally, it is widely accepted that the hydrologic behavior of a fractured rock mass is controlled by relatively few, well-connected fractures.

In previous work (Blair et al., 1997; Hardin et al., 1998, Chapter 4), we used the concept of preferential flow along critically stressed fractures (Barton et al., 1997; 1995) to develop a method for determining increased permeability. We identified the regions of a 2-D FLAC model that exhibited stress conditions that would cause slip along fractures and related increases in permeability.

\subsubsection{Stress Criterion for Shear Slip, 2-D Case}

Barton et al. (1997) presented evidence that hydraulically conductive fractures are the fractures that are critically stressed. To estimate permeability changes due to heating, we applied this concept in our previous work (Blair et al., 1997; Hardin et al., 1998, Chapter 4 ) for stress fields calculated using the 2-D FLAC code. The 2-D FLAC code used the XY plane for all modeling (that plane is the $\mathrm{XZ}$ plane in our 3-D model). The ratio of the shear stress to normal stress was calculated for potential slip planes in $30^{\circ}$ increments between $0^{\circ}$ and $180^{\circ}$. The slip planes were defined by the angle $\theta$ of their normals to the $x$ axis. Therefore, an angle of $0^{\circ}$ corresponds to a vertical slip plane, and an angle of $90^{\circ}$ corresponds to a horizontal slip plane. The rotation formulas for this definition of angle $\theta$ were taken from Turcotte and Schubert (1982, p. 82): 


$$
\begin{aligned}
& -S_{n}=\sigma_{x^{\prime} x^{\prime}}=\sigma_{x x} \cos ^{2} \theta+\sigma_{y y} \sin ^{2} \theta+\sigma_{x y} \sin 2 \theta \\
& \sigma_{y^{\prime} y^{\prime}}=\sigma_{x x} \sin ^{2} \theta+\sigma_{y y} \cos ^{2} \theta-\sigma_{x y} \sin 2 \theta
\end{aligned}
$$

and

$$
\tau=\sigma_{x^{\prime} y^{\prime}}=\frac{1}{2}\left(\sigma_{y y}-\sigma_{x x}\right)+\sigma_{x y} \cos 2 \theta
$$

where $\tau$ is the shear stress and $S_{\mathrm{n}}$ is the compressive normal stress. (Note that we use $\sigma_{x x}, \sigma_{x y}$, etc., for stresses denoted by sxx, sxy, etc., in FLAC ${ }^{3 \mathrm{D}}$ code output. The code cannot accommodate Greek letters on the plot labels.) The Mohr-Coulomb criterion is

$$
|\tau| \geq c+f S_{\mathrm{n}}
$$

where $c$ is the cohesion and $f$ is the coefficient of friction. The maximum potential for frictional slip occurs for a cohesion value of zero (i.e., shear offset occurs when the ratio $\left.|\tau| /\left(f S_{n}\right) \geq 1\right)$. This ratio was contoured for values greater than one for the six angles for slip planes (Blair et al., 1997; Hardin et al., 1998, Chapter 4). Thus, contoured regions were those in which the slip criterion is satisfied and shear offset is expected. Using this procedure in our previous work, we found regions of our 2-D FLAC models where slip would be expected to enhance permeability for fractures at certain angles. Although this provides an indication of the spatial distribution of permeability enhancement, more assumptions are needed to estimate the magnitude of the permeability changes.

\subsubsection{Relation of Slip to Permeability Change}

In our previous work, we developed a method for estimating the magnitude of the permeability changes due to fracture slip (Blair et al., 1997; Hardin et al., 1998, Chapter 4). This method is based on the work of Brown (Brown, 1994; 1995; Brown and Bruhn, 1997). Other simple assumptions could be used to relate slip to permeability changes; this is only one possible rule. Because we used it for previous 2-D modeling, we will again apply this method. Future work will incorporate effects of increasing fracture apertures and concentrations near excavations (e.g., Ouyang and Elsworth 1993).

Knowing which fractures are hydraulically conductive is necessary for estimating how the permeability of a critically stressed fracture will change if slip actually occurs. Brown (1995) and Brown and Bruhn (1997) developed a methodology to estimate permeability from fracture-aperture distributions. Their basic result is summarized in the following equation:

$$
m_{0}=-C \frac{\pi s^{\alpha-1} \sec (\alpha \pi / 2)}{2^{\alpha-1}\left[\Gamma\left(\frac{\alpha+1}{2}\right)\right]^{2}}
$$

where $m_{0}$ is the variance of the fracture aperture, $s$ is the shear offset along the fracture, $\alpha$ is the exponent in the power law power spectrum describing fracture-surface roughness (typically $2<\alpha<3$ ) (Brown 1995, p. 5844), $C$ is a scale factor, and $\Gamma$ is the specialized mathematical gamma function. This model (Brown 1995) assumes that the probability density 
function describing the distribution of asperity heights about the mean value, on either side of a fracture, is represented by a Gaussian distribution. The model also assumes that the power spectrum describing surface roughness can be written as a power law. The slip on the fracture is assumed to be very small compared to the length of the fracture. The aperture $b$ is related to variance by $b=3 \sqrt{m_{0}}$ for a Gaussian distribution of surface heights (Brown 1995). Finally, the permeability $k$ is assumed to satisfy the standard parallel-plate equation $k=b^{2} / 12$. Combining these assumptions and taking logarithmic derivatives gives the fractional change in $k$ as

$$
\frac{\Delta k}{k}=(\alpha-1) \frac{\Delta s}{s} .
$$

The scaling exponent $\alpha$ is related to the fractal dimension $D$ of the fracture surface according to $\alpha=7-2 \cdot \mathrm{D}$ (Brown 1995, p. 5944). $D$ ranges between 2, for smooth fractures, and 2.5, for rough fractures (Brown 1995). Therefore, maximum changes occur for $\alpha-3$. Assuming that the (small) shear offset from thermal stress is the same as for a pre-existing slip (i.e., $\Delta s / s=1$ ) gives $\Delta k / k=2$. If $\alpha=1$, no change can occur in the permeability. In other words, the maximum change in permeability with this set of assumptions is that it doubles as a result of frictional slip. We therefore estimate that regions of the model in which shear slip is likely to occur along a particular set of fractures may have permeability increases of a factor of two. If slip can occur along two or more sets of fractures oriented at different angles, the permeability may increase by a factor of four or more, assuming slip is small enough that the effects of slip along another set of fractures can be added linearly.

One limitation of the shear-slip model derived here is that stresses are not redistributed as a result of slip. Therefore, the possibility that multiple slip events could occur during heating has not been addressed. Under different assumptions from those used here, each occurrence of fracture slip could enhance the permeability. Laboratory experiments on fractured blocks of tuff are needed to provide more information to better quantify our THM modeling of permeability changes. For example, the work begun in Blair and Costantino (1997) could be extended to include slip along the fracture.

\subsubsection{Extending the Stress Criterion for Shear Slip to the 3-D Case}

The stress field in 3-D is considerably more complicated than it is in 2-D. Two rotation angles are required for relating principle stress directions to fracture orientations, and the fractures of interest may lie anywhere within the model volume. Calculating and displaying the results for the 3-D case are much more complicated than for the 2-D case.

Yet some simplification is possible because most of the fractures of interest are likely to be horizontal or vertical. In general, three fracture sets have been identified in the ESF (Albin et al., 1997, p. 1):

- Set \#1 is a steeply dipping set of fractures striking east-west (EW).

- Set \#2 is a steeply dipping set of fractures striking north-south (NS).

- Set \#3 is a subhorizontal $(\mathrm{H})$ set of fractures striking east-west.

In our 3-D modeling for this report, we will only consider vertical and horizontal fractures. Because our model is 3-D, this includes many possible fracture sets.

An additional simplifying assumption is to consider only vertical fractures that are parallel to the $X Z$ or the $Y Z$ planes. This assumption is reasonable for preliminary modeling because the axis of the heated drift for the Drift-Scale Test (Blair et al. 1998) is oriented 
east-west; hence, EW set \#1 and $\mathrm{H}$ set \#3 strike perpendicular to the plane containing the drift cross section, and NS set \#2 is perpendicular to the drift axis. For our model geometry, we can assume that EW set \#1 is represented by vertical fractures parallel to the YZ plane, NS set $\# 2$ is represented by vertical fractures parallel to the $X Z$ plane, and $H$ set $\# 3$ is represented by horizontal fractures parallel to the $X Y$ plane.

Thus, the calculations of shear slip for vertical and horizontal fractures in the 3-D model can make use of equations (1) through (3) if appropriate substitutions are made for $X$ and $Y$ in each case. The geometry of the axes, stress directions, and fracture orientations is illustrated in Figure 10. Note that $\theta$ will always be $0^{\circ}$ or $90^{\circ}$ for our simplified 3-D case, and therefore the sine and cosine terms will go to $-1,0$, or 1 .

XZ planes
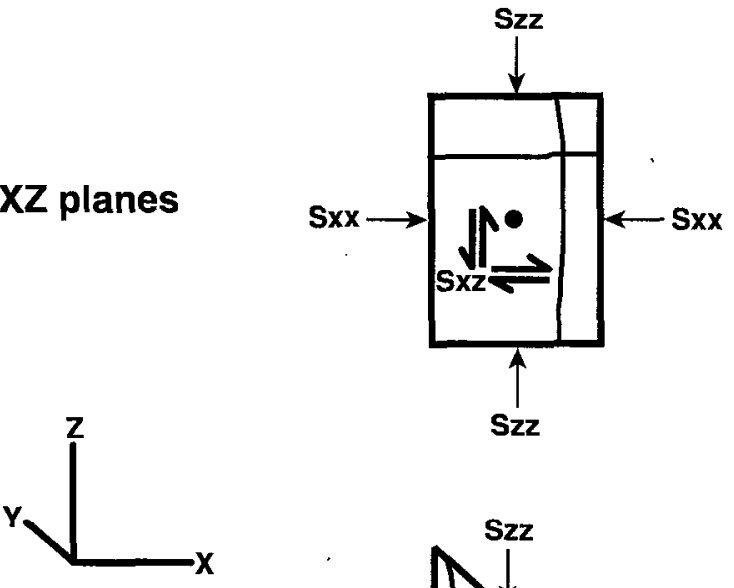

YZ planes

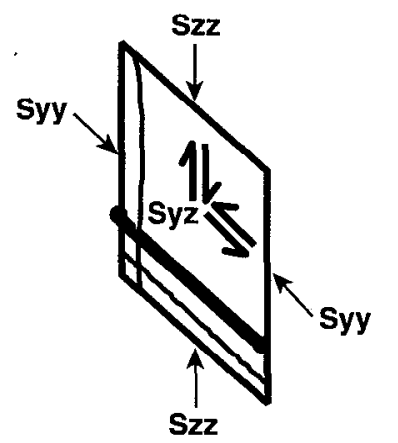

XY planes

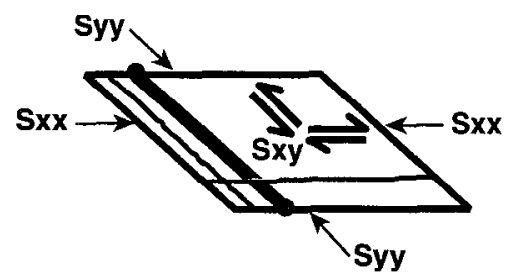

Figure 10. Illustration of geometry for vertical and horizontal fractures (light lines) cutting XZ, YZ, and XY planes (DTN LL980805604243.023)

Horizontal, vertical, and shear stresses are indicated. Dot in top sketch and heaviest lines in other sketches indicate drift location.

For fractures cutting the $X Y$ plane, the equations are used as is, with the understanding that an angle of $\theta=0^{\circ}$ corresponds to a vertical slip plane parallel to the $Y Z$ plane (EW set $\# 1$, whereas an angle of $\theta=90^{\circ}$ corresponds to a vertical slip plane parallel to the XZ plane (NS set \#2), and results should be contoured only in planes parallel to the $X Y$ plane. 
For fractures cutting the $X Z$ plane, the equations are used as is except that $Z$ replaces $Y$ everywhere in the equations and the angle $\theta=0^{\circ}$ corresponds to a vertical slip plane parallel to the $Y Z$ plane (NS set \#2), while an angle of $\theta=90^{\circ}$ corresponds to a horizontal slip plane parallel to the $X Y$ plane (H set \#3). These results should be contoured only in planes parallel to the $\mathrm{XZ}$ plane.

For fractures cutting the $Y Z$ plane, the angle $\theta$ is defined relative to the $Y$ axis rather than to the $X$ axis. In this case, all occurrences of $Y$ in the equations first must be replaced by $Z$, and then all occurrences of $X$ must be replaced by $Y$. Then an angle of $\theta=0^{\circ}$ corresponds to a vertical slip plane parallel to the $X Z$ plane (NS set \#2), and an angle of $\theta=90^{\circ}$ corresponds to a horizontal slip plane parallel to the $X Y$ plane (H set \#3). These results should be contoured only in planes parallel to the $Y Z$ plane.

We used these simplifying assumptions for our initial modeling of permeability enhancement due to shear slip in the 3-D model. The same assumptions as those used in the 2-D case were applied, after we had found regions where shear slip would be expected to occur along horizontal or vertical fractures, for estimating the magnitude of the permeability change due to shear slip.

\subsubsection{Results from Estimating Changes in Permeability}

We used the procedure described in the previous section to find regions of the 3-D model where shear slip may be expected to occur along vertical or horizontal fractures. We display these regions, using contour plots for the Mohr-Coulomb criterion (Jaeger and Cook, 1976, p. 399), in Figure 11 through Figure 22. Here the ratio of the shear stress to the frictional resistance for particular fractures is contoured. A ratio of one or more means that shear slip may occur in that region. Values less than one mean that no slip is expected to occur. 


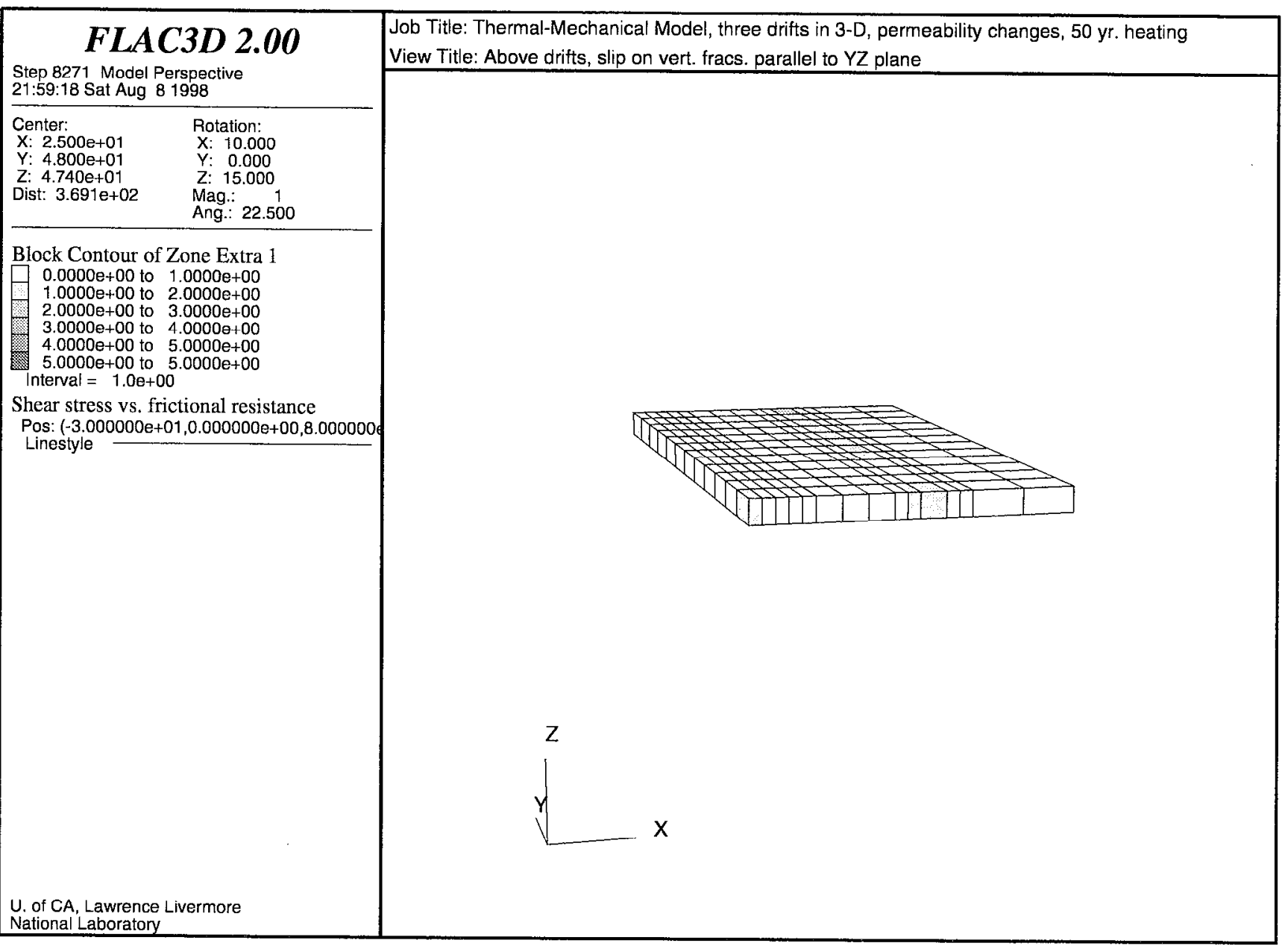

Figure 11. Contours of the ratio of shear stress to frictional resistance for slip planes parallel to the $Y 7$. plane and cutting the $X Y$ plane (region about $10 \mathrm{~m}$ above drifts) (DTN LL980805604243.023) 


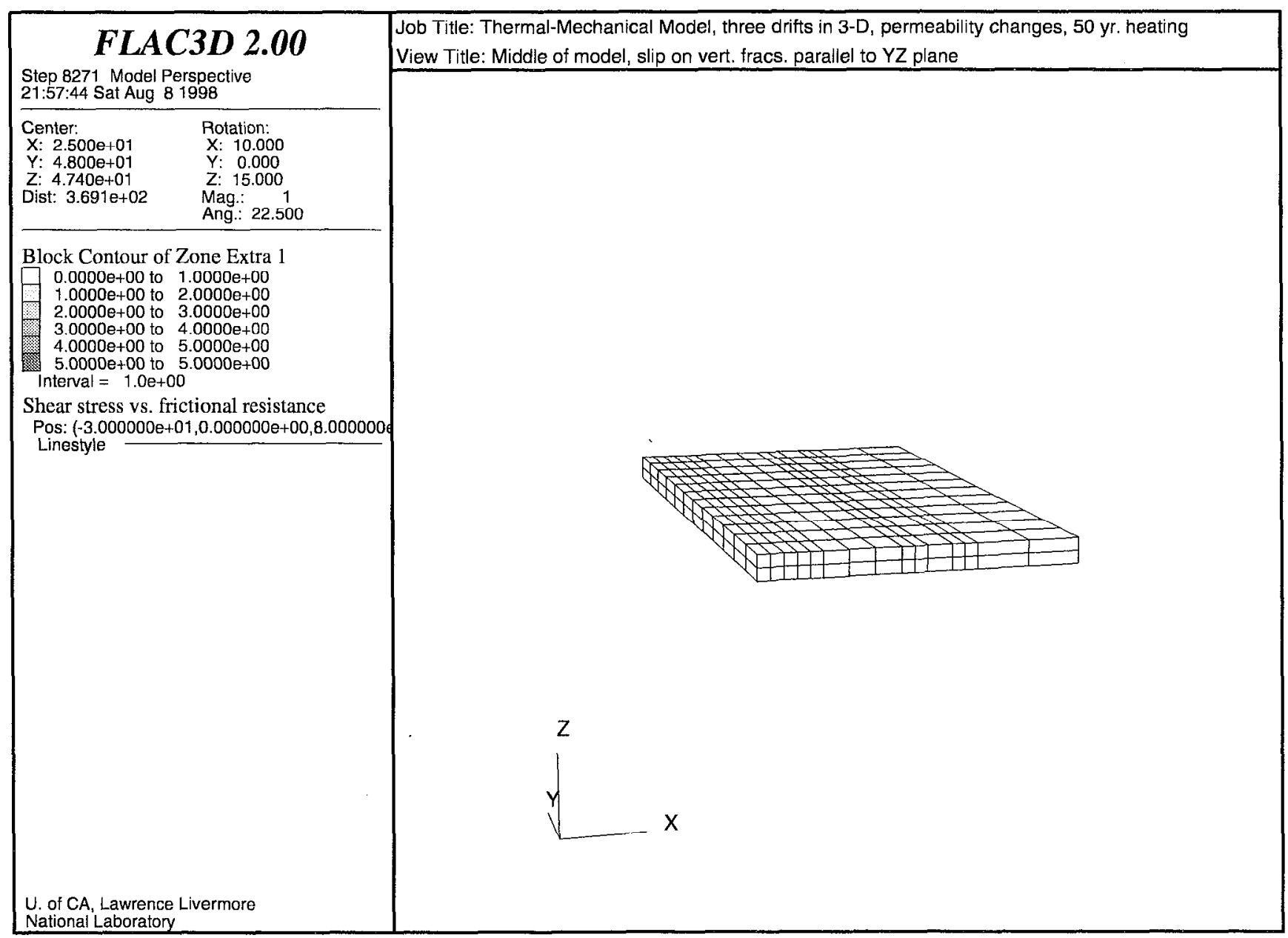

Figure 12. Contours of the ratio of shear stress to frictional resistance for slip planes parallel to the $Y Z$ plane and cutting the $X Y$ plane (region at the level of drifts) (DTN LL980805604243.023) 


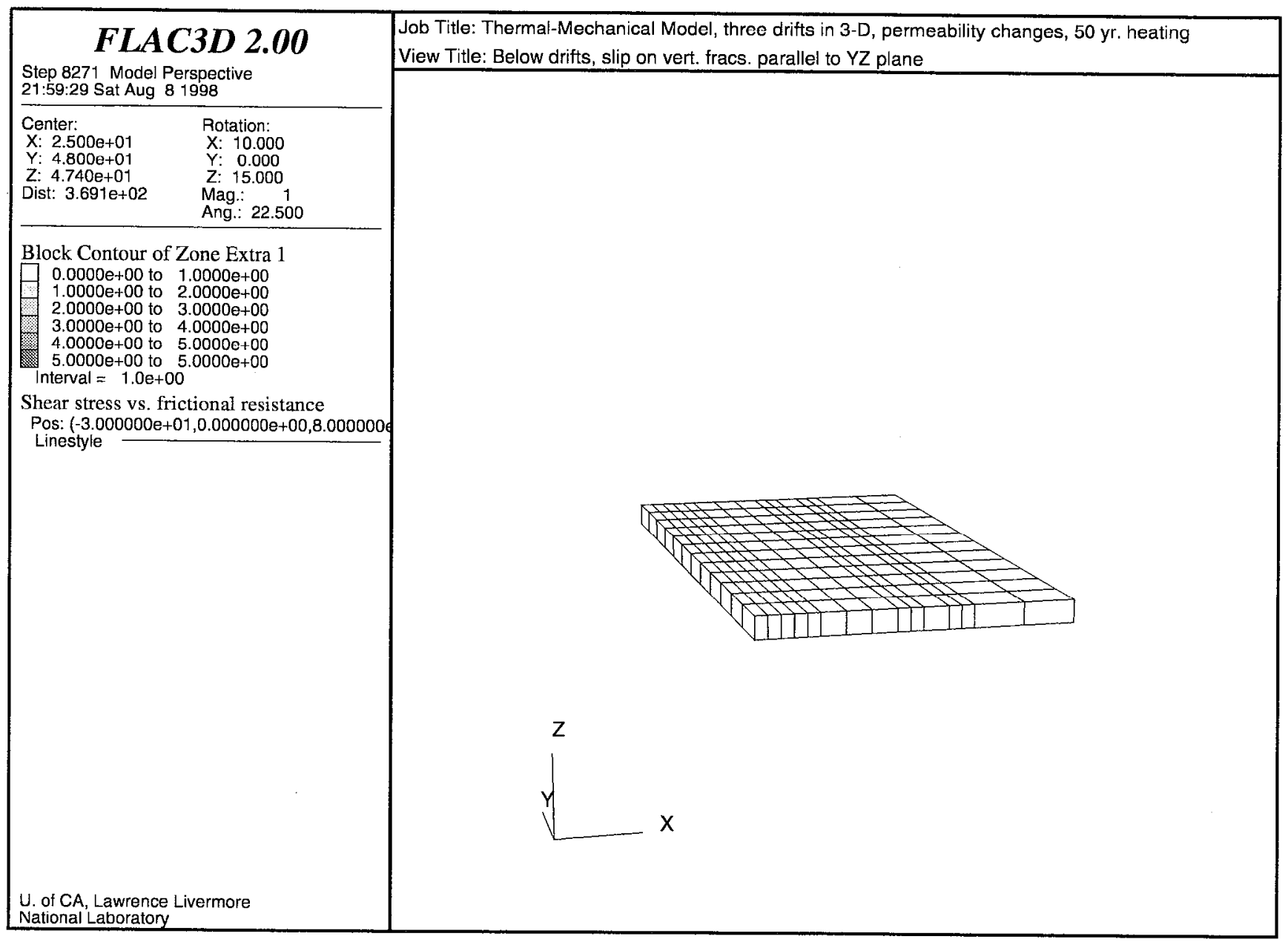

Figure 13. Contours of the ratio of shear stress to frictional resistance for slip planes parallel to the $\mathrm{YZ}$ plane and cutting the $\mathrm{XY}$ plane (region about $10 \mathrm{~m}$ below drifts) (DTN LL980805604243.023) 


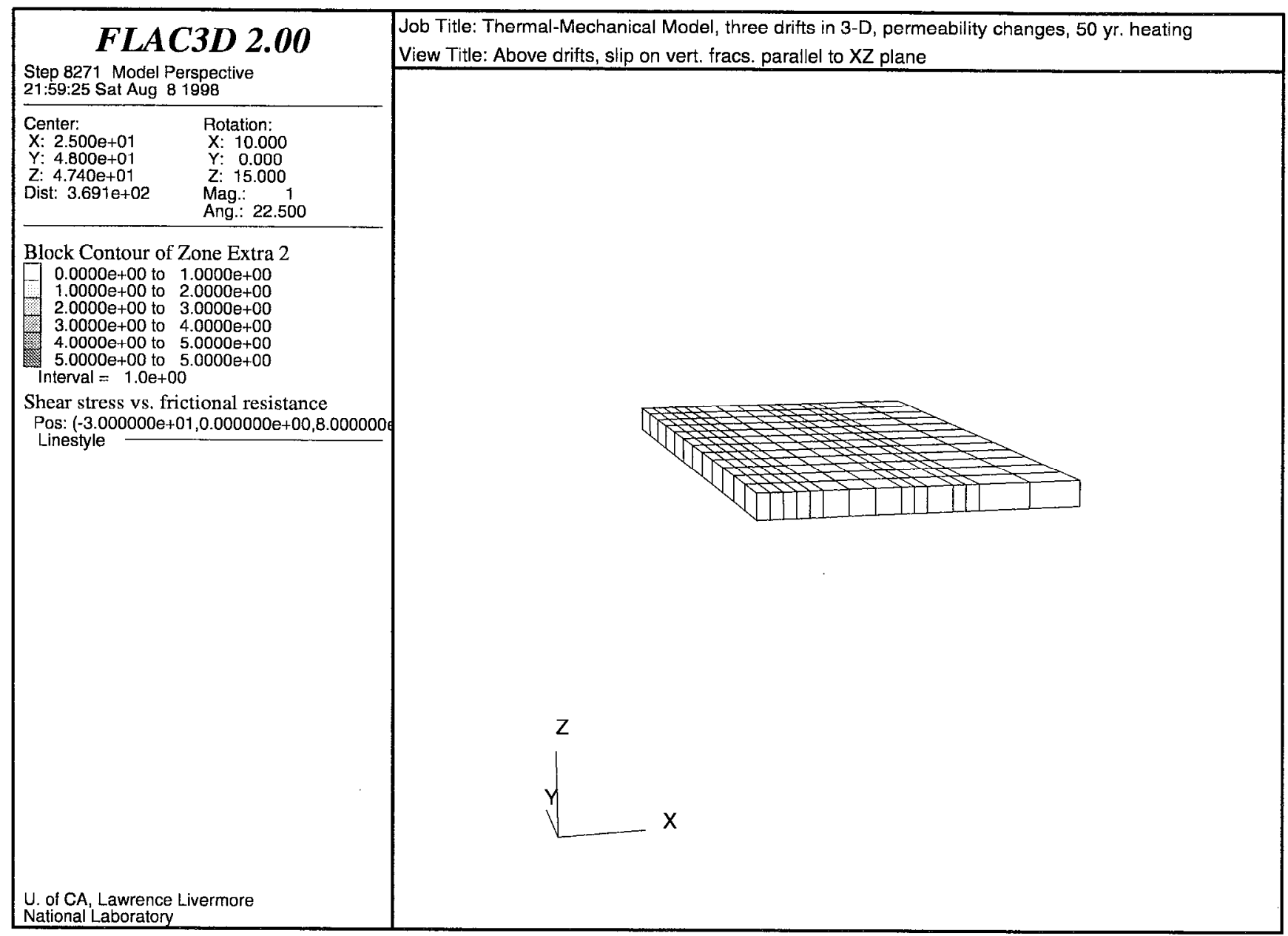

Figure 14. Contours of the ratio of shear stress to frictional resistance for slip planes parallel to the $X Z$ plane and cutting the $X Y$ plane (region about $10 \mathrm{~m}$ above drifts) (DTN LL980805604243.023) 


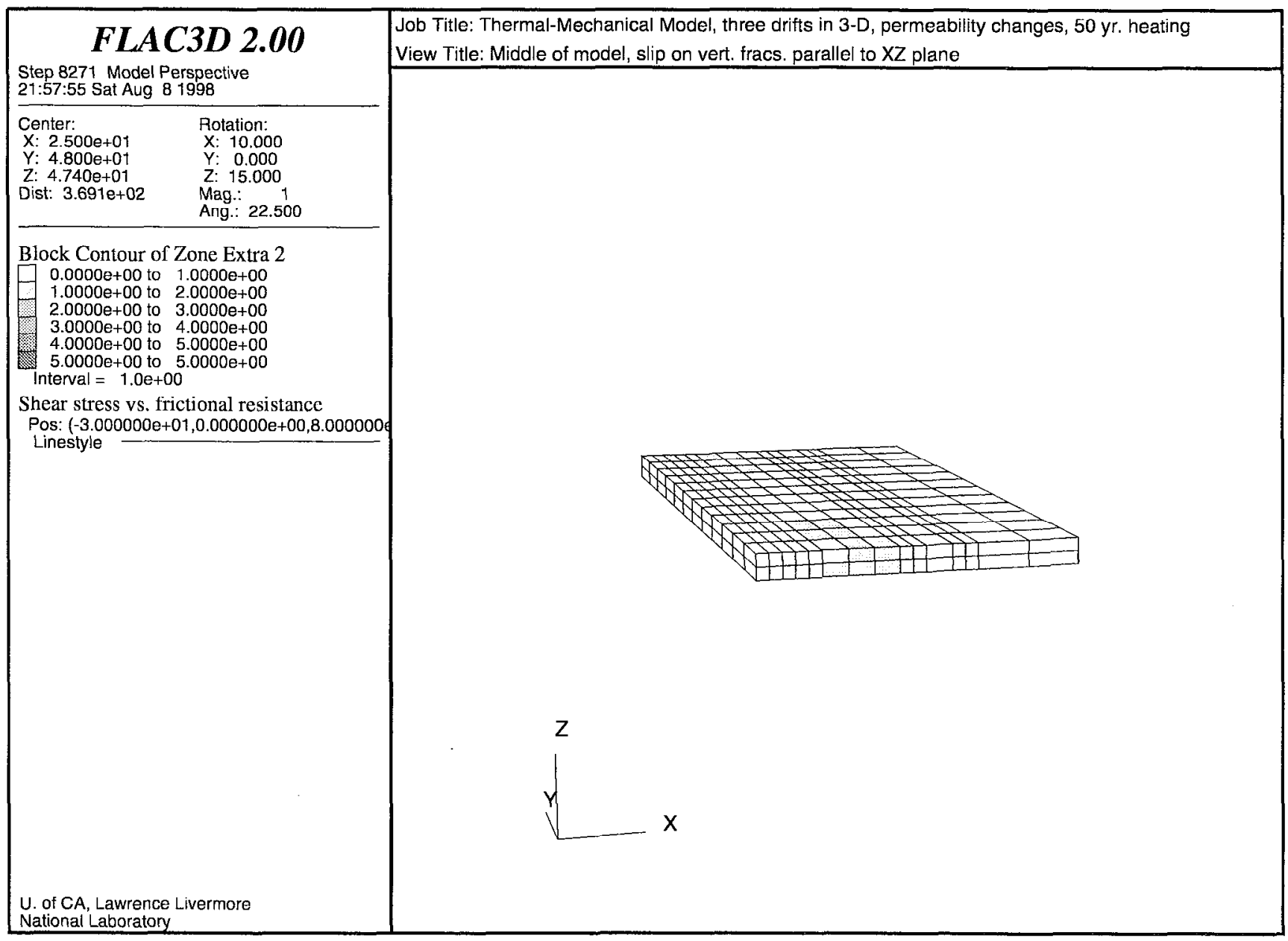

Figure 15. Contours of the ratio of shear stress to frictional resistance for slip planes parallel to the $X Z$ plane and cutting the $X Y$ plane (region at the level of drifts) (DTN LL980805604243.023) 


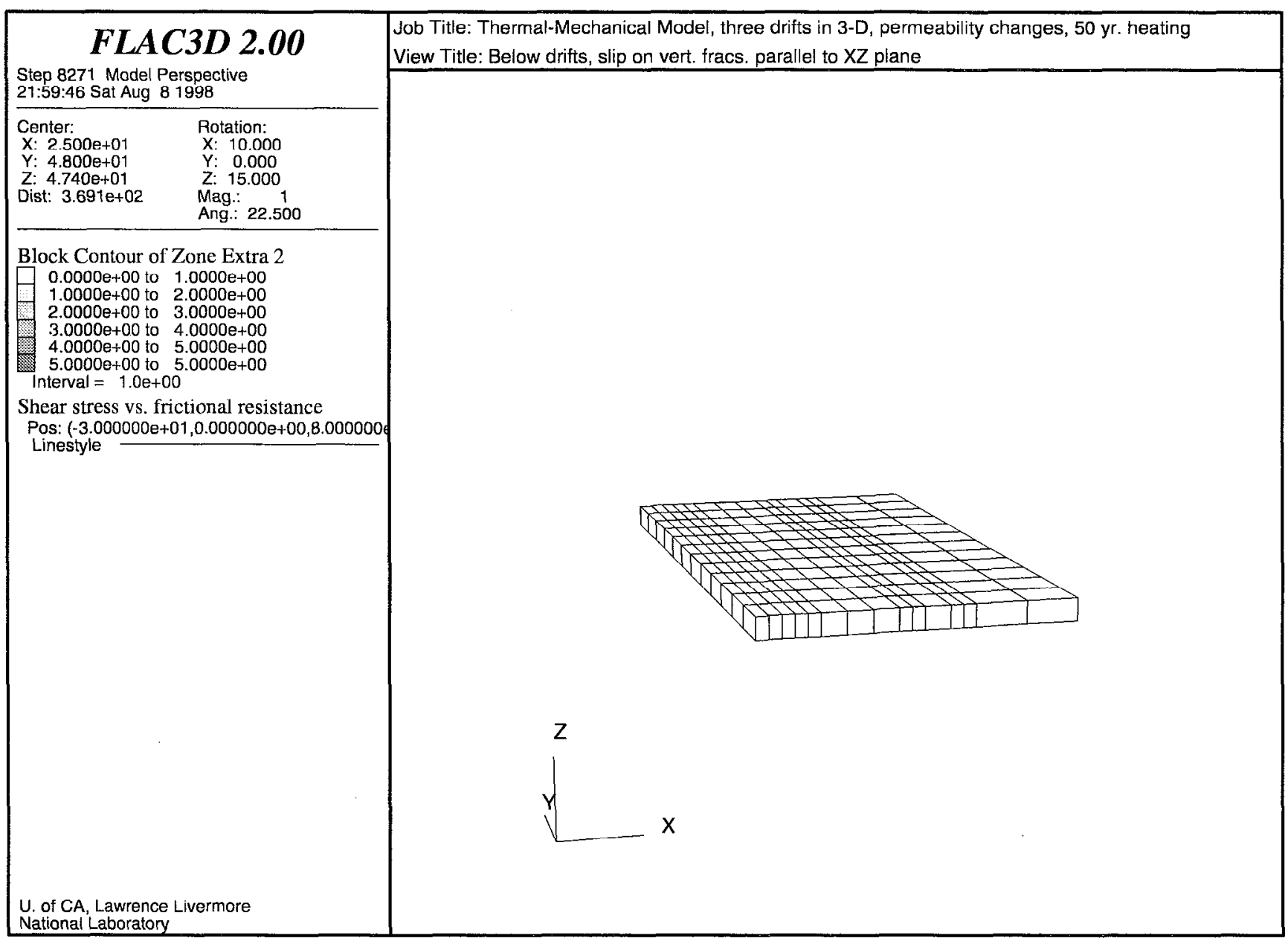

Figure 16. Contours of the ratio of shear stress to frictional resistance for slip planes parallel to the $X Z$ plane and cutting the $X Y$ plane (region about $10 \mathrm{~m}$ below drifts) (DTN LL980805604243.023) 


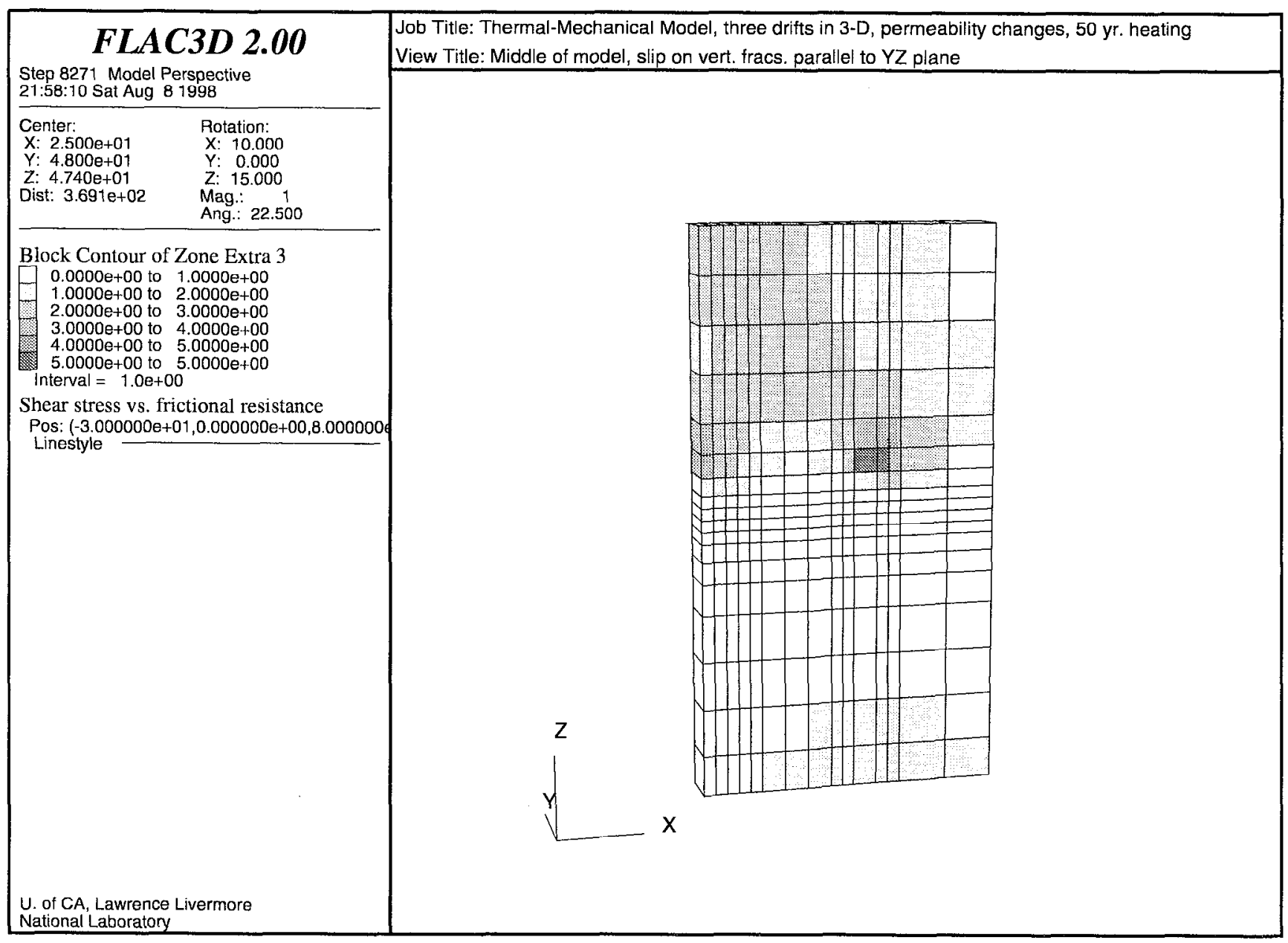

Figure 17. Contours of the ratio of shear stress to frictional resistance for slip planes parallel to the $\mathrm{YZ}$ plane and cutting the $\mathrm{XZ}$, plane (region near middle of model) (DTN LL980805604243.023) 


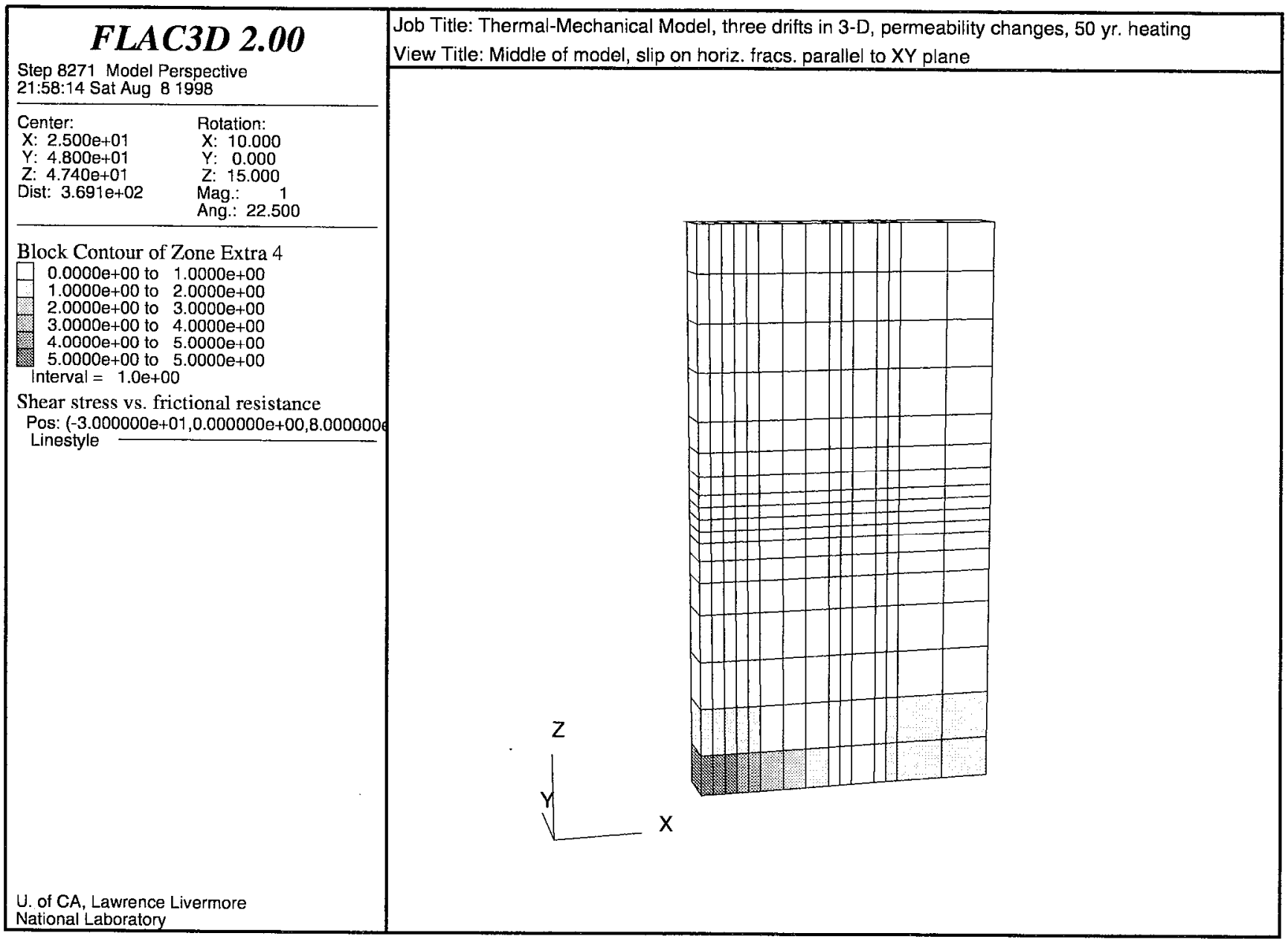

Figure 18. Contours of the ratio of shear stress to frictional resistance for slip planes parallel to the $X Y$ plane and cutting the $X Z$ plane (region near middle of model) (DTN LL980805604243.023) 


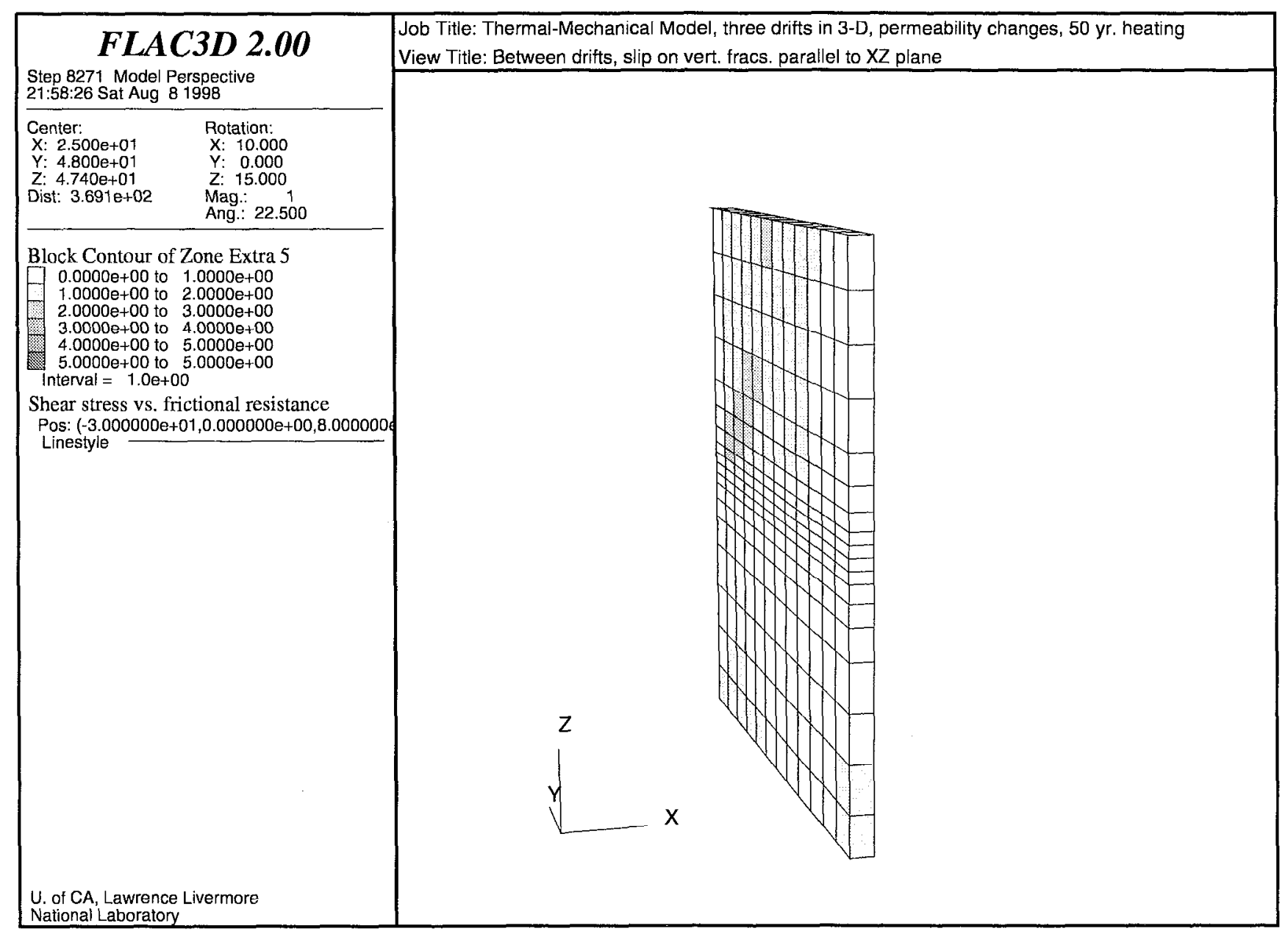

Figure 19. Contours of the ratio of shear stress to frictional resistance for slip planes parallel to the $\mathrm{XZ}$ plane and cutting the $\mathrm{YZ}$ plane (region midway between drifts) (DTN LL980805604243.023) 


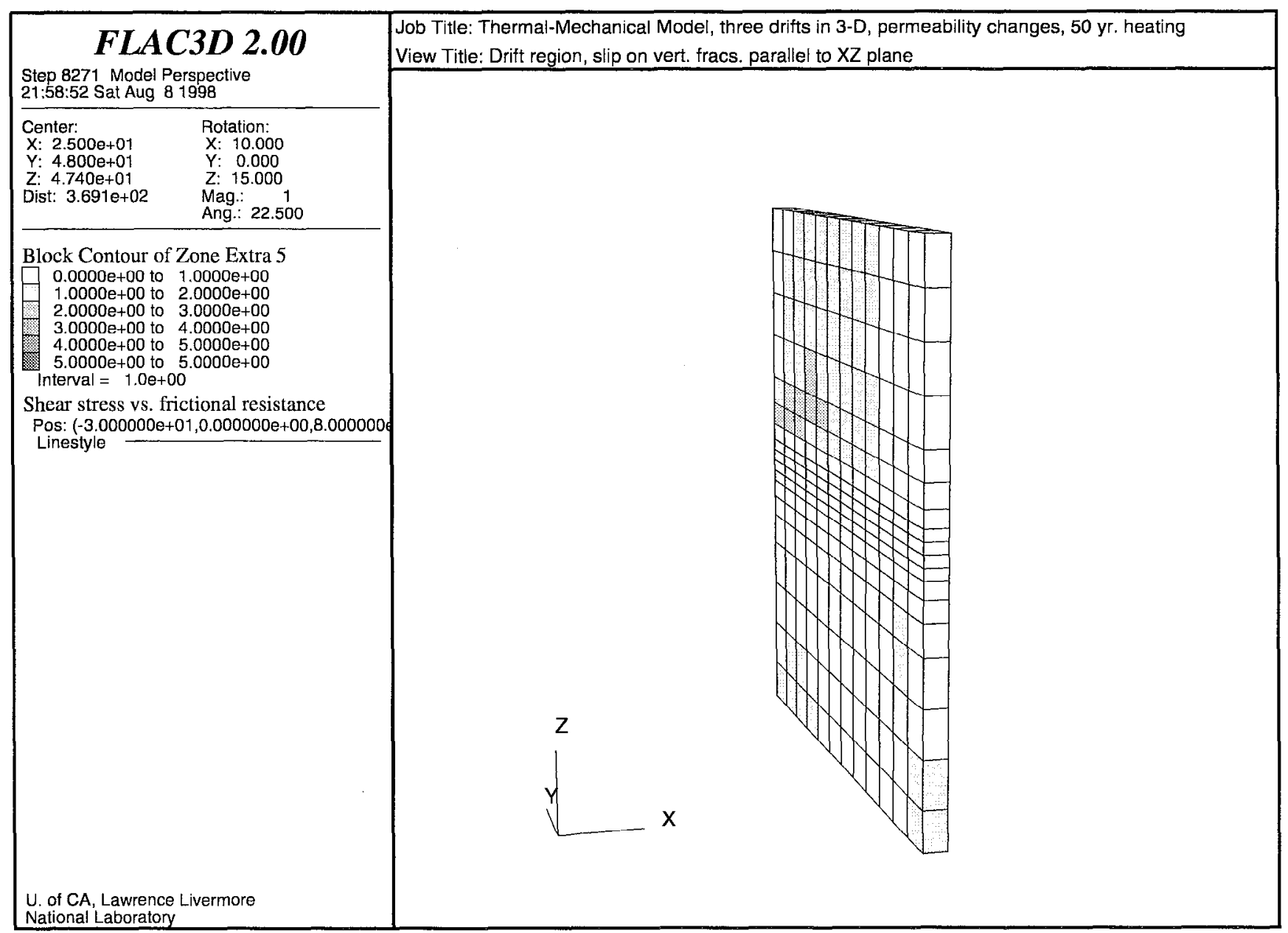

Figure 20. Contours of the ratio of shear stress to frictional resistance for slip planes parallel to the $X Z$ plane and cutting the $Y Z$ plane (region near drift) (DTN LL980805604243.023) 


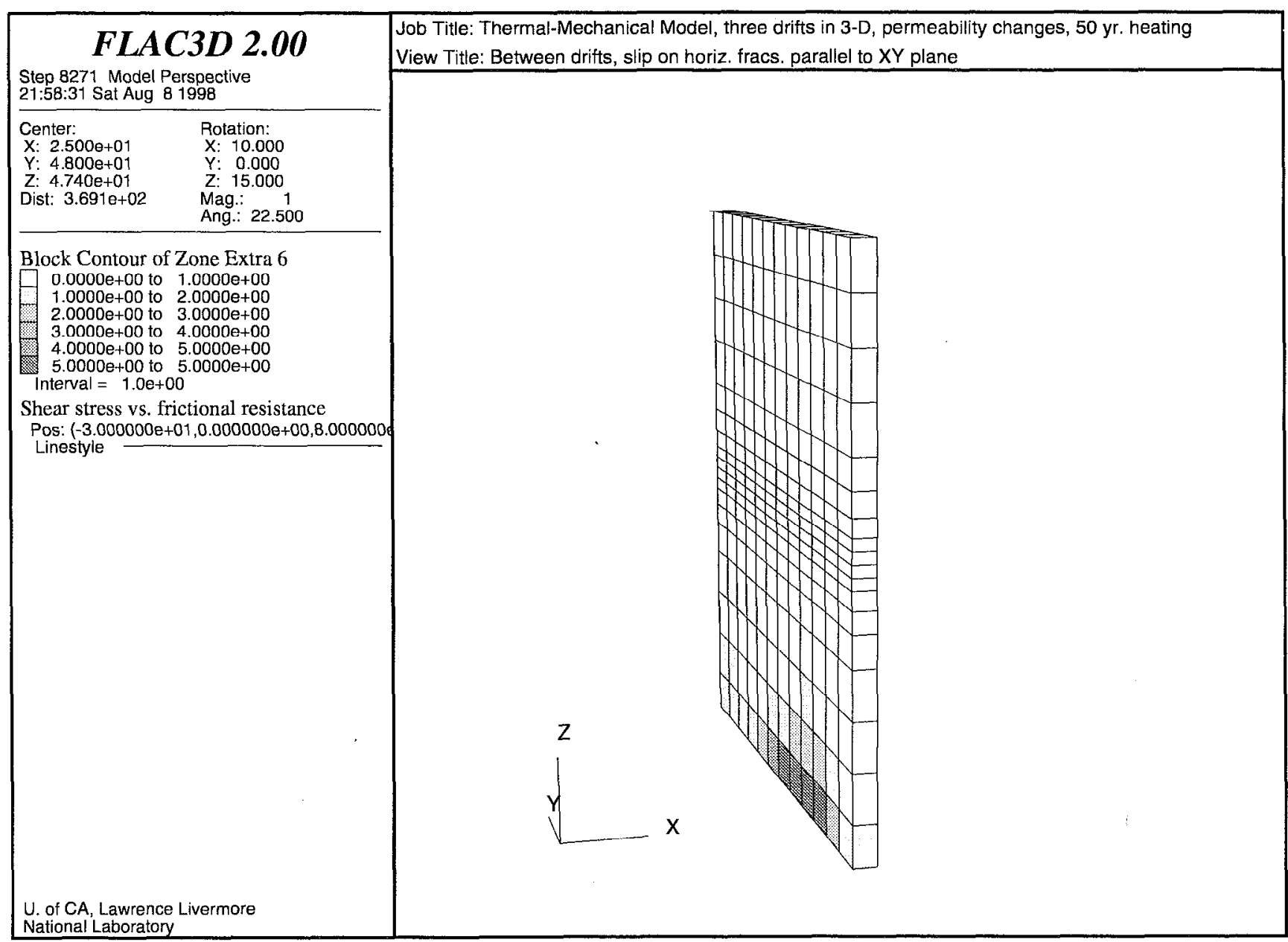

Figure 21. Contours of the ratio of shear stress to frictional resistance for slip planes parallel to the $X Y$ plane and cutting the $Y Z$ plane (region midway between drifts) (DTN LL980805604243.023) 


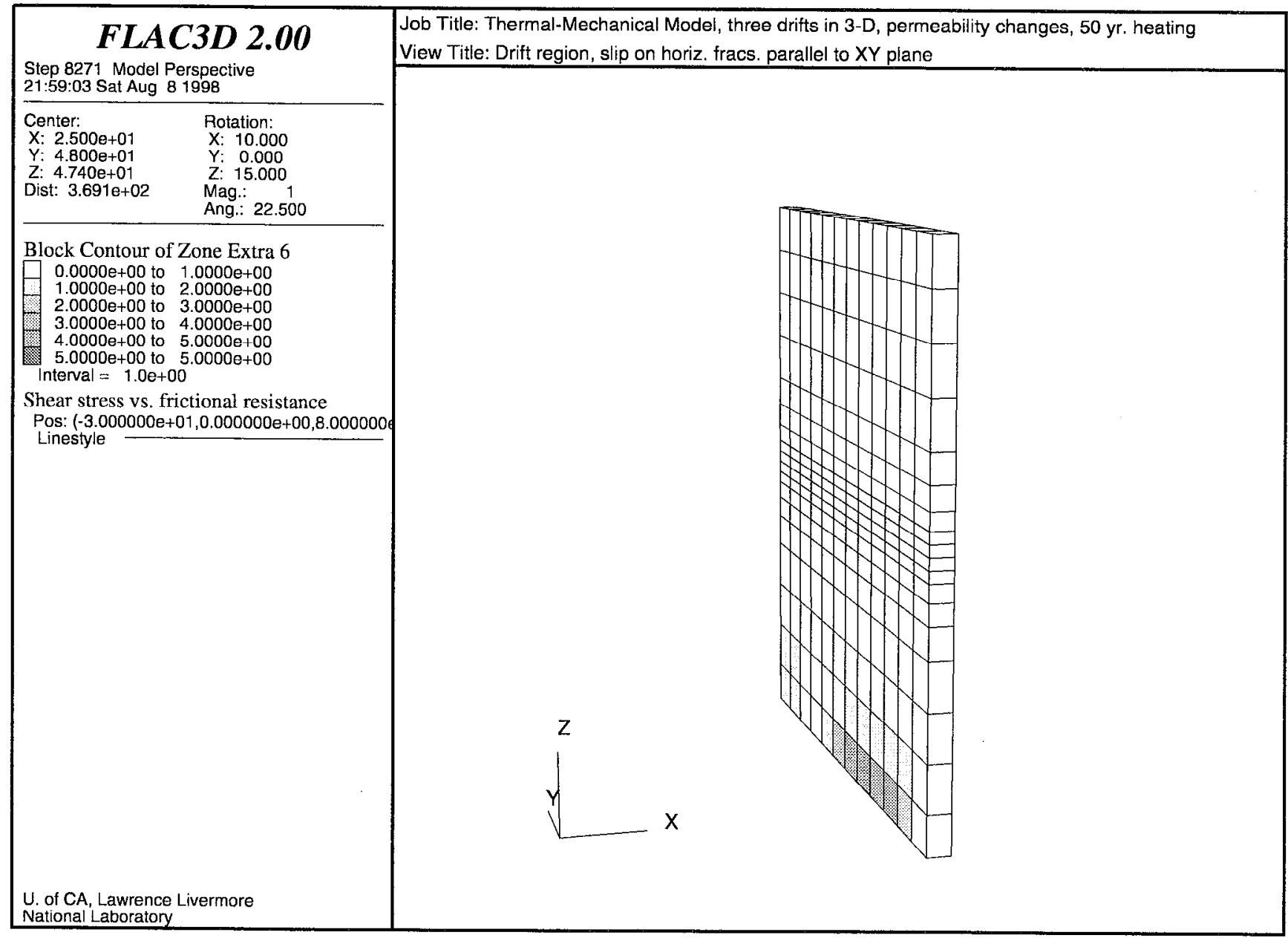

Figure 22. Contours of the ratio of shear stress to frictional resistance for slip planes parallel to the $X Y$ plane and cutting the $Y Z$ plane (region near drift) (DTN LL980805604243.023)

In Figure 11 through Figure 13, we show contours for EW fracture set \#1 in regions lying about $10 \mathrm{~m}$ above, at, and about $10 \mathrm{~m}$ below the drifts in our 3-D model. We see that slip is only expected along these fractures in regions approximately $10 \mathrm{~m}$ above the drifts. Figure 14 through Figure 16 show results in the same regions for NS fracture set \#2. These plots indicate that slip may occur along fractures parallel to NS set \#2 near the drifts, but no slip is expected in regions approximately $10 \mathrm{~m}$ above or $10 \mathrm{~m}$ below the drifts. Note that our previous 2-D FLAC modeling (Hardin et al., 1998, Chapter 4) could not assess the possibility of slip in these directions because the $X Y$ plane in the 3-D model is perpendicular to the plane of the 2-D FLAC model.

We plot results for fracture sets \#2 (NS) and \#3 (H) in Figure 17 and Figure 18, respectively. These figures show that slip is quite likely for NS fracture set \#2 in most parts of the model above the drifts, but no slip is expected for $H$ fracture set \#3. Our 2-D results showed the same slip regions near the bottom of the model but did not show slip in the region above the heaters shown in Figure 17. 
Results for slip along NS fracture set \#2 are also plotted in Figure 19 and Figure 20 for the region halfway between the drifts and for the drift region. These results show that slip is expected along the fractures in regions above the drifts and near the top of the model in regions between the drifts. Note that the 2-D FLAC model was perpendicular to the YZ plane and thus could not assess slip along these directions (Hardin et al., 1998, Chapter 4).

In Figure 21 and Figure 22, we show results for $\mathrm{H}$ fracture set \#3 that indicate no slip is expected along the horizontal fractures anywhere in the 3-D model.

The results show consistently that NS fracture set \#2 is likely to exhibit slip due to thermal stresses, in many parts of the model, and EW fracture set \#1 may have slip in regions just above the drifts, but $\mathrm{H}$ fracture set \#3 is unlikely to have any thermally induced slip. Therefore, we conclude that widespread permeability enhancement of about a factor of two is likely for fractures parallel to NS fracture set \#2, the vertical fractures that strike north-south, for regions above the drifts. In some regions just above the drifts, permeability may increase by a factor of four if slip also occurs along the vertical fractures in EW set \#1. Note that slip on NS fracture set \#2 could not be modeled in the previous 2-D FLAC modeling (Hardin et al., 1998, Chapter 4) because these fractures lie in the plane of the 2-D FLAC model rather than intersecting that plane. 


\subsection{Summary}

We performed THM modeling to estimate bounds on permeability changes in the NFE. For our modeling, we used the TM three-dimensional (3-D) finite-difference code FLAC ${ }^{3 \mathrm{D}}$ version 2.0 (Itasca Consulting Group Inc. 1997) to compute changes in stress and displacement in an elastic model subjected to temperature changes over time. Output from TH modeling (Hardin et al., 1998, Chapter 3) using the code NUFT (Nitao 1993) provided the temperature changes for input to $\mathrm{FLAC}^{3 \mathrm{D}}$. We then estimated how the stress changes could affect permeability.

For this report, we chose to base our 3-D THM modeling on a coarser version of the 2-D model we ran for the work described in Chapter 4 of the Near-Field/Altered Zone Models Report (Hardin et al., 1998, Chapter 4). The grid and temperature field were based on those used by the TH code for $50 \mathrm{yr}$ of heating for the reference Case $1 \mathrm{TH}$ model calculated using Total System Performance Assessment-Viability Assessment (TSPA-VA) base-case properties, nominal infiltration, and a point-load repository design (Hardin et al., 1998, Chapter 3).

The stress field rotated in the region between and below the drifts after $50 \mathrm{yr}$ of hcating. High vertical shear stresses were computed for these regions. The maximum computed displacement was about $7 \mathrm{~cm}$, mainly vertical.

Estimates of permeability changes were obtained by analyzing stresses, following a method we developed previously for 2-D models. In our 3-D modeling for this report, we only considered vertical and horizontal fractures. We extended our 2-D method to a simplified 3-D case.

We conclude that widespread permeability enhancement is likely for fractures parallel to NS fracture set \#2, the vertical fractures that strike north-south, for regions above the drifts. In some regions just above the drifts, permeability may increase by a minimum of a factor of two and possibly more than a factor of four if slip also occurs along the vertical fractures in EW set \#1, the east-west fractures. Our 3-D results agree with those obtained in previous 2-D modeling, with the added advantage that we were able to model permeability changes in directions orthogonal to the 2-D model. 


\subsection{References}

Albin, A.L., Singleton, W.L., Moyer, T.C., Lee, A.C., Lung, R.C., Eatman, G.L.W., and Barr, D.L. 1997. Geology of the Main Drifl-Slation 28+00 to 55+00, Exploralory Studies Facility. Yucca Mountain Project, Yucca Mountain, Nevada. Denver, Colorado: Bureau of Reclamation and U.S. Geological Survey. MOL.19970625.0096.

Bandis, S., Lumsden, A.C., and Barton, N.R. 1983. "Fundamentals of rock joint deformation." International Journal of Rock Mechanics and Mining Science E Geomechanics Abstracts Abstr. 20):249-268. 224201.

Barton, C.A., Hickman, S., Morin, R., Zoback, M.D., Finkbeiner, T., Sass, J., and Benoit, D. 1997. "Fracture permeability and its relationship to in-situ stress in the Dixie Valley, Nevada, Geothermal Reservoir." In proceedings from Twenty-Second Workshop on Geothermal Reservoir Engineering. Stanford University, Stanford, California: January 27-29, 1997. MOL.19980710.0823.

Barton, C.A., Zoback, M.D., and Moos, D. 1995. "Fluid flow along potentially active faults in crystalline rock." Geology 23(8):683-686.

Barlon, N.R., Bandis, S., and Bakhtar, K. 1985. "Strength, deformation, and conductivity coupling of rock joints." International Journal of Rock Mechanics and Mining Science E Geomechanics Abstracts 22(3):121-140. 217135.

Berge, P.A., Wang, H.F., Shaffer, R.J., and Blair, S.C. 1997. Evaluation of Models for Estimating Changes in Fracture Permeability due to Thermo-Mechanical Stresses in Host Rock Surrounding a Potential Repository. February 18, 1997. Milestone report for the CRWMS Management and Operating Contractor, United States Department of Energy. SPLF1M4. Also UCRL-ID-131704. Livermore, California: Lawrence Livermore National Laboratory.

Blair, S.C., Berge, P.A., and Wang, H.F. 1995. Geomechanical Analysis of the Large Block Test. UCRL-ID-122898. Livermore, California: Lawrence Livermore National Laboratory. MOL:19970506.0117.

Blair, S.C., Berge, P.A., and Wang, H.F. 1997. Bounding Models for Estimating Changes in Fracture Permeability due to Thermo-Mechanical Stresses in Host Rock Surrounding the Repository. I: Permeability Changes Estimated for the Heated Drift Test. Milestone report for the CRWMS Management and Operating Contractor, U.S. Department of Energy. SPLF2M4. Livermore, California: Lawrence Livermore National Laboratory. MOL.19980107.0411.

Blair, S.C., Buscheck, T.A., Carlberg, E., Carlson, R., Costantino, M.S., Daily, W.D., DeLoach, L.D., Lee, K., Lin, W., Pletcher, R., Ramirez, A.L., Roberts, J.J., Rosenberg, N.D., Ruddle, D., and Wagoner, J.L. 1998. Drift-Scale Test Status Report. July 1998. SP2670M4 and SP2931M4. Also UCRL-ID-131195. Livermore, California: Lawrence Livermore National Laboratory.

Blair, S.C., and Costantino, M.S. 1997. Results of a Coupled Fracture-Flow Test at the 0.5-m Scale. September 30, 1997. Milestone report for the CRWMS Management and Operating Contractor, U.S. Department of Energy. SPLFA2M4. Livermore, California: Lawrence Livermore National Laboratory. MOL.19980114.0112. 
Bodvarsson, G.S., and Bandurraga, T.M. 1996. Development and Calibration of the ThreeDimensional Site-Scale Unsaturated Zone Model of Yucca Mountain, Nevada. Berkeley, California: Lawrence Berkeley National Laboratory, Earth Sciences Division. MOL.19970211.0176.

Bodvarsson, G.S., Bandurraga, T.M., and Wu, Y.S. 1997. The Site-Scale Unsaturated Zone Model of Yucca Mountain, Nevada, for the Viability Assessment. June, 1997. LBNL-40376, UC-814. Berkeley, California: Lawrence Berkeley National Laboratory, in collaboration with the U.S. Geological Survey. MOL.19971014.0232.

Brown, S.R. 1994. Simple Mathematical Model of a Rough Fracture. S $\Lambda$ ND92-2216J. Albuquerque, New Mexico: Sandia National Laboratories. MOL.19941106.0040.

Brown, S.R. 1995. "Simple mathematical model of a rough fracture." J. Geophys. Res. 100:59415952. 222415.

Brown, S.R., and Bruhn, R.L. 1997. Fluid Permeability of Deformable Fracture Networks. SAND970159. Albuquerque, New Mexico: Sandia National Laboratories.

MOL.19980514.0045.

Damjanac, B. 1998. Numerical Analysis of Effects of the Drift Scale Test on the Permeability of the Rock Mass at Yucca Mountain. May 1998. Ref: 0840. Minncapolis, Minnesota: Itasca Consulting Group, Inc.

Hardin, E.L., Blair, S.C., Buscheck, T.A., Chesnut, D.A., DeLoach, L.D., Glassley, W.E., Johnson, J.W., Knapp, R.B., Lee, K., Meike, A., Myers, K., Nitao, J.J., Palmer, C.E., Rogers, L.L., Rosenberg, N.D., Viani, B.E., Wang, H.F., Wittwer, C., and Wolery, T.J. 1998. Near-Field/Altered-Zone Models Report. Milestone report for the CRWMS Management and Operating Contractor, U.S. Department of Energy. SP3100M3. Also UCRL-ID-129179. Livermore, California: Lawrence Livermore National Laboratory. MOL.19980630.0560. MOL.19980715.0247.

Hardin, E.L., and Chesnut, D.A. 1997. Synthesis Report on Thermally Driven Coupled Processes. Milestone report for the CRWMS Management and Operating Contractor, U.S. Department of Energy. SPL8BM3. Also UCRL-ID-128495. Livermore, California: Lawrence Livermore National Laboratory. MOL.19980120.0035.

Hart, R.D., and Cundall, P.A. 1992. "Microcomputer programs for explicit numerical analysis in geotechnical engineering." In proceedings from International Seminar on Numerical Methods in Geomechanics. Moscow, Russia:

Hibbitt, K.S., Inc.,. 1994. ABAQUS/Standard User's Manual (Version 5.4), Vols. I and II. Pawtucket, Rhode Island: Hibbitt, Karlsson \& Sorensen, Inc.

Itasca Consulting Group Inc. 1996. FLAC, Fast Lagrangian Analysis of Continua, Version 3.3, Vol. I-IV, User's Manuals. Minneapolis, Minnesota: Itasca Consulting Group, Inc.

Itasca Consulting Group Inc. 1997. FLAC ${ }^{3 D}$ : Fast Lagrangian Analysis of Continua, Version 2.0, Vol. I-IV, User's Manuals. Minneapolis, Minnesota: Itasca Consulting Group, Inc.

Jaeger, J.C., and Cook, N.G.W. 1976. Fundamentals of Rock Mechanics. London, United Kingdom: Chapman and Hall. 209863. 
Nitao, J.J. 1993. "The NUFT Code for modeling nonisothermal, multiphase, multicomponent flow and transport in porous media." EOS, Trans. Am. Geophys. Union, Fall Meeting Supplement 74(43):313-314. (Also UCRL-JC-114769-ABS, Lawrence Livermore National Laboratory, Livermore, California)

Nitao, J.J. 1995. Reference Manual for the NUFT Flow and Transport Code, Version 1.0. Livermore, California: Lawrence Livermore National Laboratory. (UCRL-IC-113520)

Ouyang, Z., and Elsworth, D. 1993. "Evaluation of groundwater flow into mined panels." International Journal of Rock Mechanics and Mining Science E Geomechanics Abstracts 30(2):

Raven, K.G., and Gale, J.E. 1985. "Water flow in a natural rock fracture as a function of stress and sample size." International Journal of Rock Mechanics and Mining Science $\mathcal{E}$ Geomechanics Abstracts 22(4):251-261.

Stock, J.M., Healy, J.H., and Hickman, S.H. 1984. Report on Televiewer Log and Stress Measurements in Core Hole USW G-2, Nevada Test Site. OFR-84-172. Denver, Colorado: U.S. Geological Survey. NNA.870406.0157. 208153.

Stock, J.M., Healy, J.H., Hickman, S.H., and Zoback, M.D. 1985. "Hydraulic fracturing stress measurements at Yucca Mountain, Nevada, and relationship to regional stress field." J. Geophys. Res. 90(B10):8691-8706. HQS.19880517.1509. 219009.

Turcotte, D.L., and Schubert, G. 1982. Geodynamics Applications of Continuum Physics to Geological Problems. New York, New York: John Wiley \& Sons. 235924.

Wilder, D.G. 1987. Influence of Stress-Induced Deformations on Observed Water Flow in Fractures at the Climax Granitic Stock. UCRL-95539, Rev. 1. Livermore, California: Lawrence Livermore National Laboratory. NNA.19880425.0044. 203036. 



\section{Appendix A}

Additional Plots of Displacements and Stress 



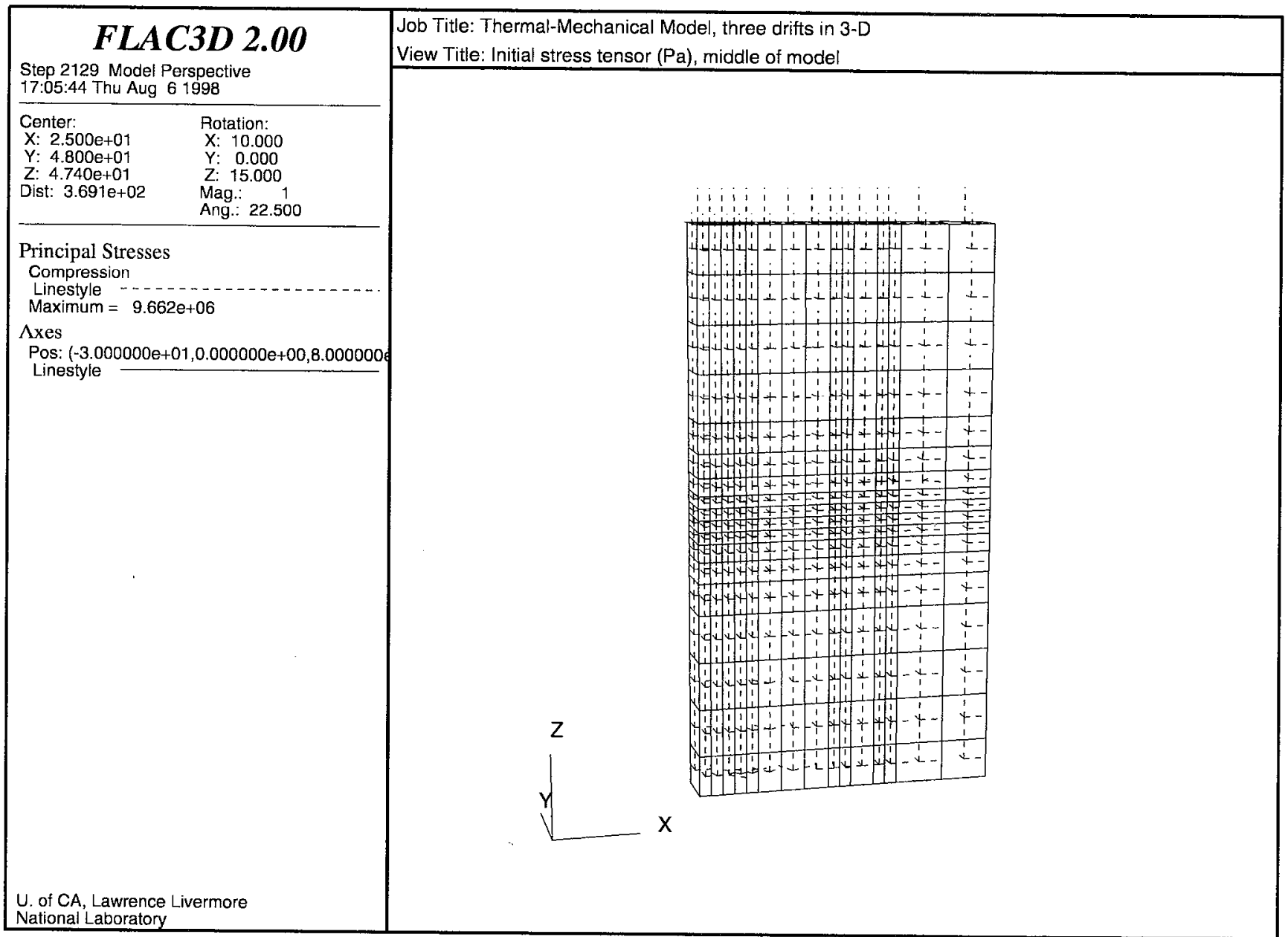

Figure A1. Model for 1.5 drifts in 3-D, initial stress field near model center (DTN LL980805604243.023) 


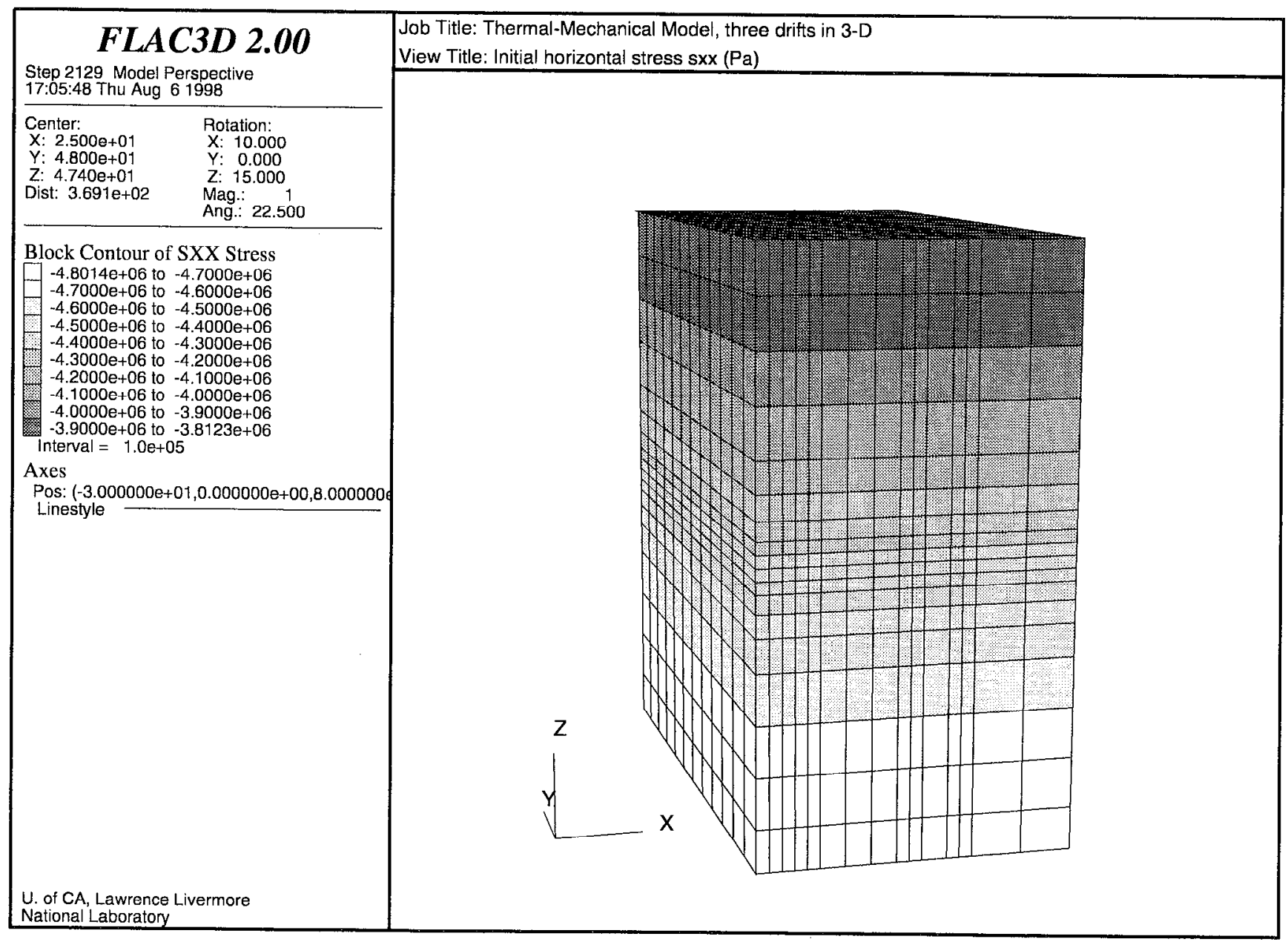

Figure A2. Model for 1.5 drifts in 3-D, initial horizontal stress component sxx, entire model (same as syy) (DTN LL980805604243.023) 


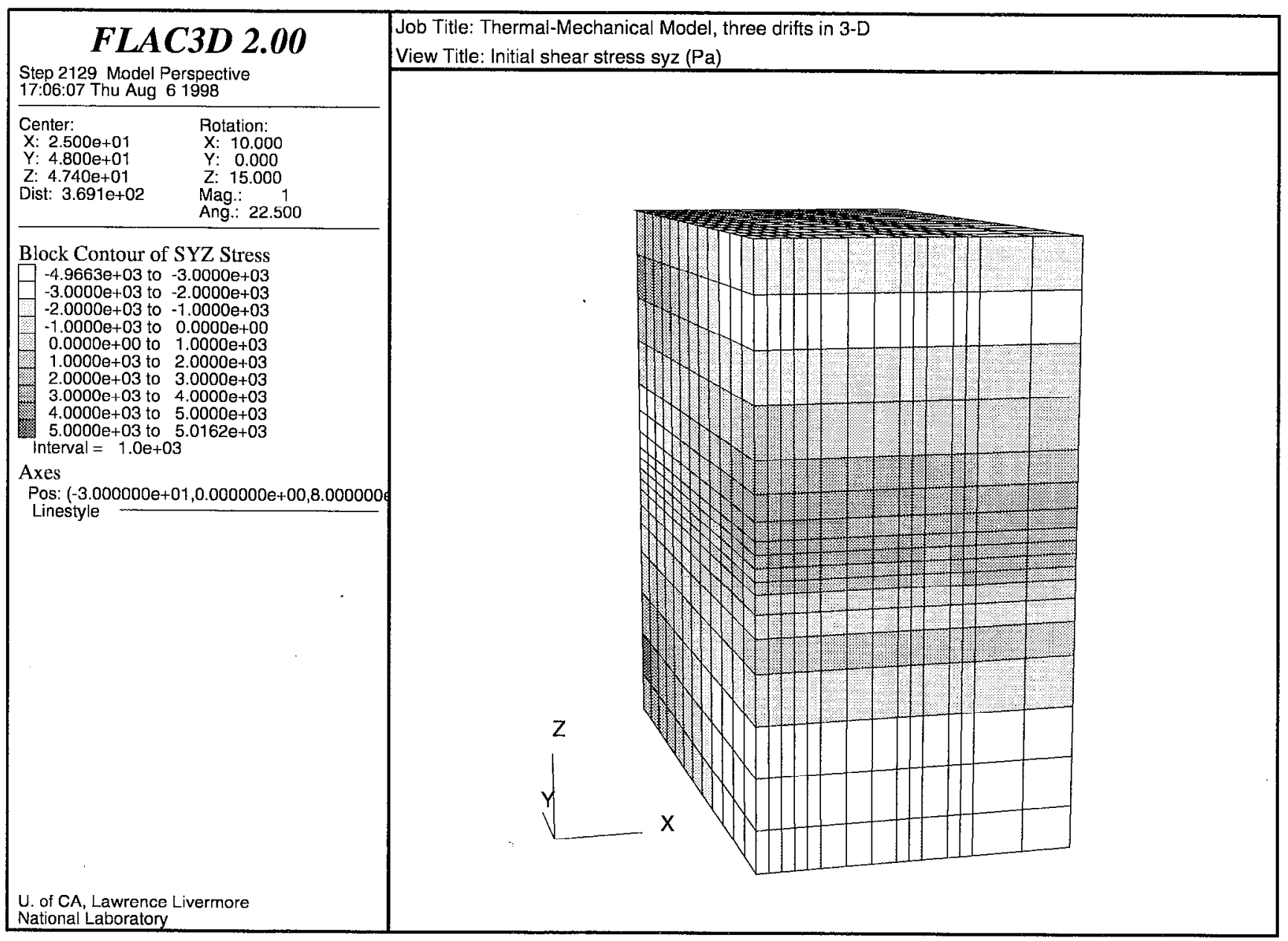

Figure A3. Model for 1.5 drifts in 3-D, initial shear stress component syz (DTN LL980805604243.023)

The sxy and sxz components are also small $(<<1 \mathrm{MPa})$. 


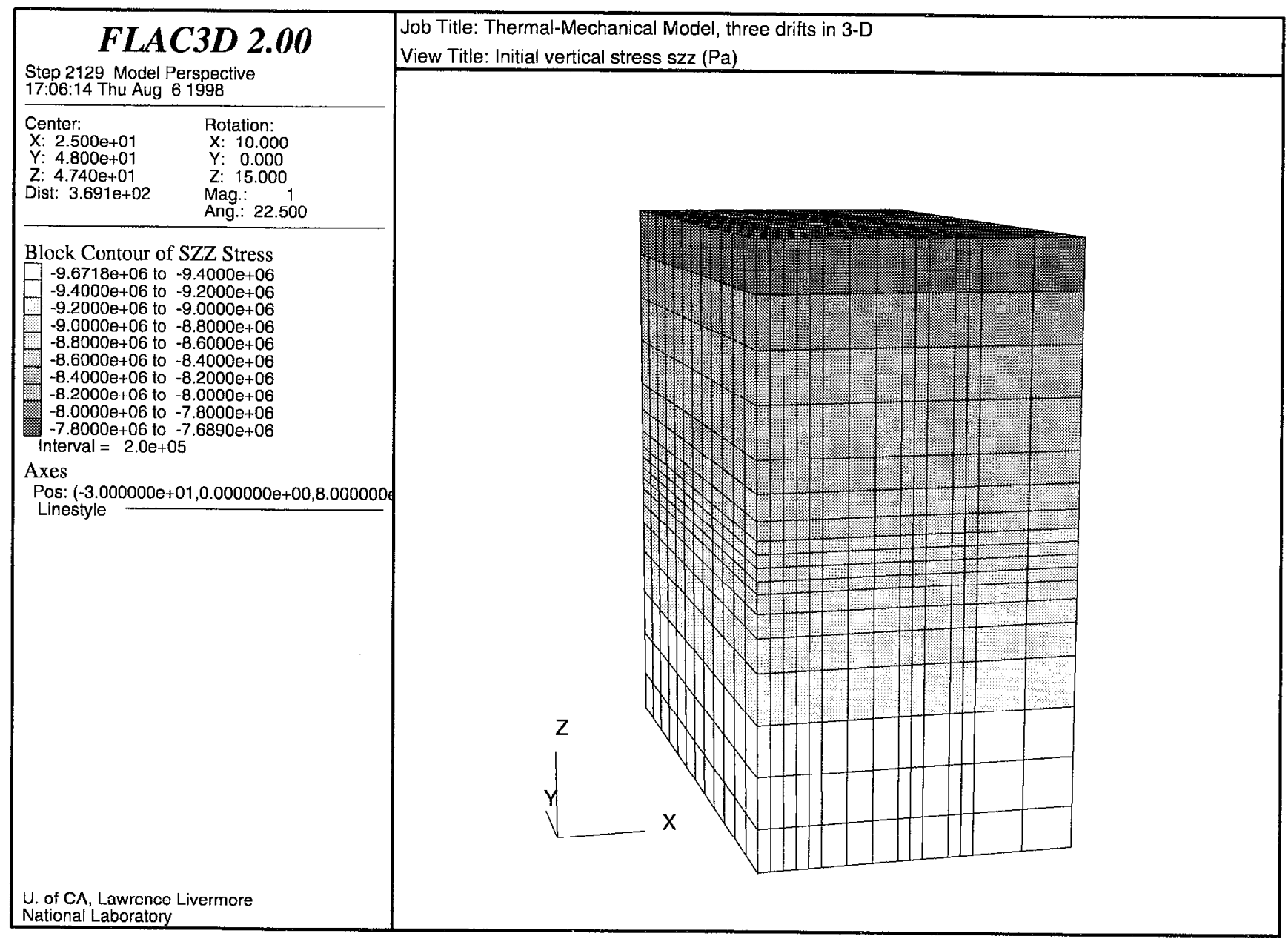

Figure A4. Model for 1.5 drifts in 3-D, initial vertical stress component szz (DTN LL980805604243.023) 


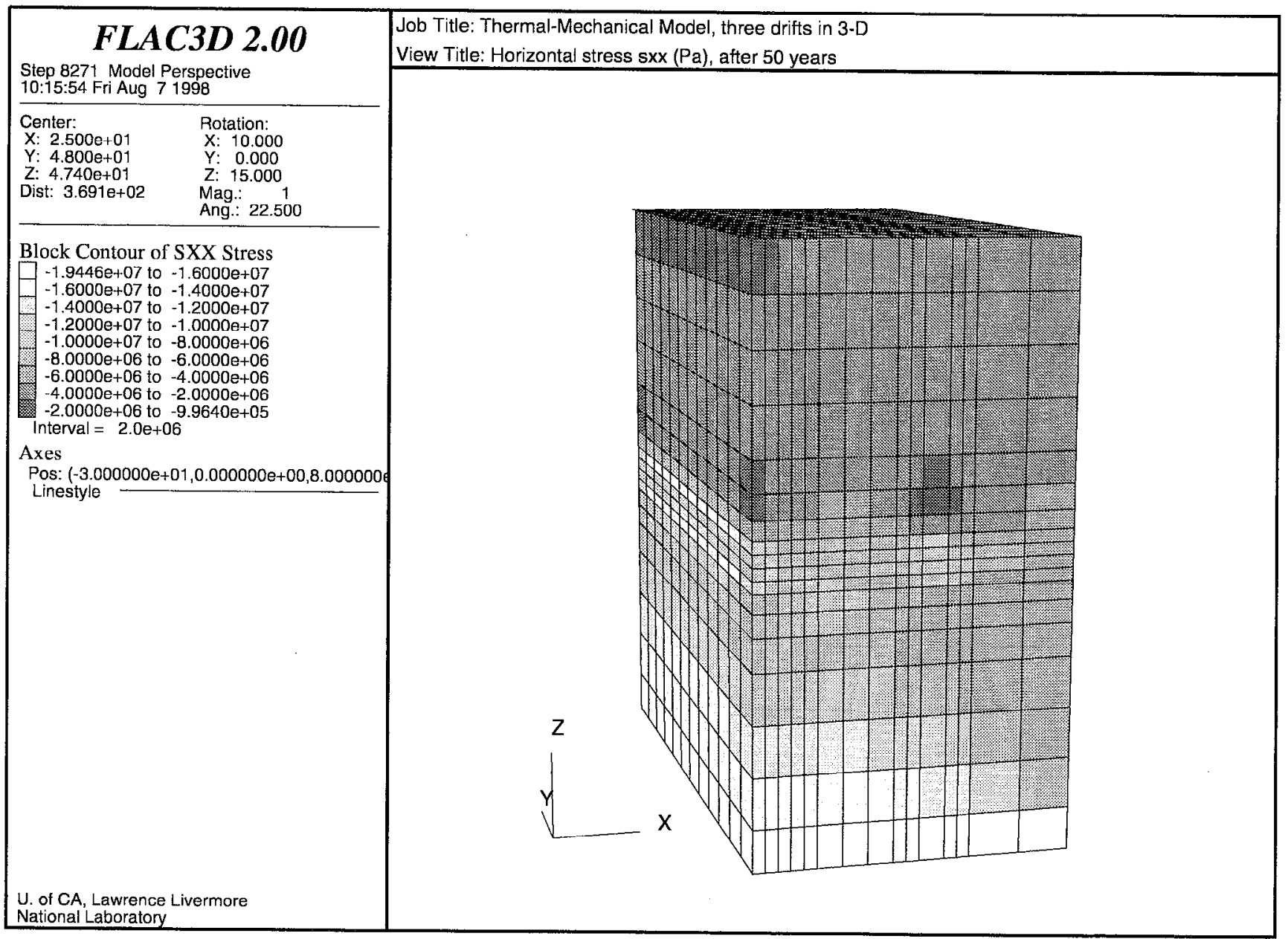

Figure A5. Model for 1.5 drifts in 3-D, horizontal stress component sxx after 50 yr heating, entire model (DTN LL980805604243.023) 


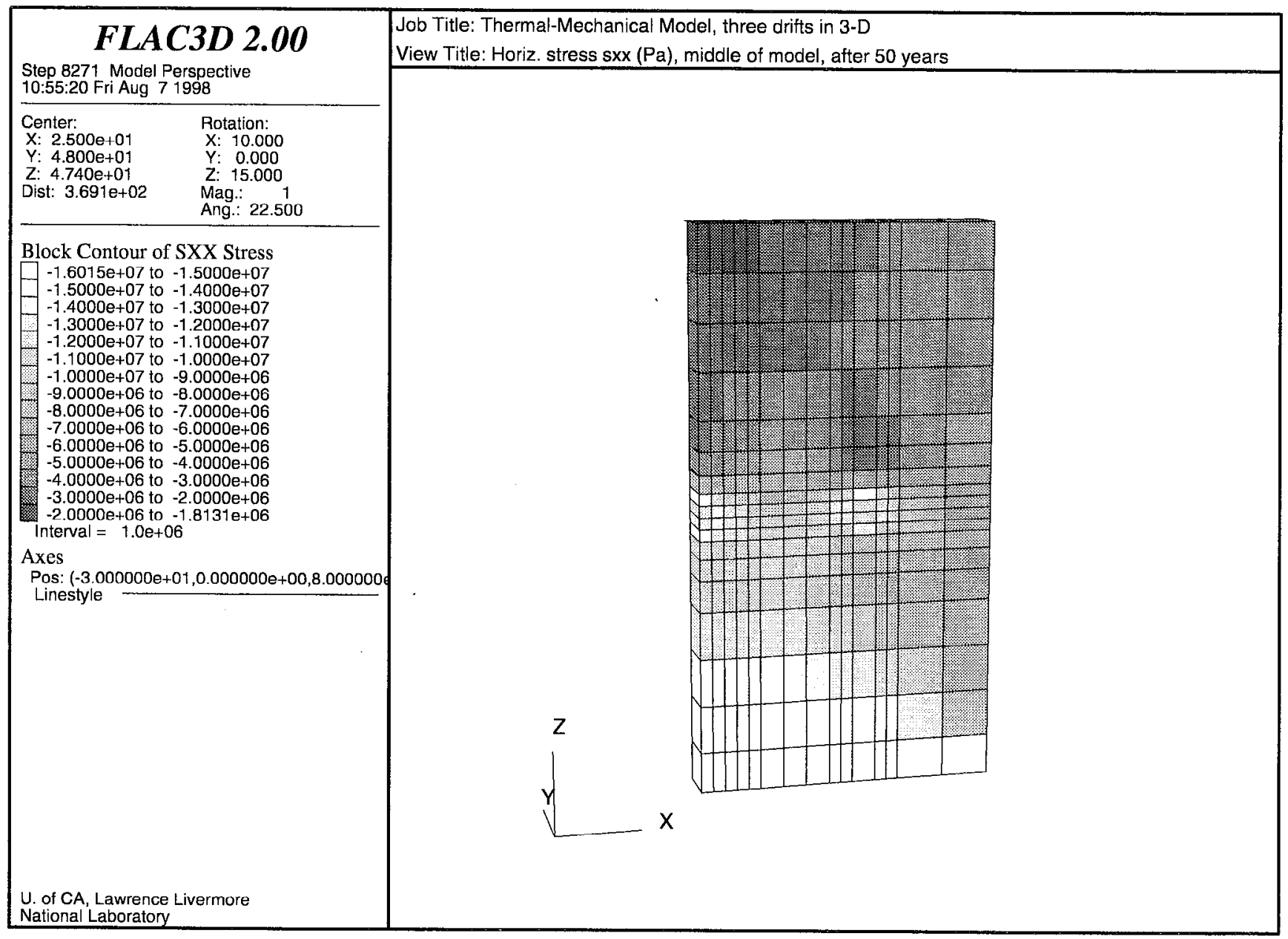

Figure A6. Model for 1.5 drifts in 3-D, horizontal stress component sxx after 50 yr heating, region near middle of model (DTN LL980805604243.023) 


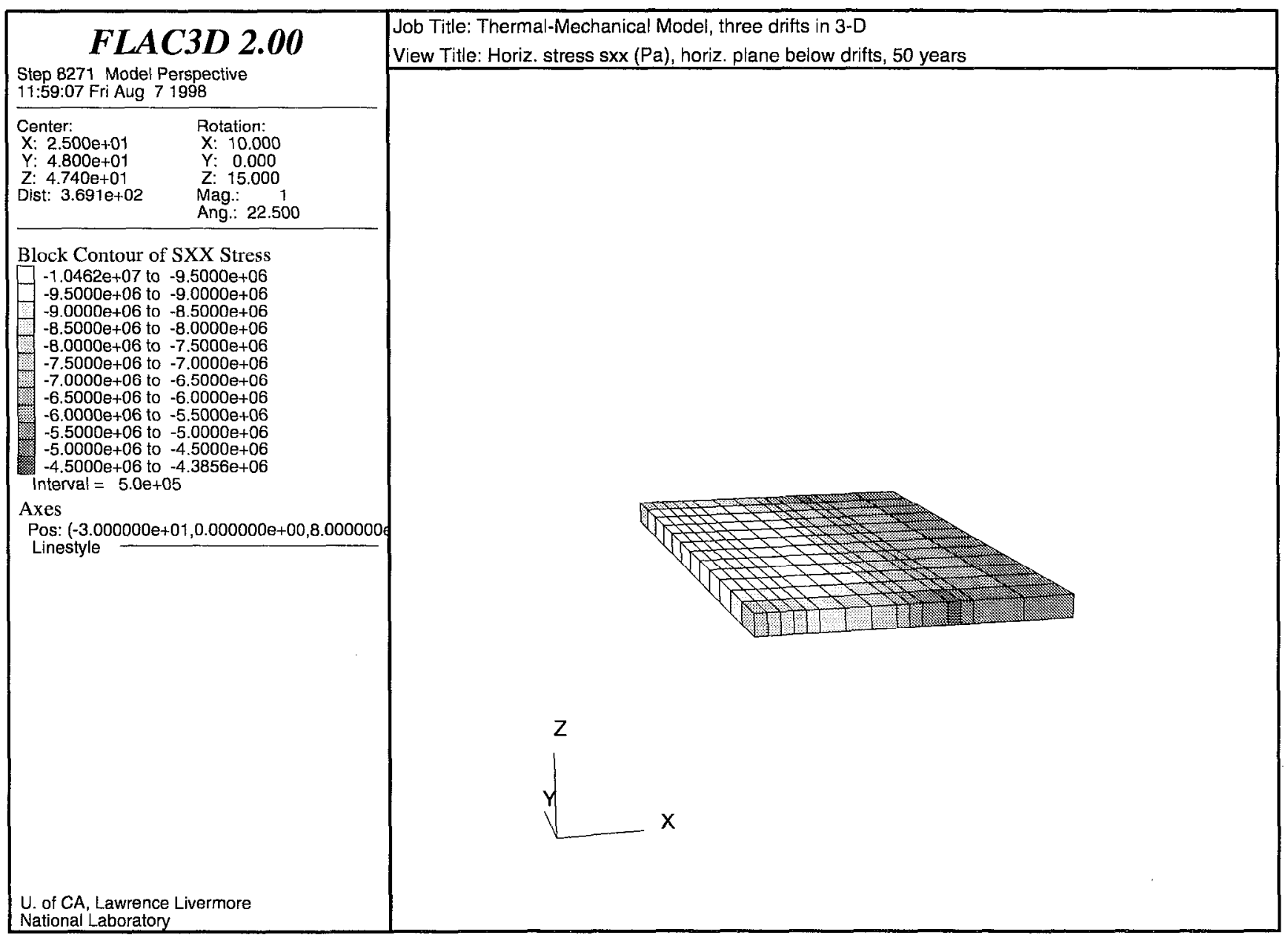

Figure A8. Model for 1.5 drifts in 3-D, horizontal stress component sxx after 50 yr heating, region near drifts (DTN LL980805604243.023) 


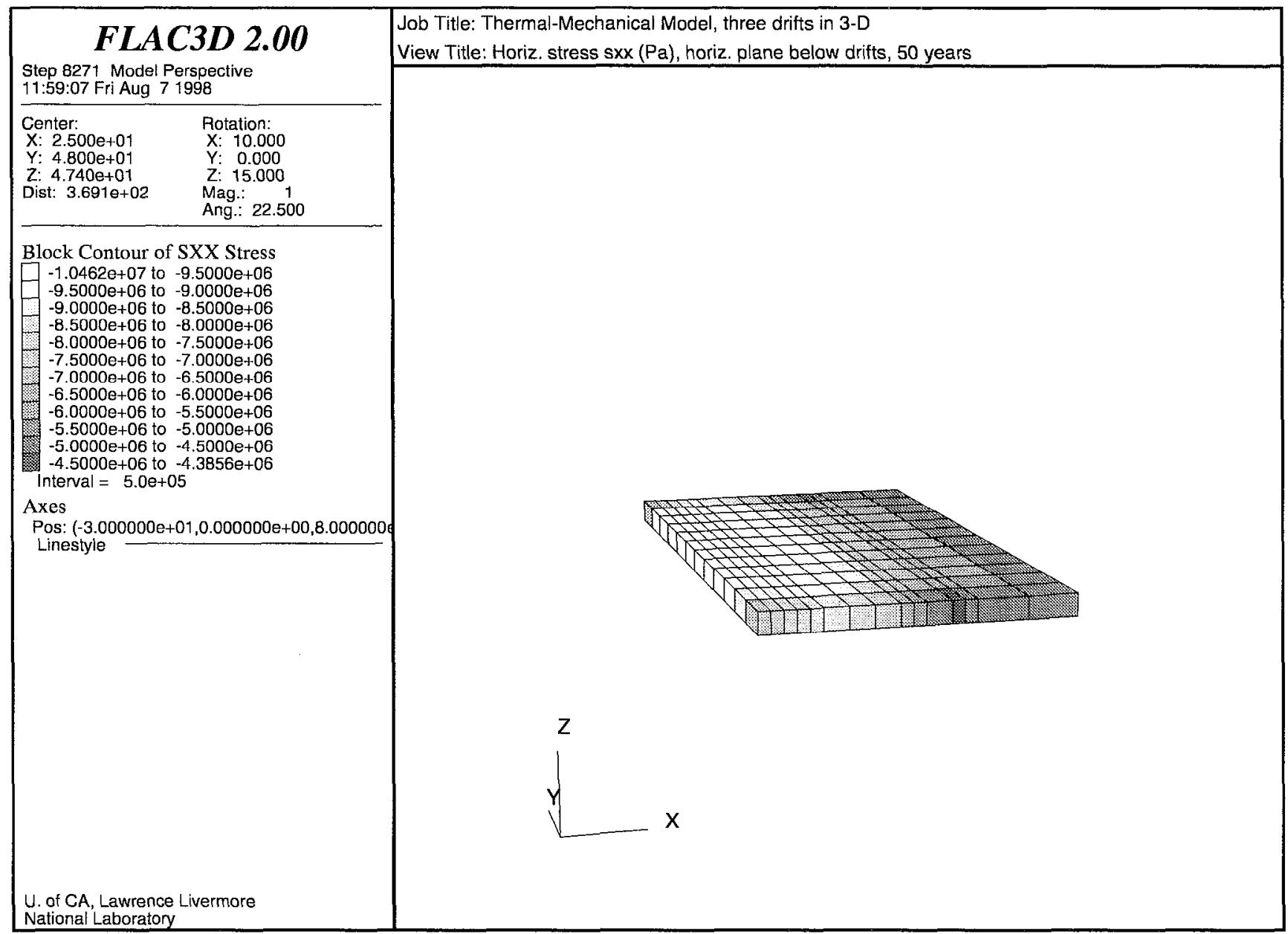

Figure A9. Model for 1.5 drifts in 3-D, horizontal stress component sxx after 50 yr heating, region about $10 \mathrm{~m}$ below drifts (DTN LL980805604243.023) 


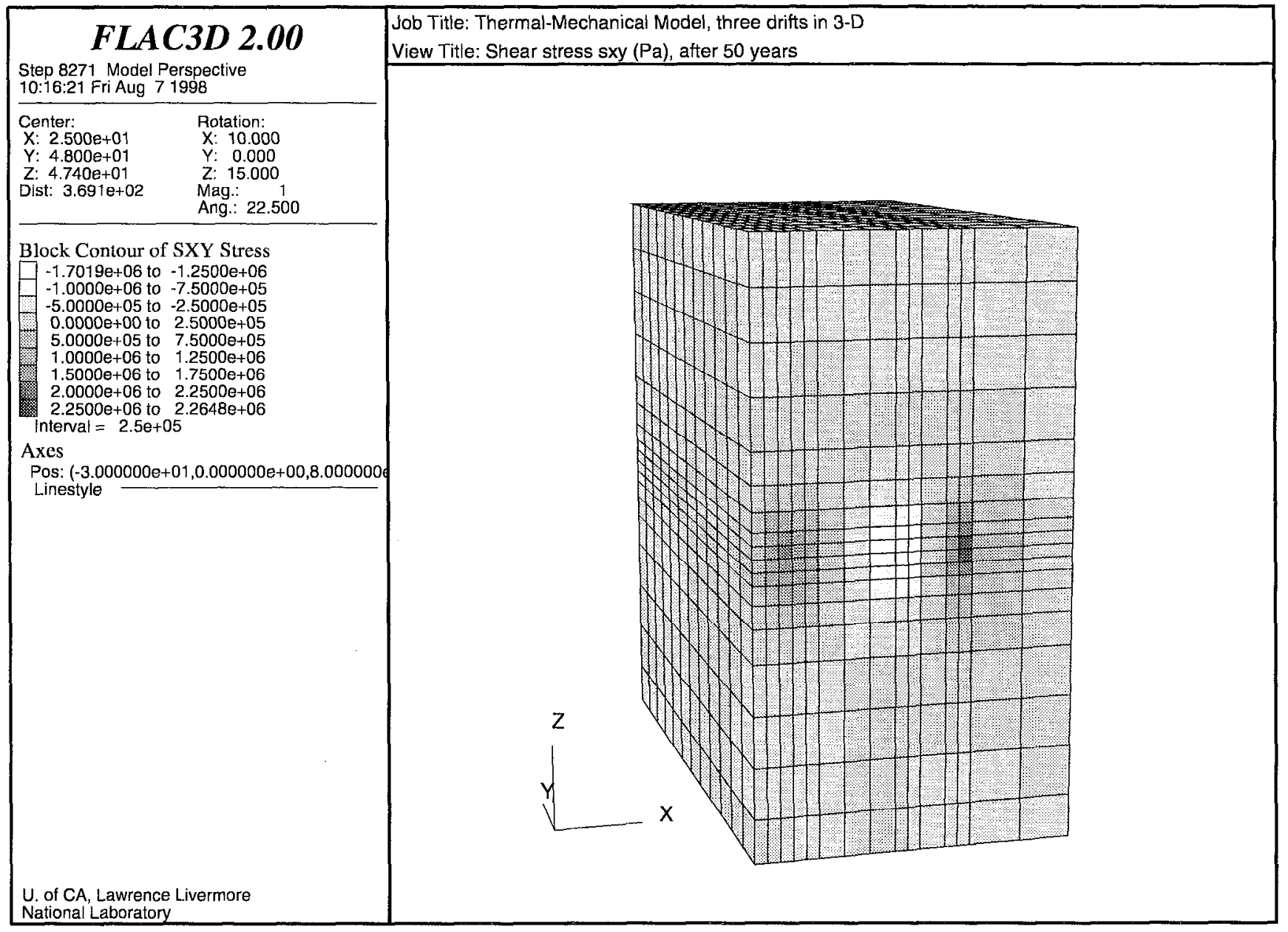

Figure A10. Model for 1.5 drifts in 3-D, shear stress component sxy after 50 yr heating, entire model (DTN LL980805604243.023) 


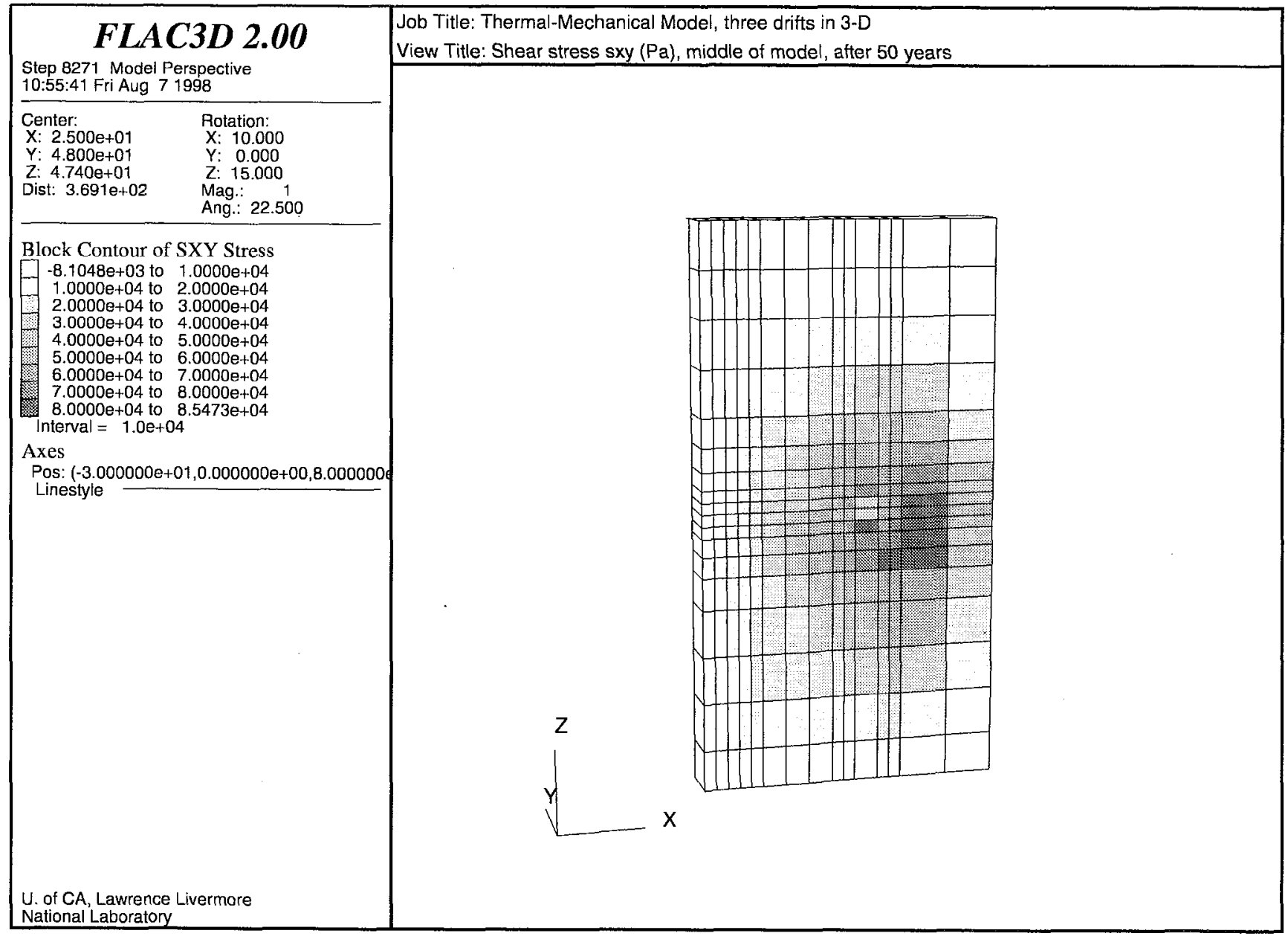

Figure A11. Model for 1.5 drifts in 3-D, shear stress component sxy after 50 yr heating, region near middle of model (DTN LL980805604243.023) 


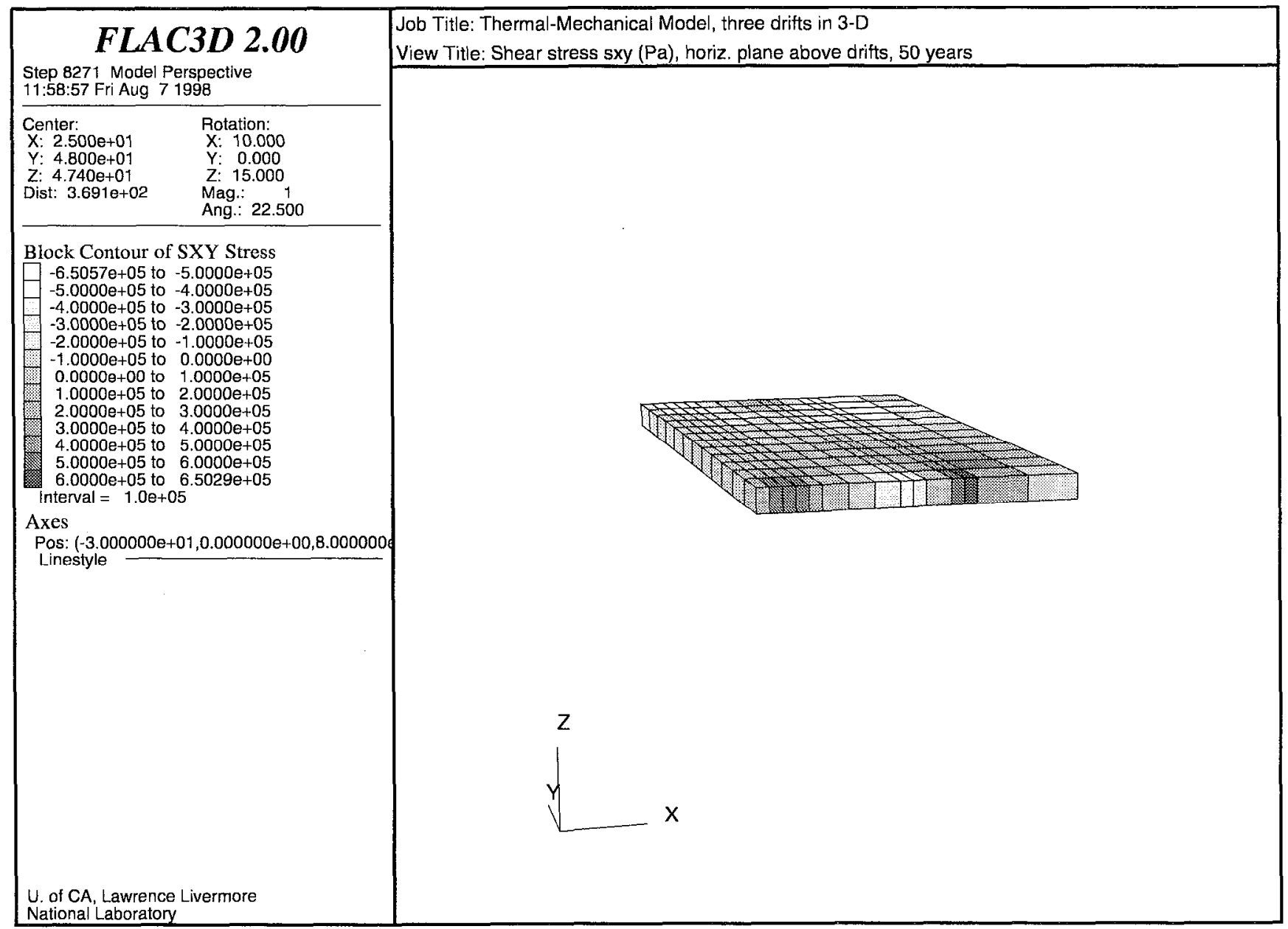

Figure A12. Model for $1.5 \mathrm{drifts}$ in 3-D, shear stress component sxy after $50 \mathrm{yr}$ heating, region about $10 \mathrm{~m}$ above drifts (DTN LL980805604243.023) 


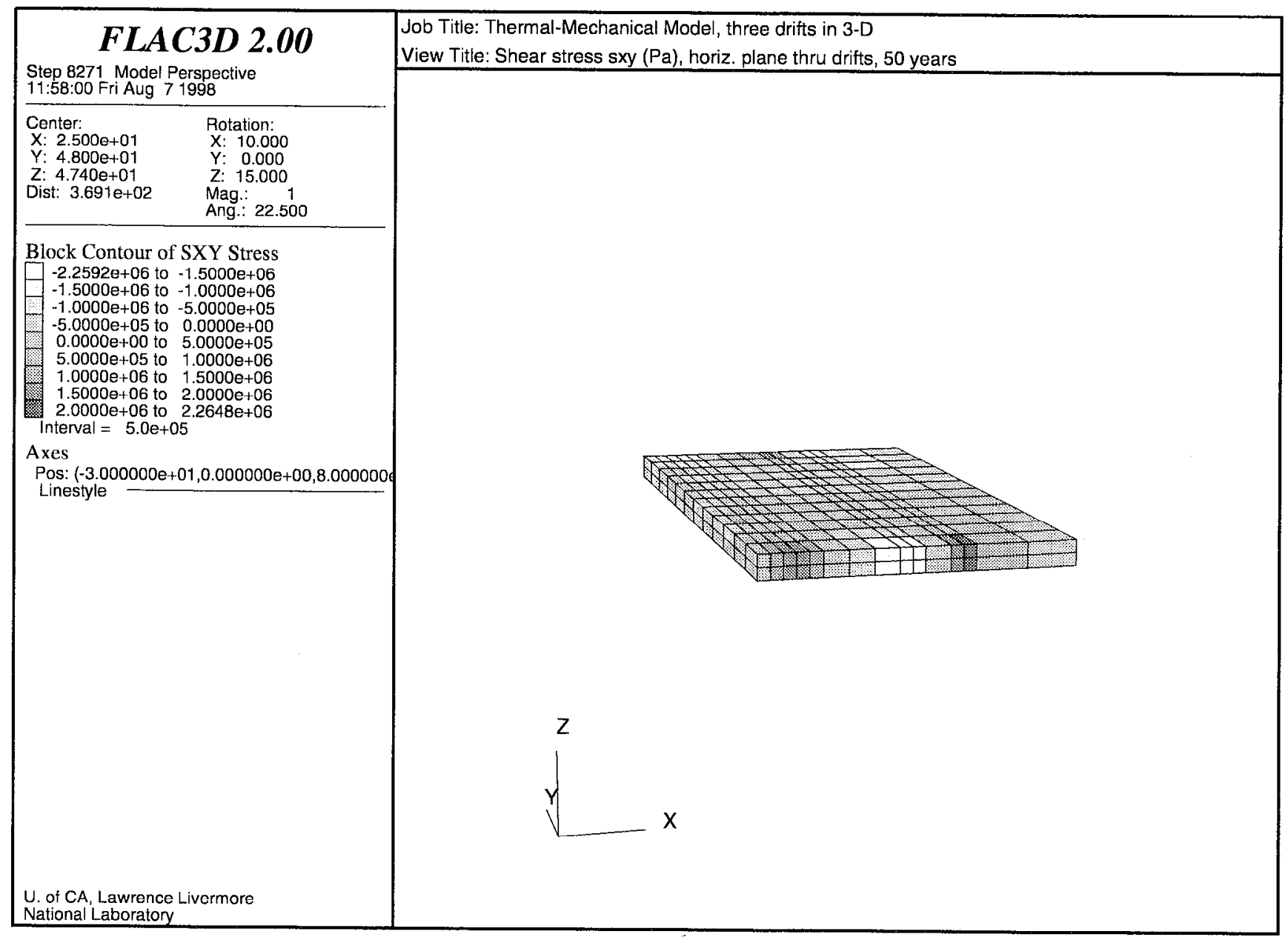

Figure A13. Model for 1.5 drifts in 3-D, shear stress component sxy after 50 yr heating, region near drifts (DTN LL980805604243.023) 


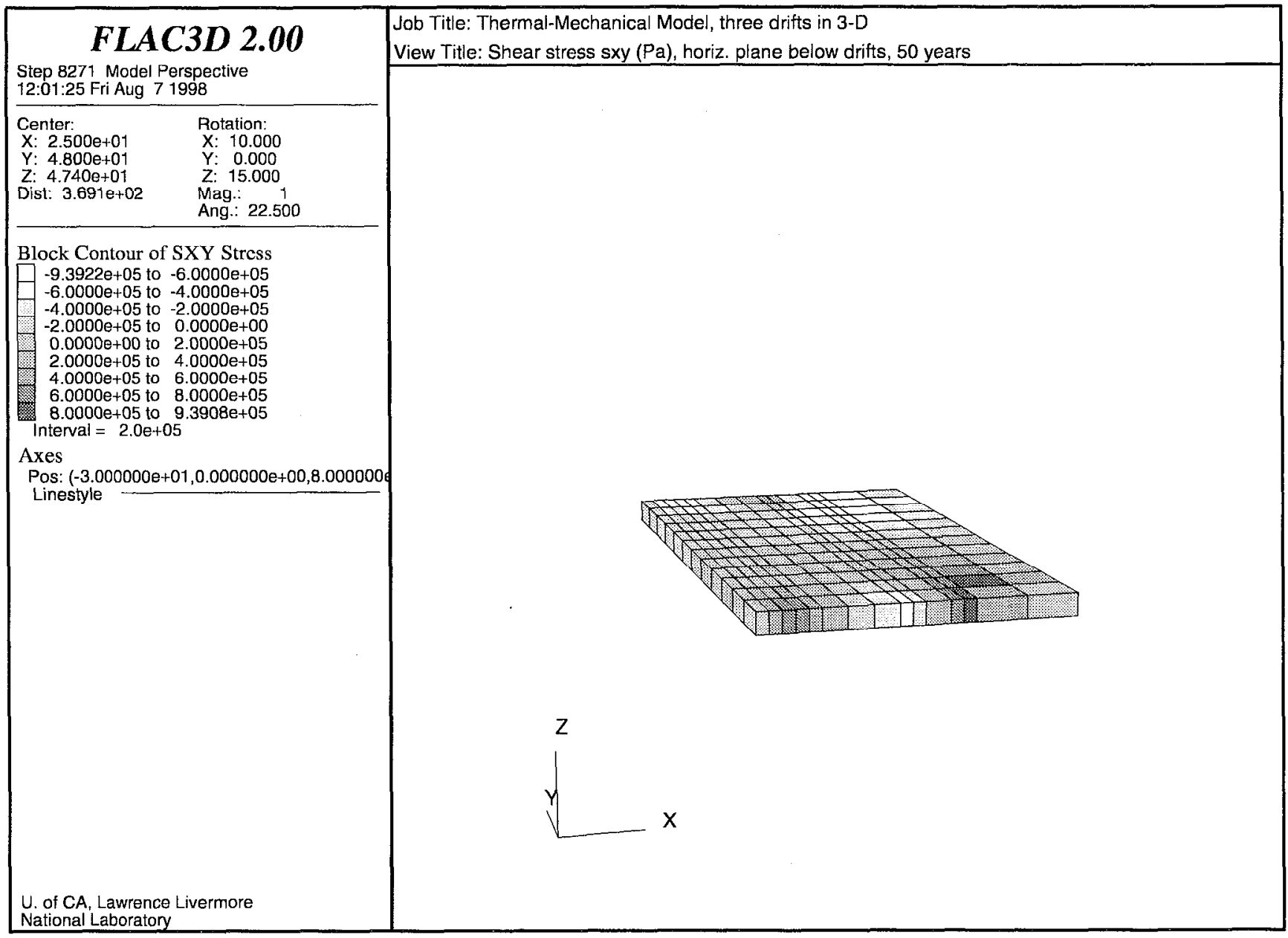

Figure A14. Model for 1.5 drifts in 3-D, shear stress component sxy after 50 yr heating, region about $10 \mathrm{~m}$ below drifts (DTN LL980805604243.023) 


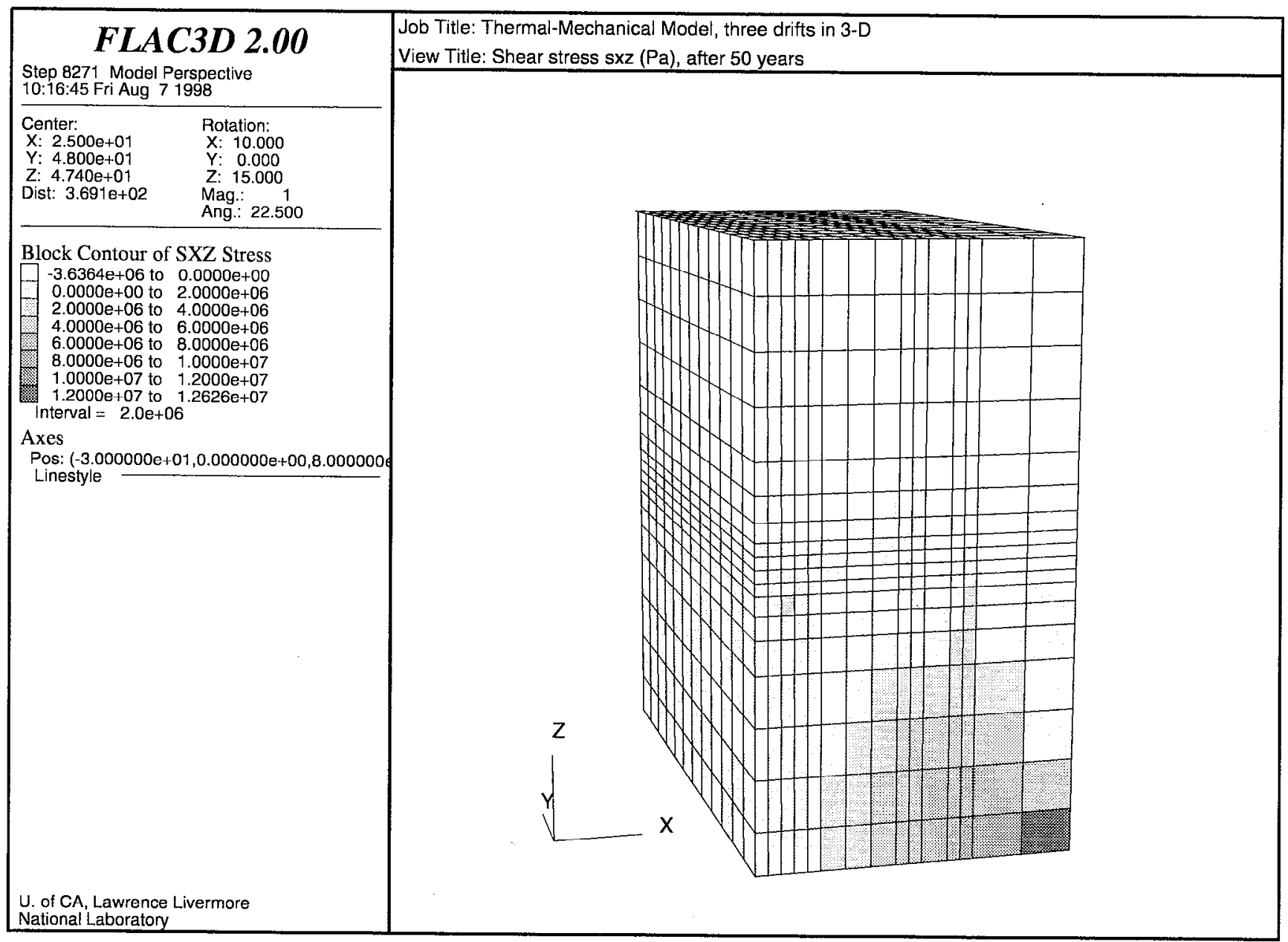

Figure A15. Model for 1.5 drifts in 3-D, shear stress component sxz after 50 yr heating, entire model (DTN LL980805604243.023) 


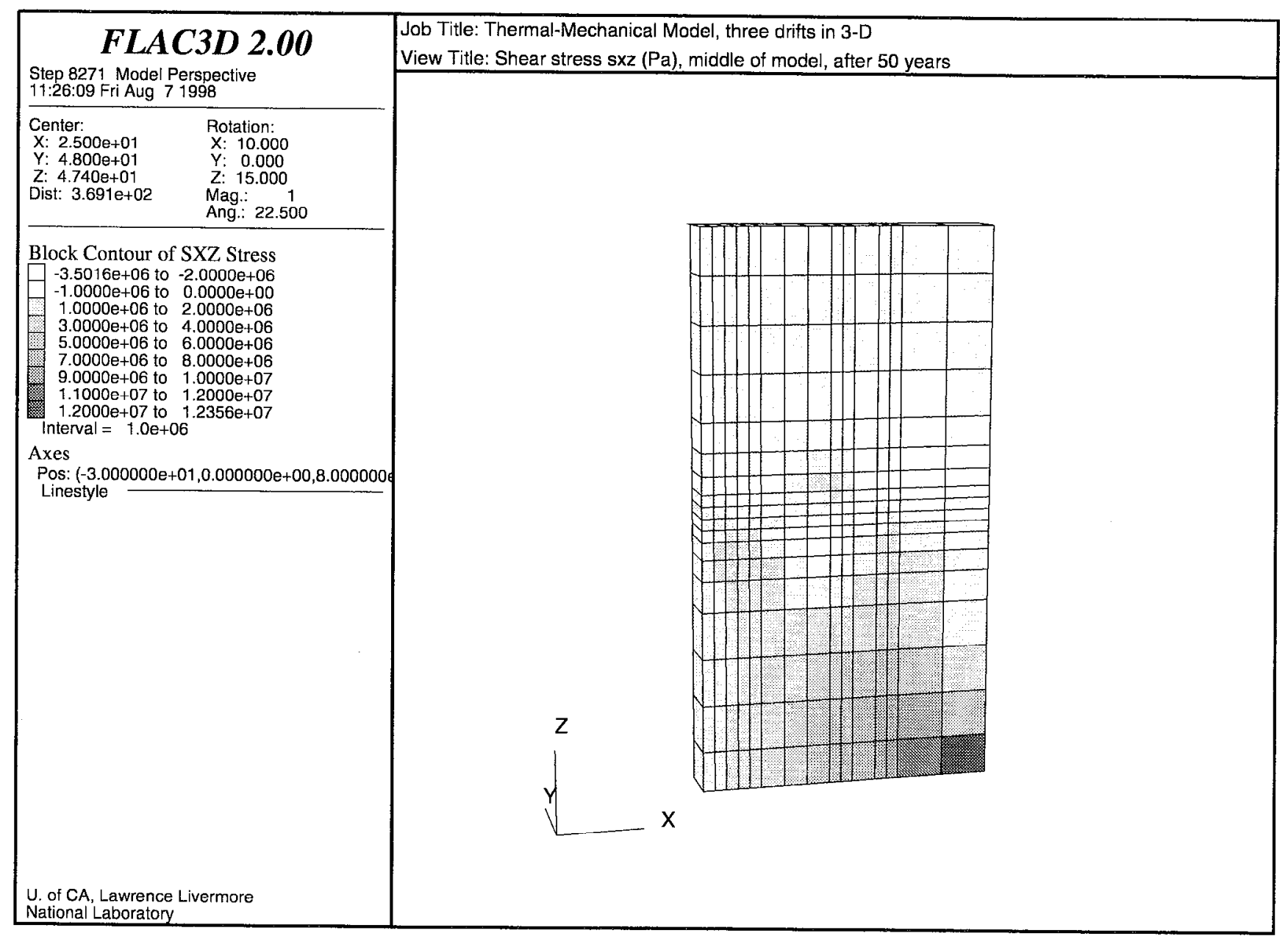

Figure A16. Model for 1.5 drifts in 3-D, shear stress component sxz after 50 yr heating, region near middle of model (DTN LL980805604243.023) 


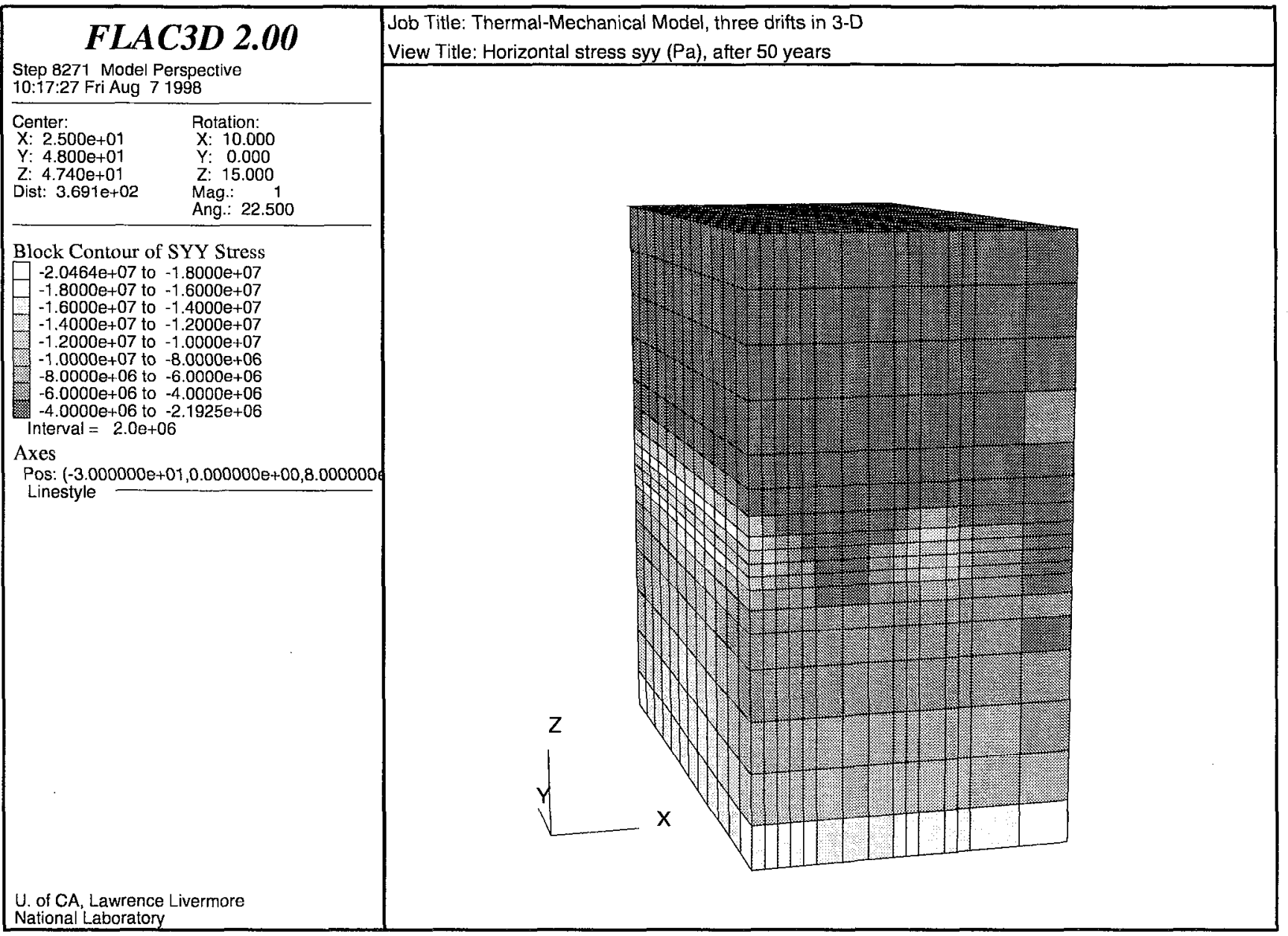

Figure A17. Model for 1.5 drifts in 3-D, horizontal stress component syy after 50 yr heating, entire model (DTN LL980805604243.023) 


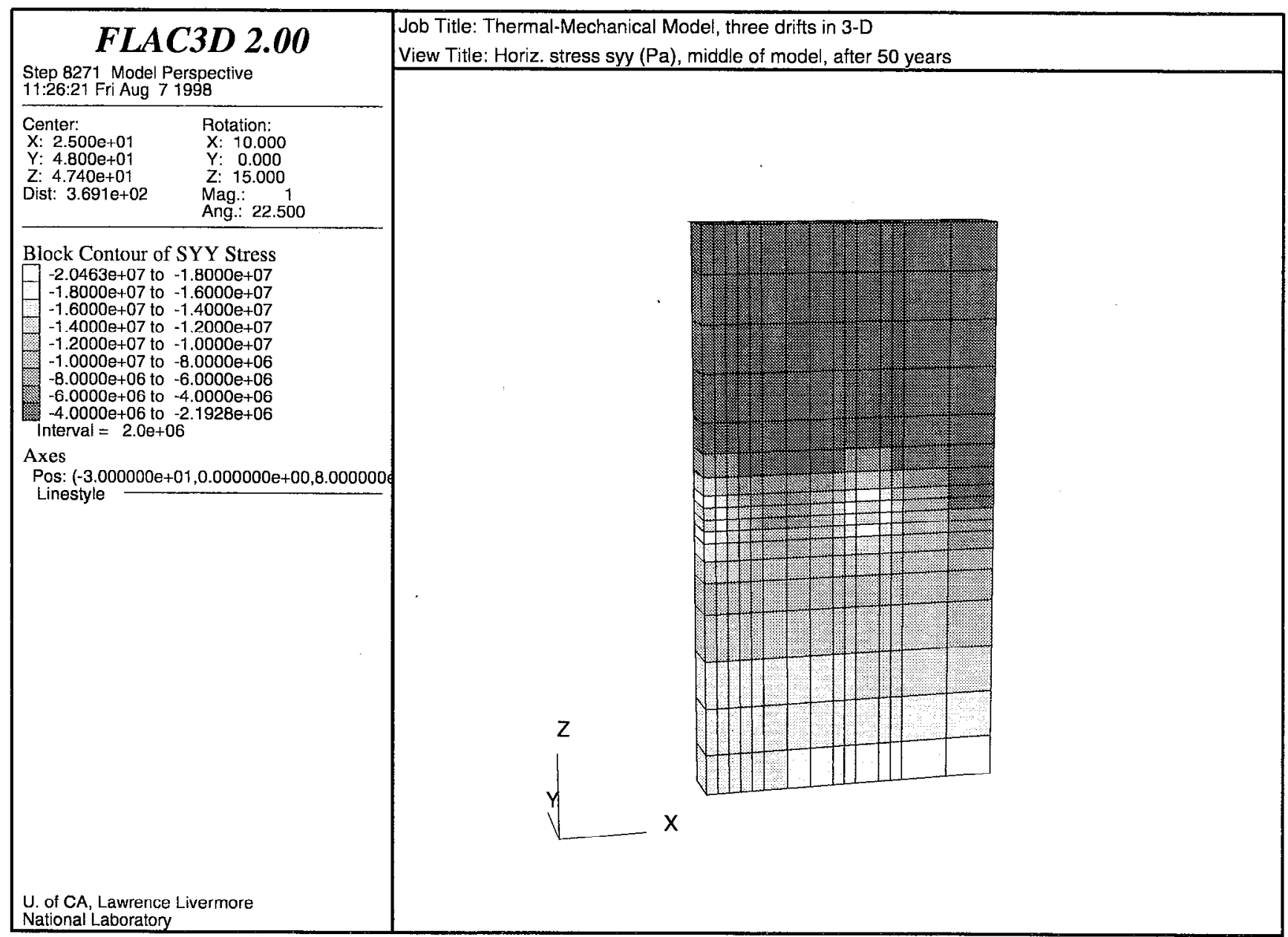

Figure A18. Model for 1.5 drifts in 3-D, horizontal stress component syy after 50 yr heating, region near middle of model (DTN LL980805604243.023) 


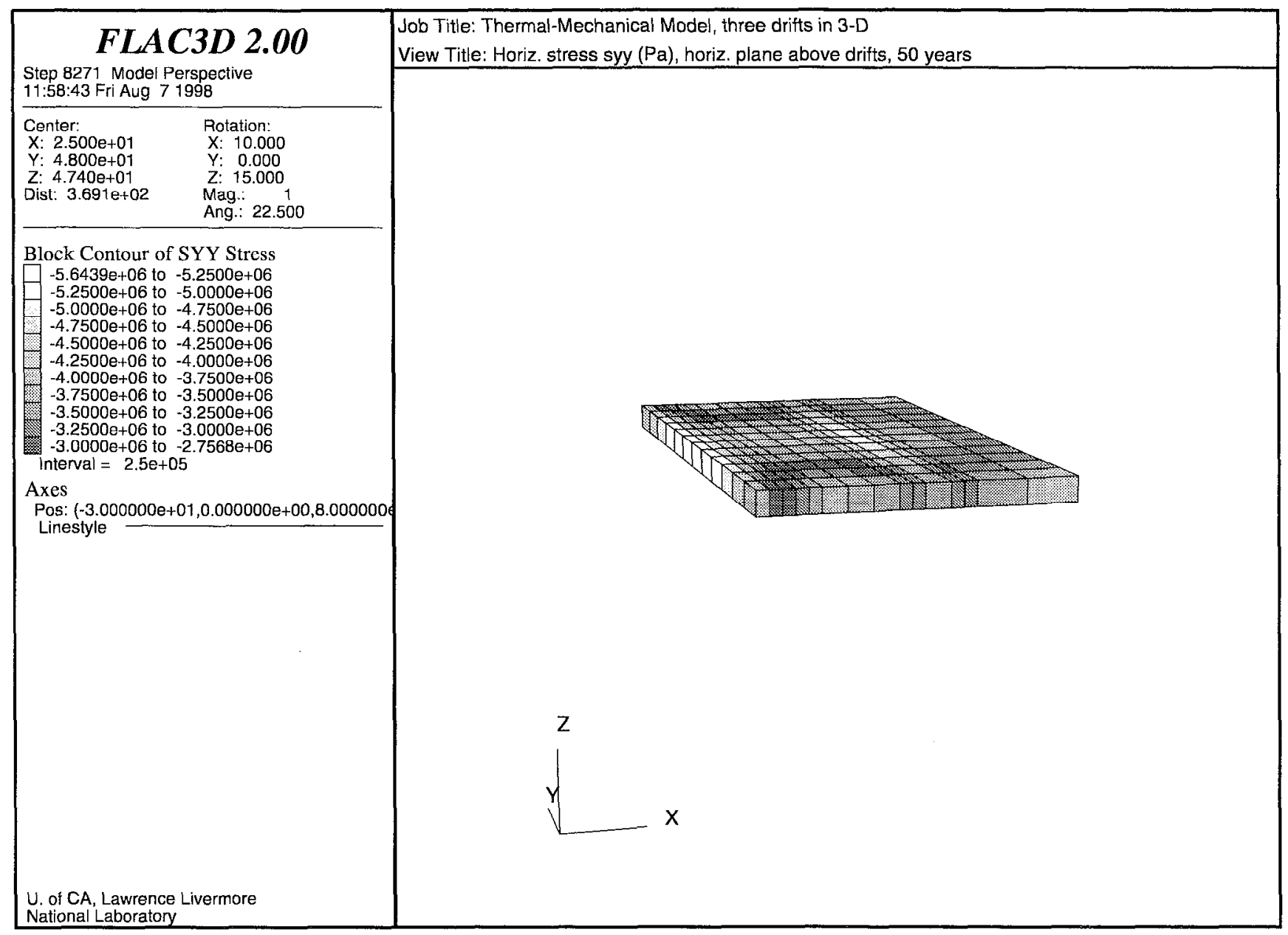

Figure A19. Model for 1.5 drifts in 3-D, horizontal stress component syy after 50 yr heating, region about $10 \mathrm{~m}$ above drifts (DTN LL980805604243.023) 


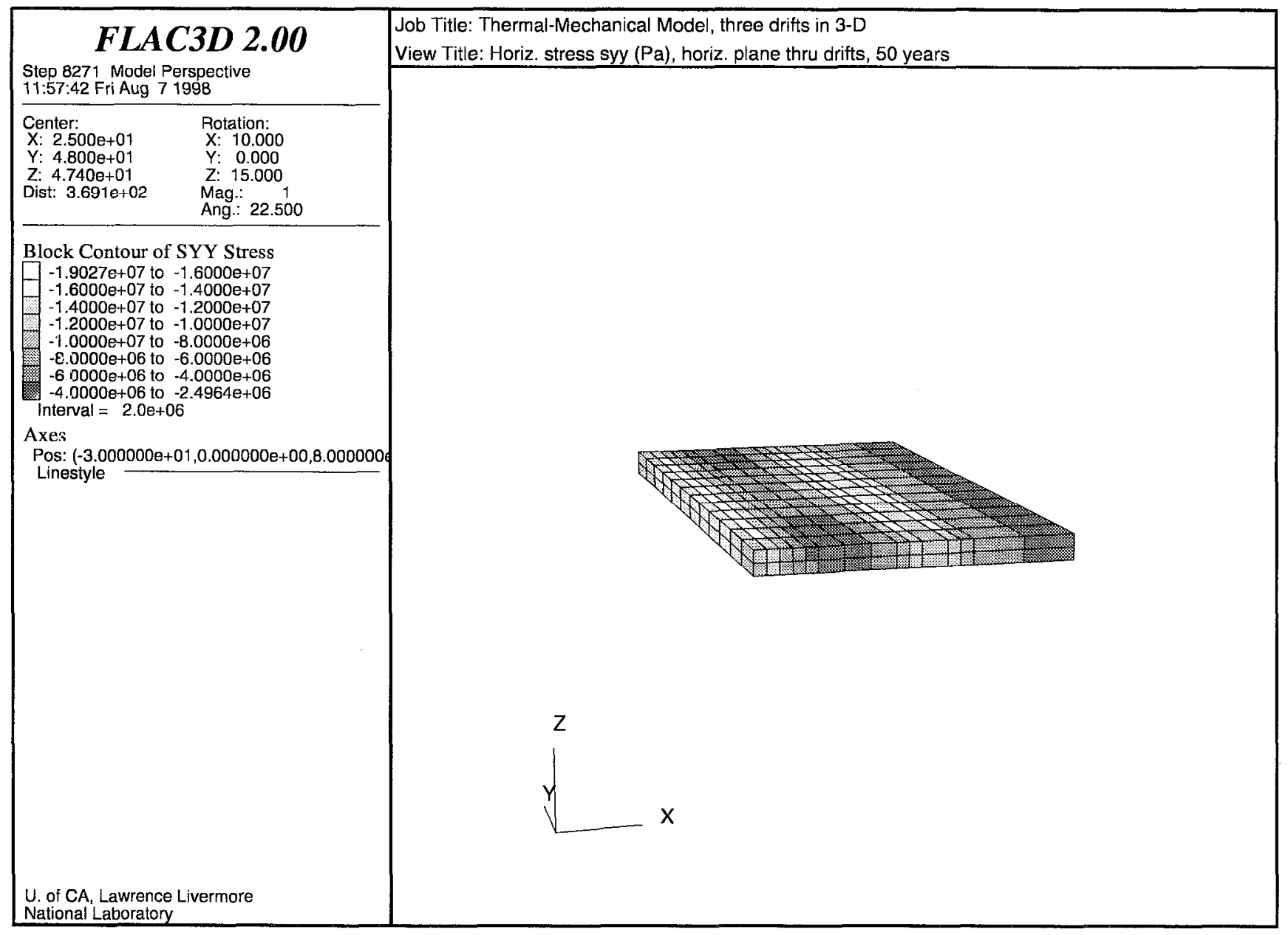

Figure A20. Model for 1.5 drifts in 3-D, horizontal stress component syy after $50 \mathrm{yr}$ heating, region near drifts (DTN LL980805604243.023) 


\begin{tabular}{|l|l|}
\hline FLAC C3D 2.00 & Job Title: Thermal-Mechanical Model, three dritts in 3-D, permeability changes, 50 yr. heating \\
View Title: Between drits, slip on horiz. fracs. parallel to XY plane
\end{tabular}

Figure A21. Model for 1.5 drifts in 3-D, horizontal stress component syy after 50 yr heating, region about $10 \mathrm{~m}$ below drifts (DTN LL980805604243.023) 


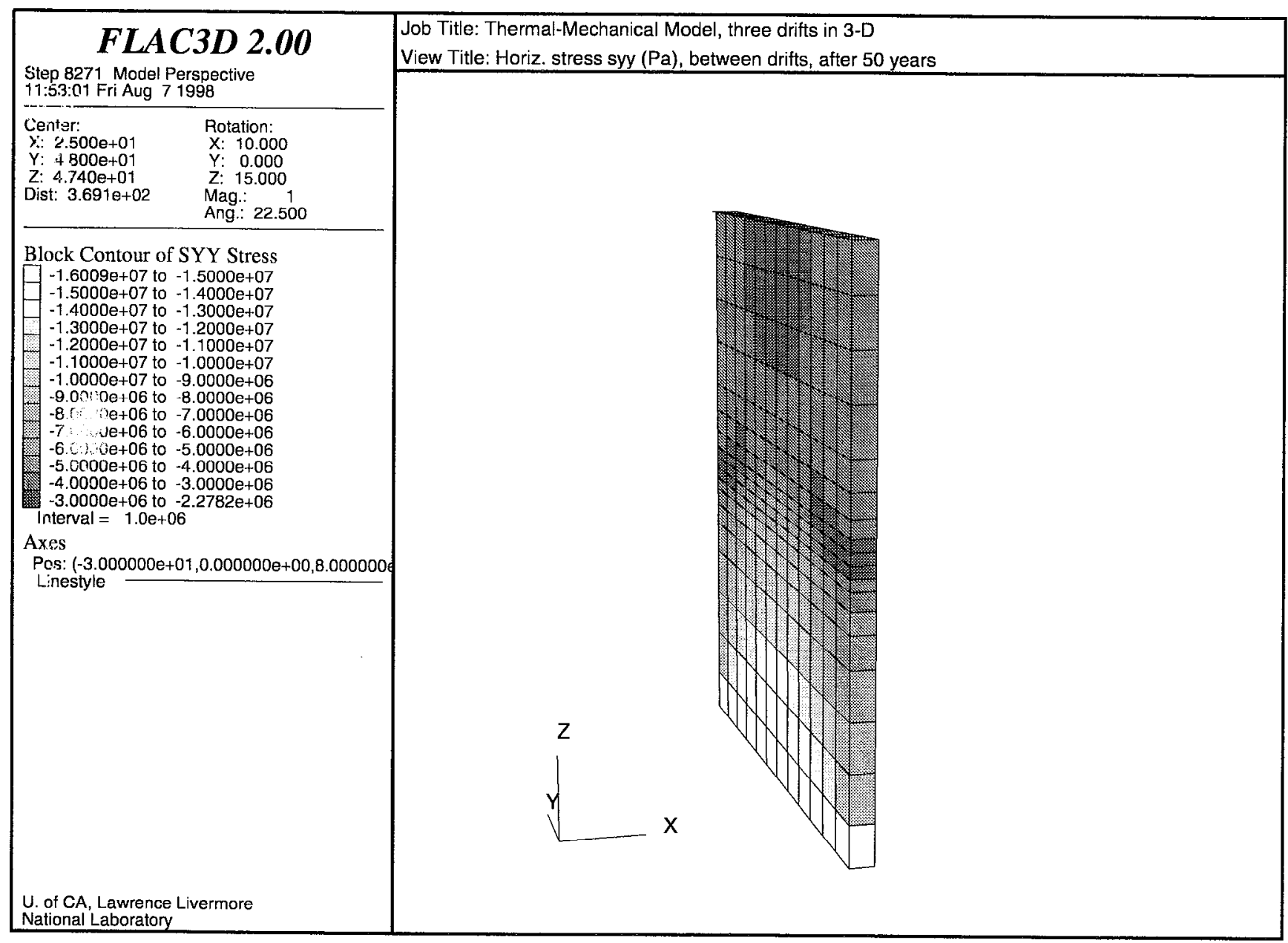

Figure A22. Model for 1.5 drifts in 3-D, horizontal stress component syy after 50 yr heating, region midway between drifts (DTN LL980805604243.023) 


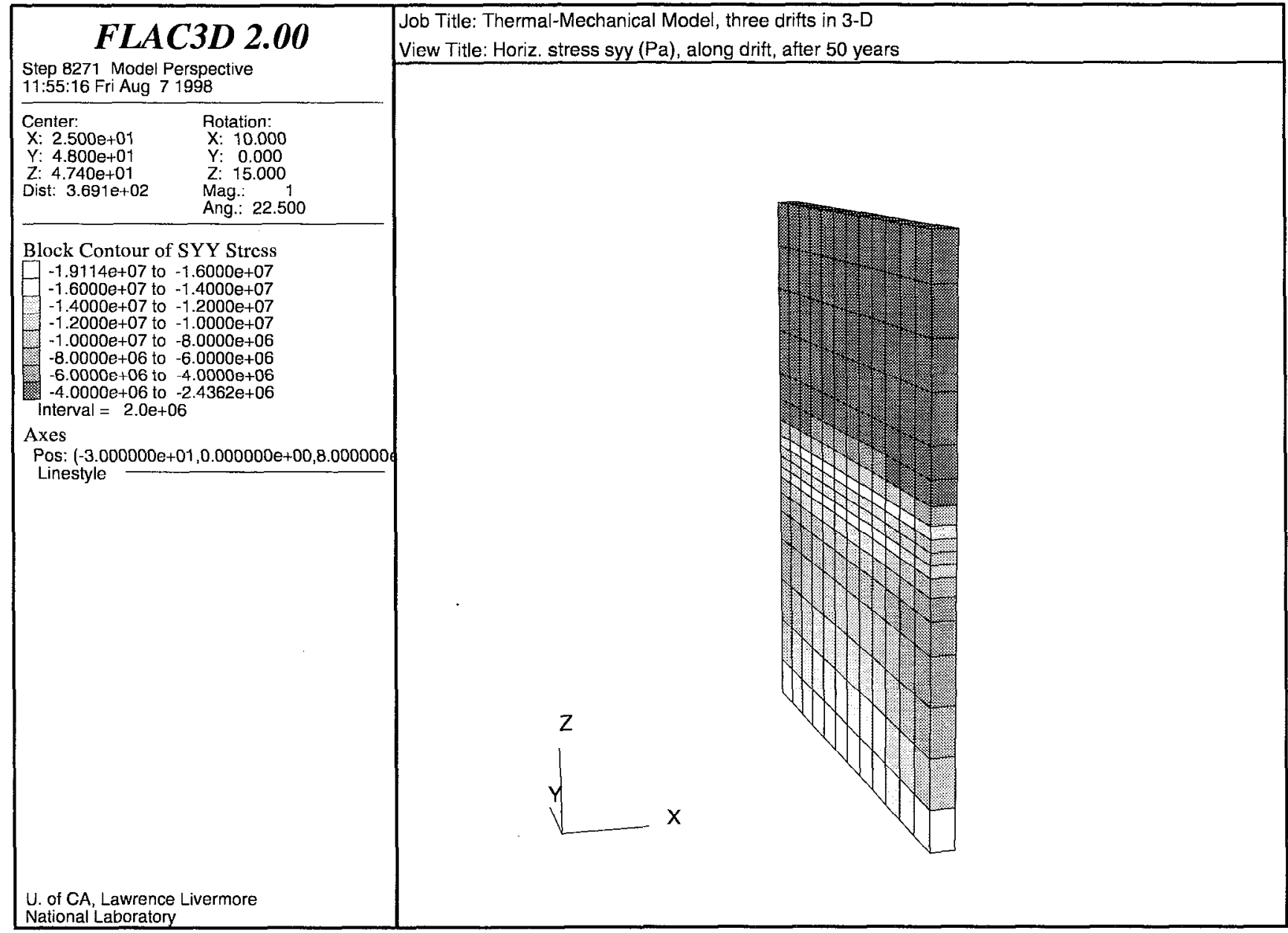

Figure A23. Model for 1.5 drifts in 3-D, horizontal stress component syy after 50 yr heating, region near drift (DTN LL980805604243.023) 


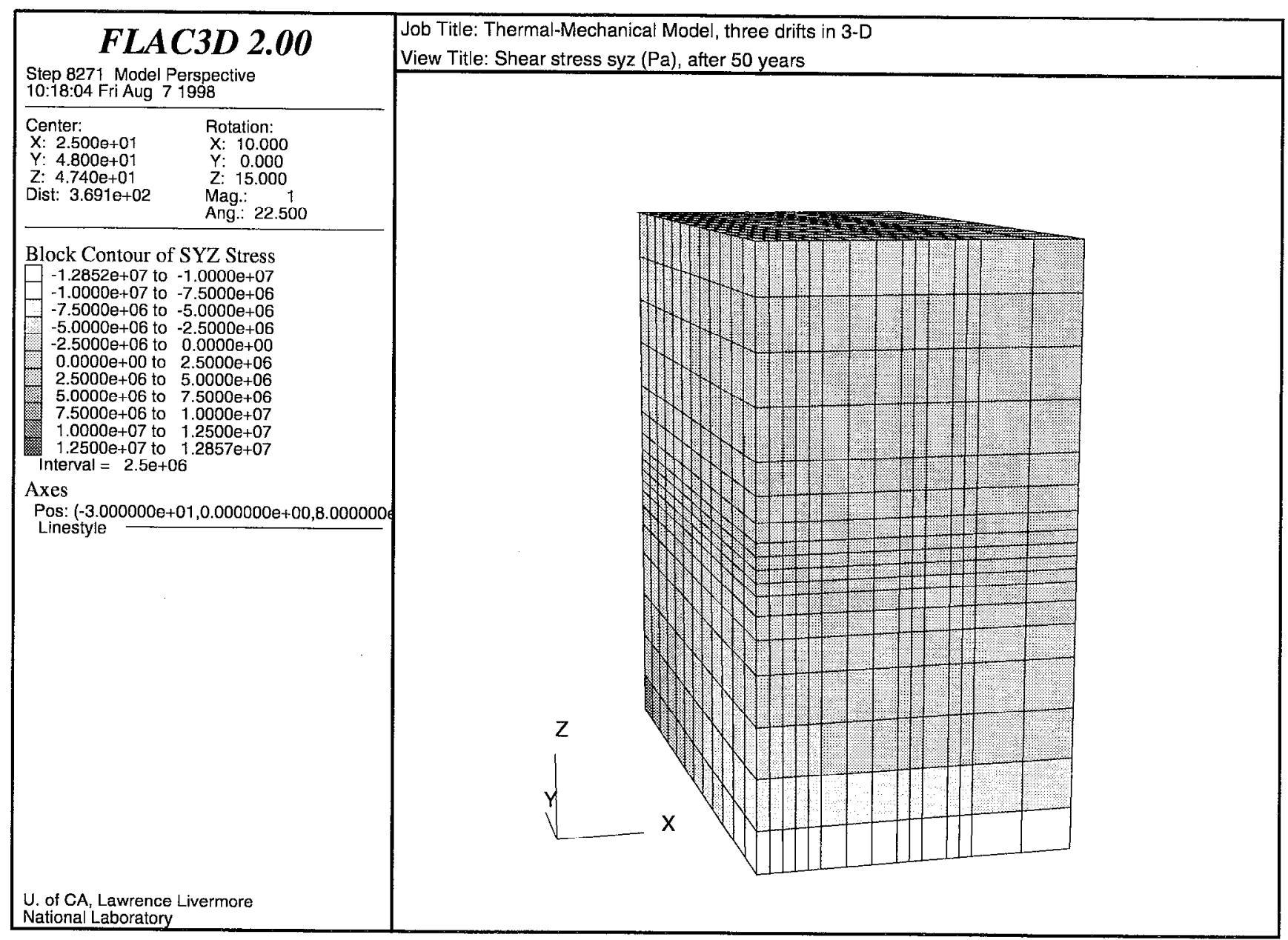

Figure A24. Model for 1.5 drifts in 3-D, shear stress component syz after 50 yr heating, entire model (DTN LL980805604243.023) 


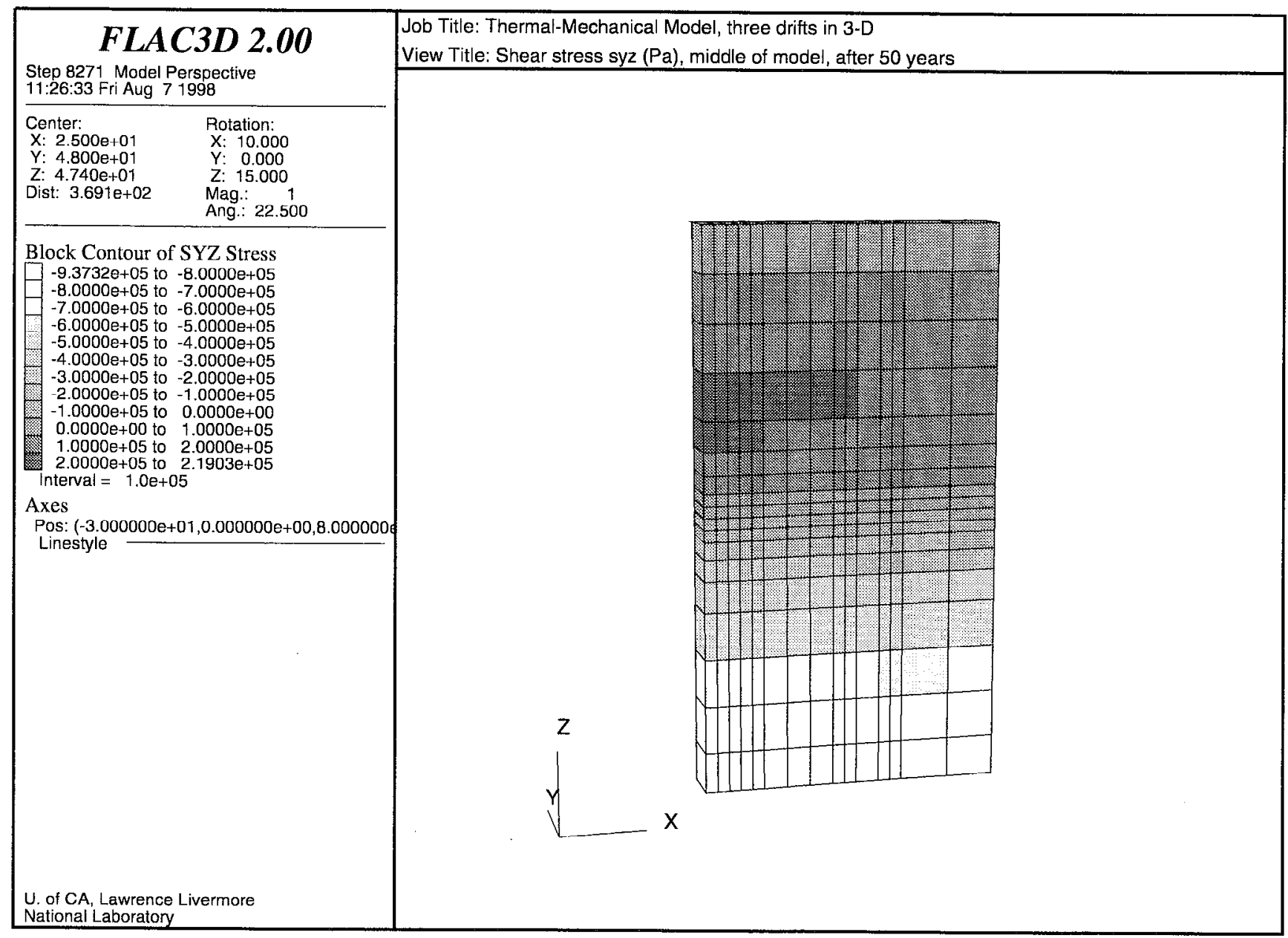

Figure A25. Model for 1.5 drifts in 3-D, shear stress component syz after 50 yr heating, middle of model (DTN LL980805604243.023) 


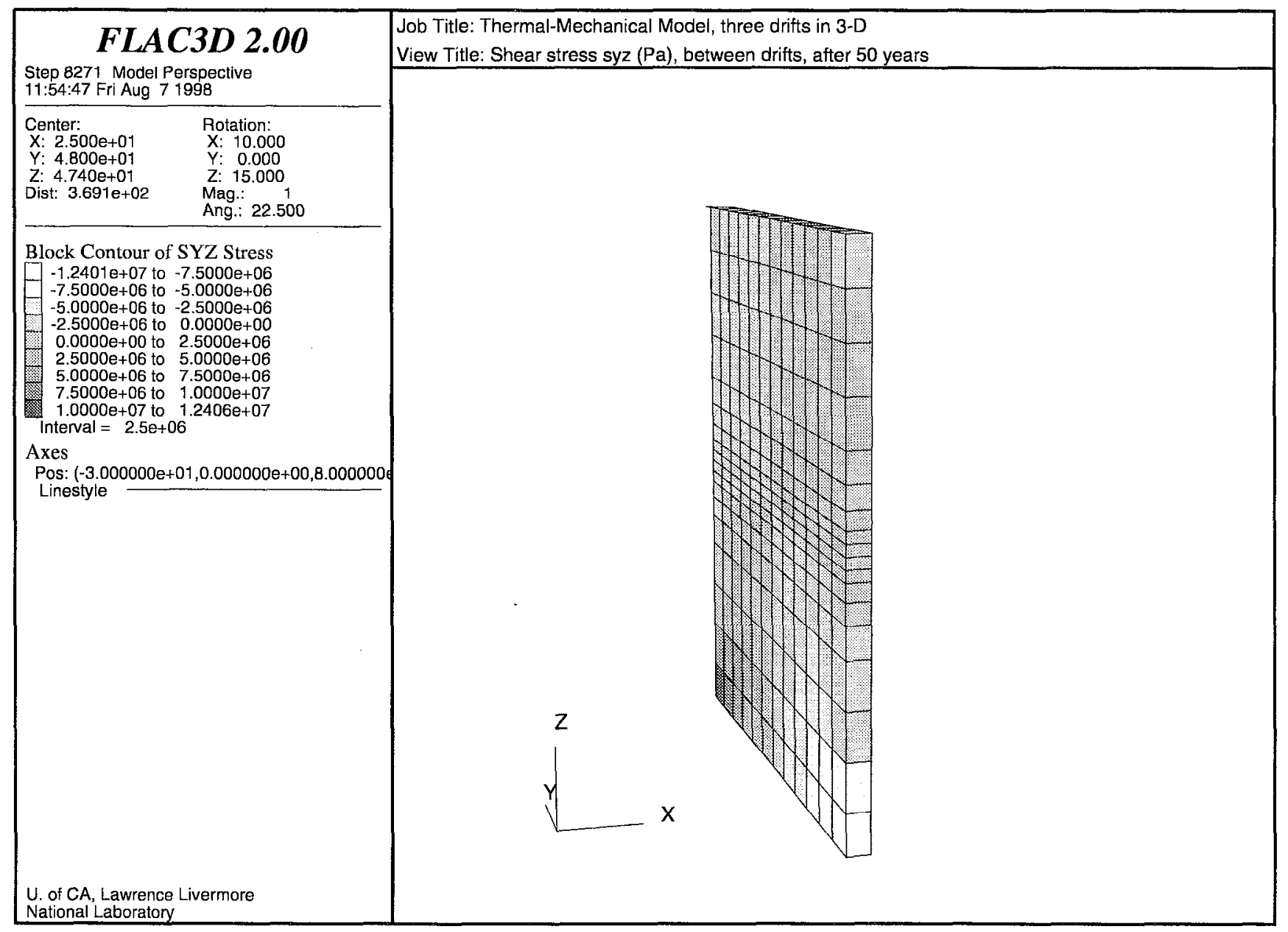

Figure A26. Model for 1.5 drifts in 3-D, shear stress component syz after $50 \mathrm{yr}$ heating, region midway between drifts (DTN LL980805604243.023) 


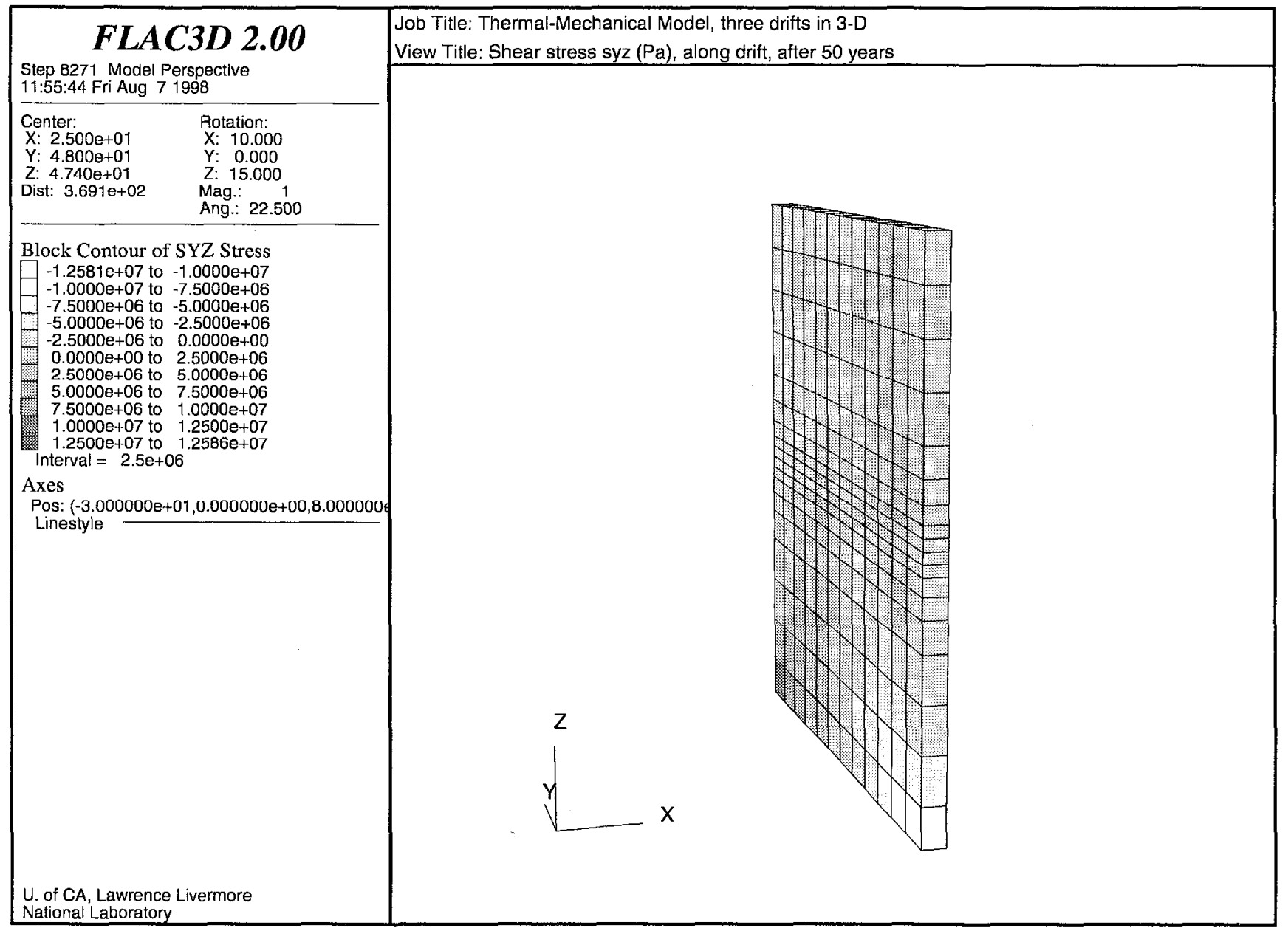

Figure A27. Model for 1.5 drifts in 3-D, shear stress component syz after 50 yr heating, region near drift (DTN LL980805604243.023) 


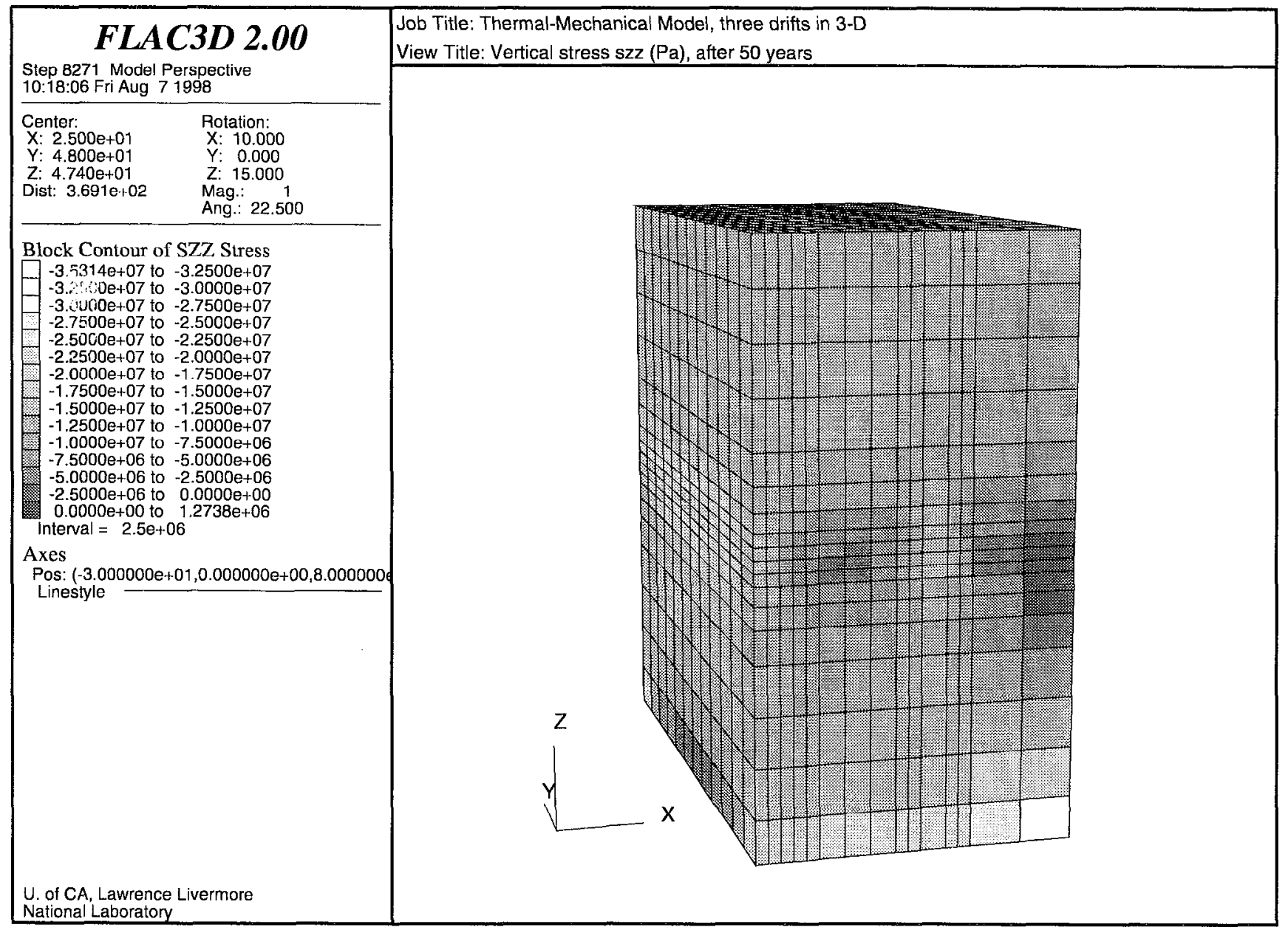

Figure A28. Model for 1.5 drifts in 3-D, vertical stress component szz after 50 yr heating, entire model (DTN LL980805604243.023) 


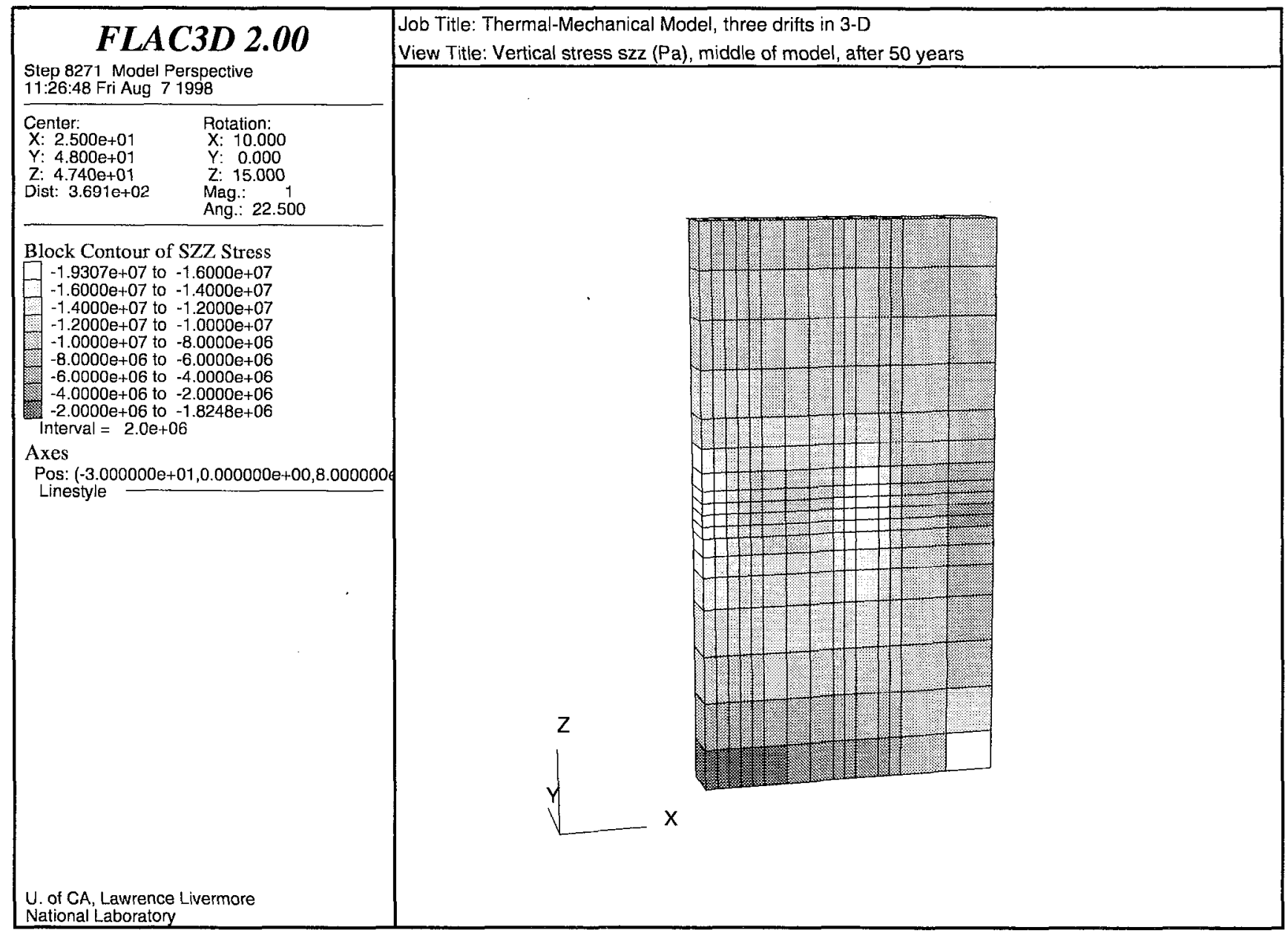

Figure A29. Model for 1.5 drifts in 3-D, vertical stress component szz after 50 yr heating, region near middle of model (DTN LL980805604243.023) 


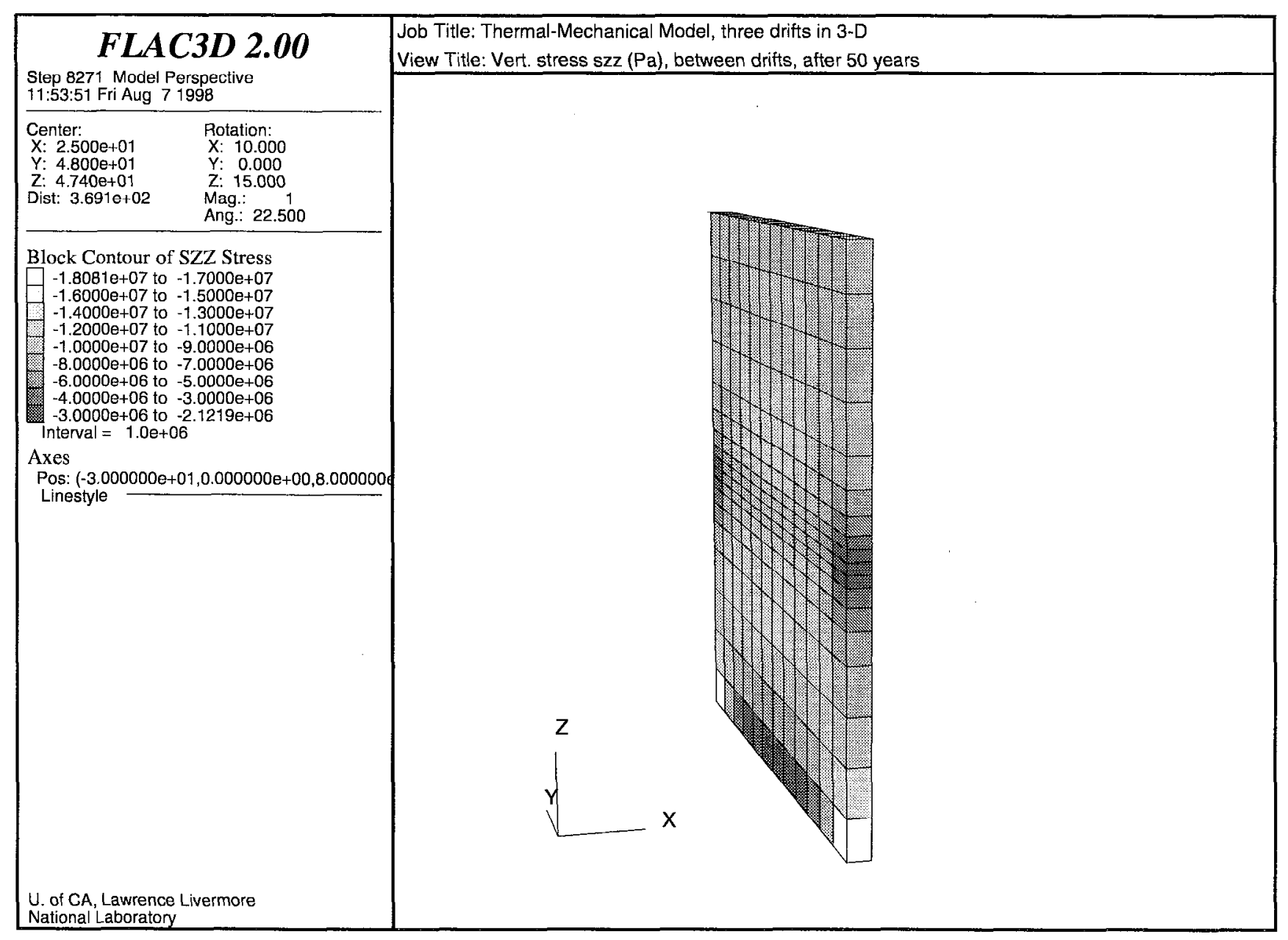

Figure A30. Model for 1.5 drifts in 3-D, vertical stress component szz after 50 yr heating, region midway between drifts (DTN LL980805604243.023) 


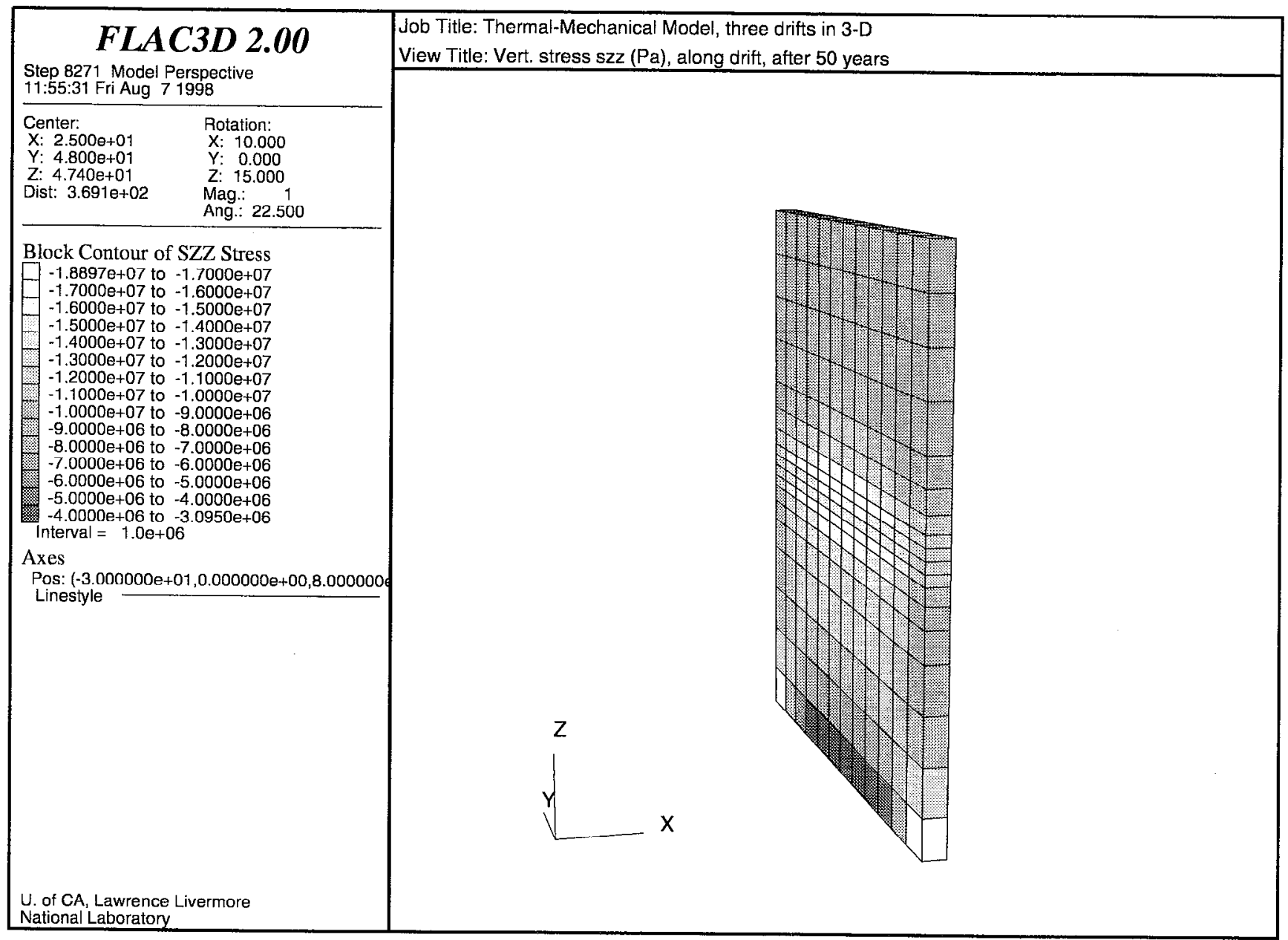

Figure A31. Model for 1.5 drifts in 3-D, vertical stress component szz after 50 yr heating, region near drift (DTN LL980805604243.023) 


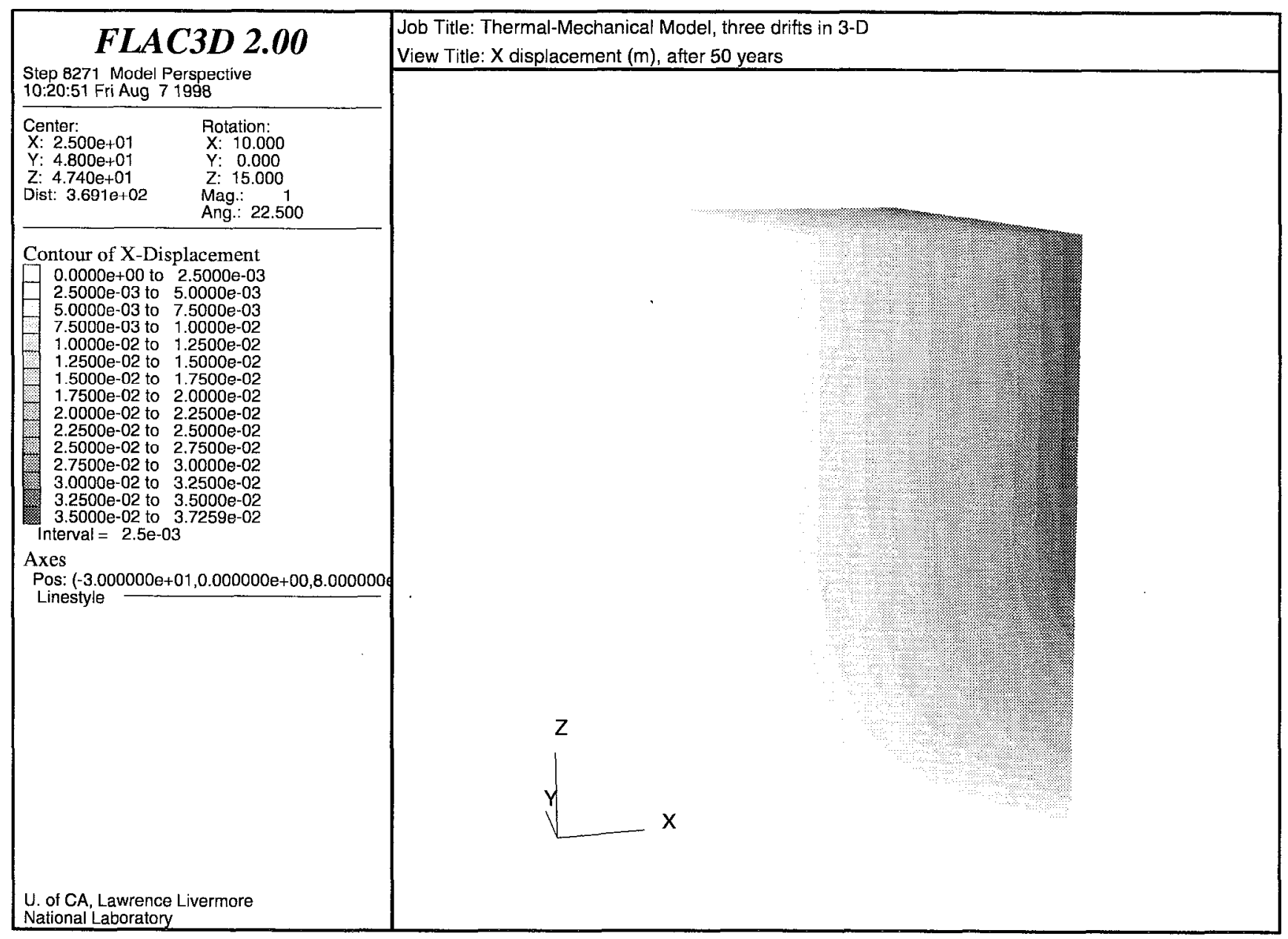

Figure A32. Model for 1.5 drifts in 3-D, horizontal $X$ displacement after $50 \mathrm{yr}$ heating, entire model (DTN LL980805604243.023) 


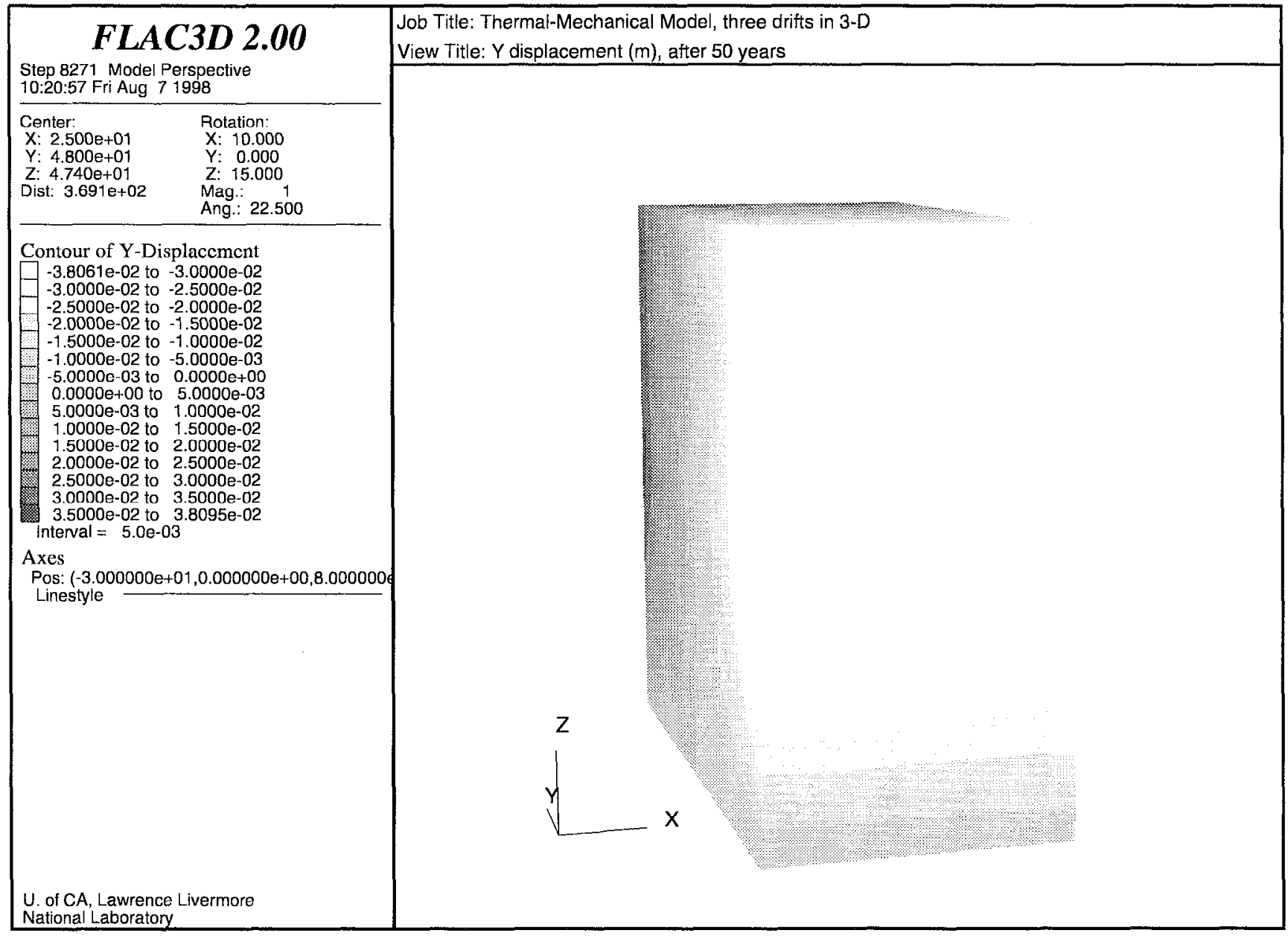

Figure A33. Model for 1.5 drifts in 3-D, horizontal $Y$ displacement after 50 yr heating, entire model (DTN LL980805604243.023) 


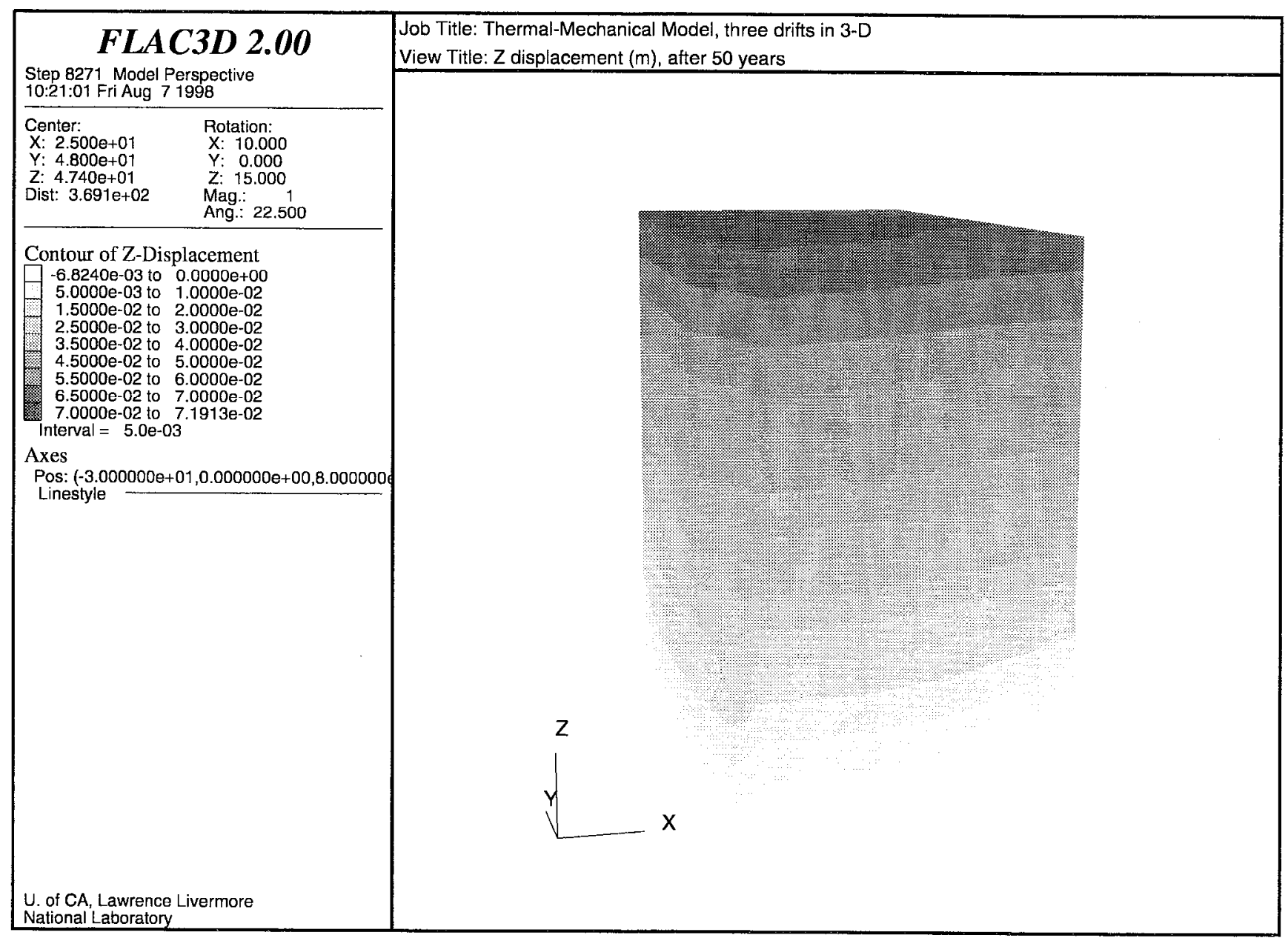

Figure A34. Model for 1.5 drifts in 3-D, vertical $Z$ displacement after 50 yr heating, entire model (DTN LL980805604243.023) 


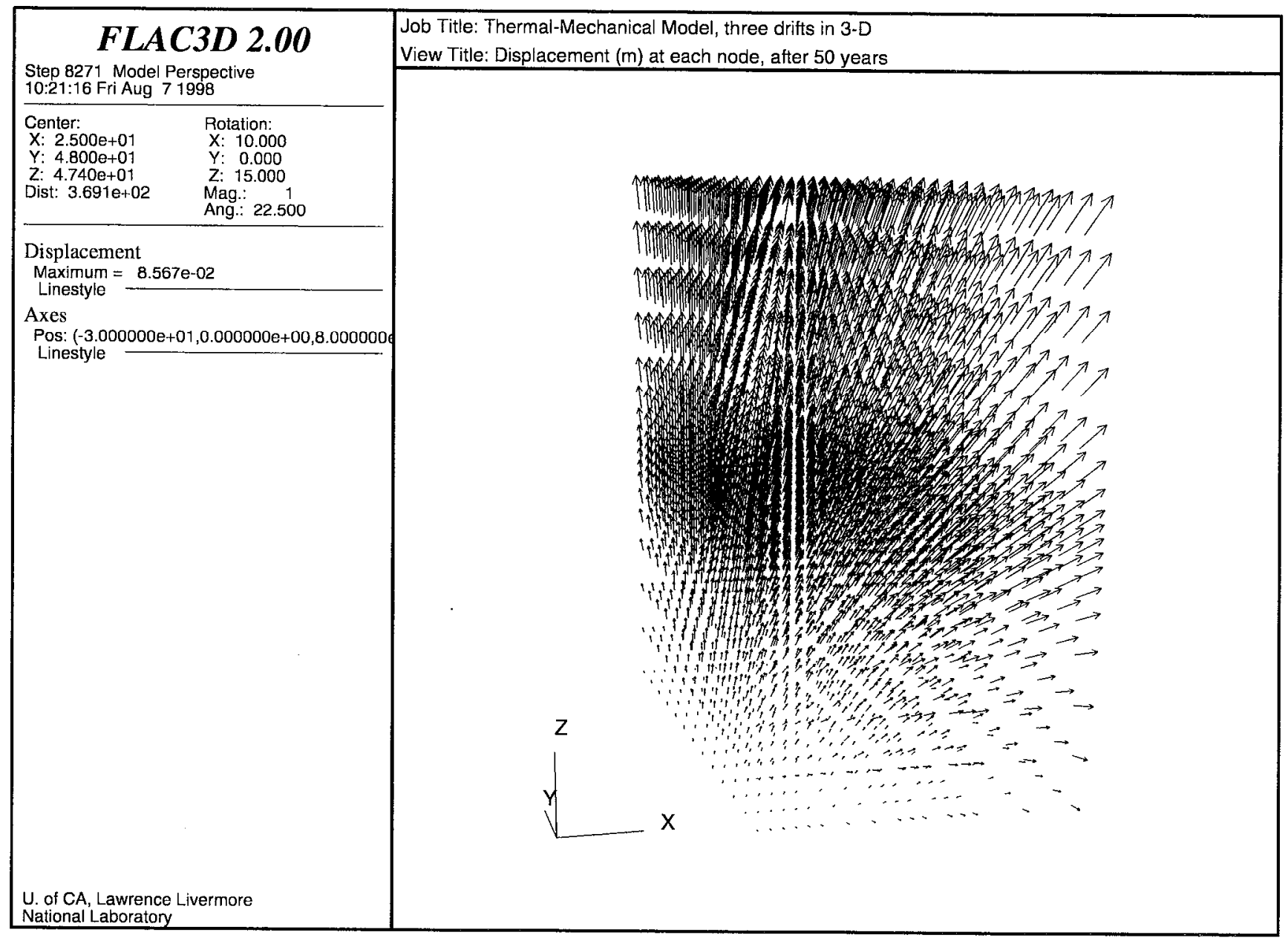

Figure A35. Model for 1.5 drifts in 3-D, displacement vectors at each node in model after $50 \mathrm{yr}$ heating (DTN LL980805604243.023) 


\section{Appendix B \\ Illustration of Effects of Different Mechanical Boundary Conditions}





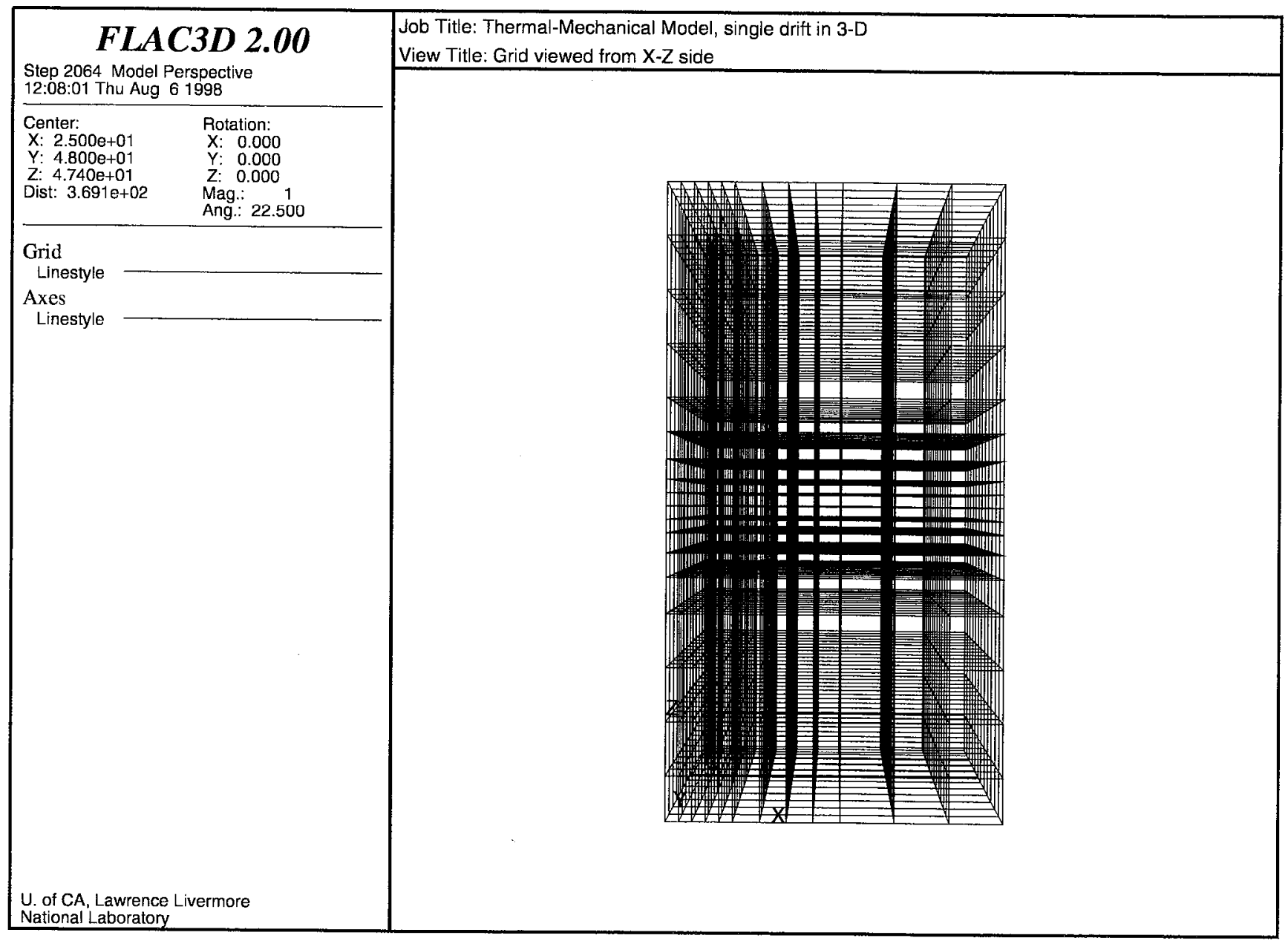

Figure B1. Model for .5 drift in 3-D, grid viewed from XZ direction (DTN LL980805604243.023) 


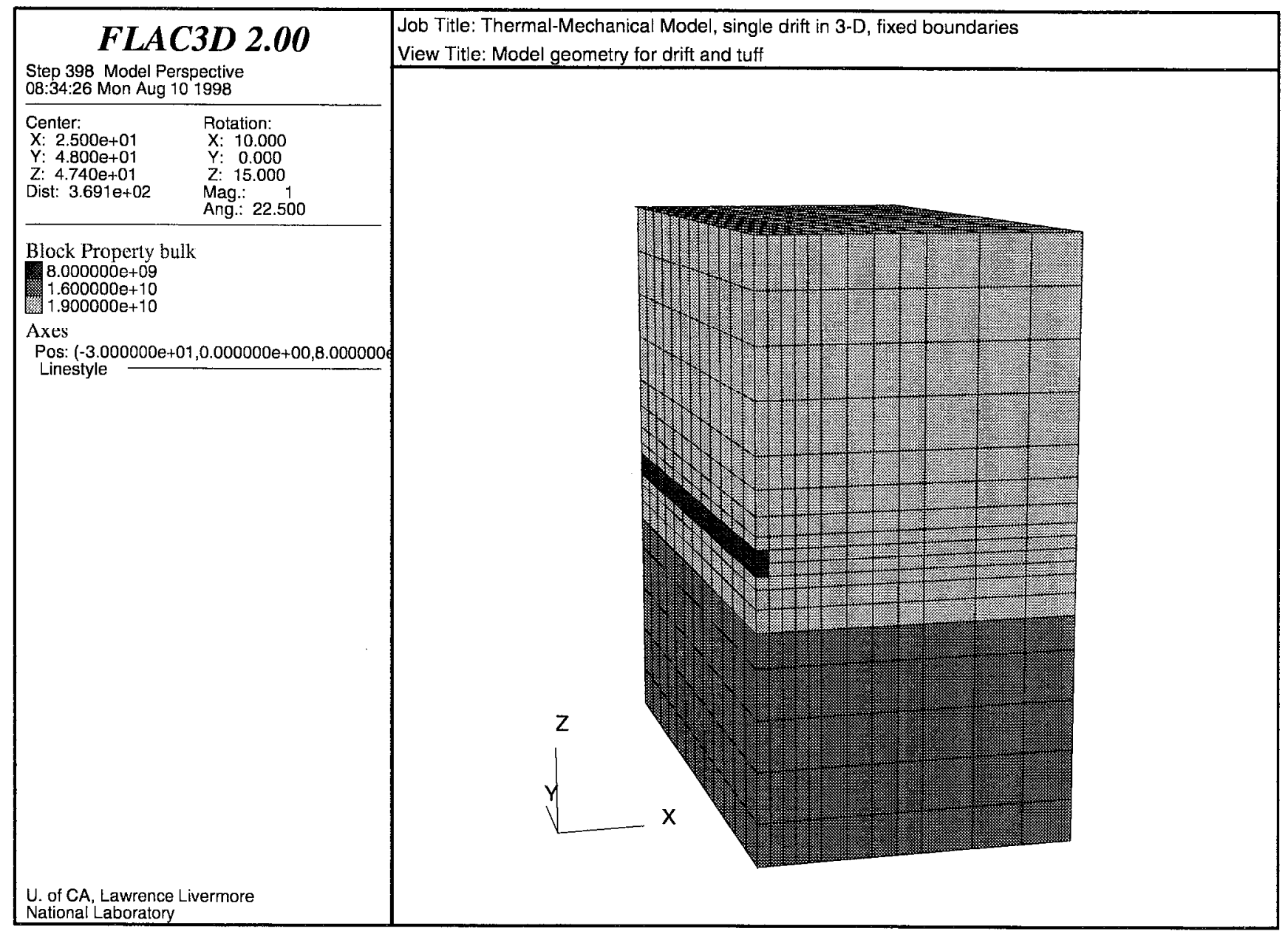

Figure B2. Model geometry for model using .5 drift in 3-D; darkest regions indicate drift location (DTN LL980805604243.023) 


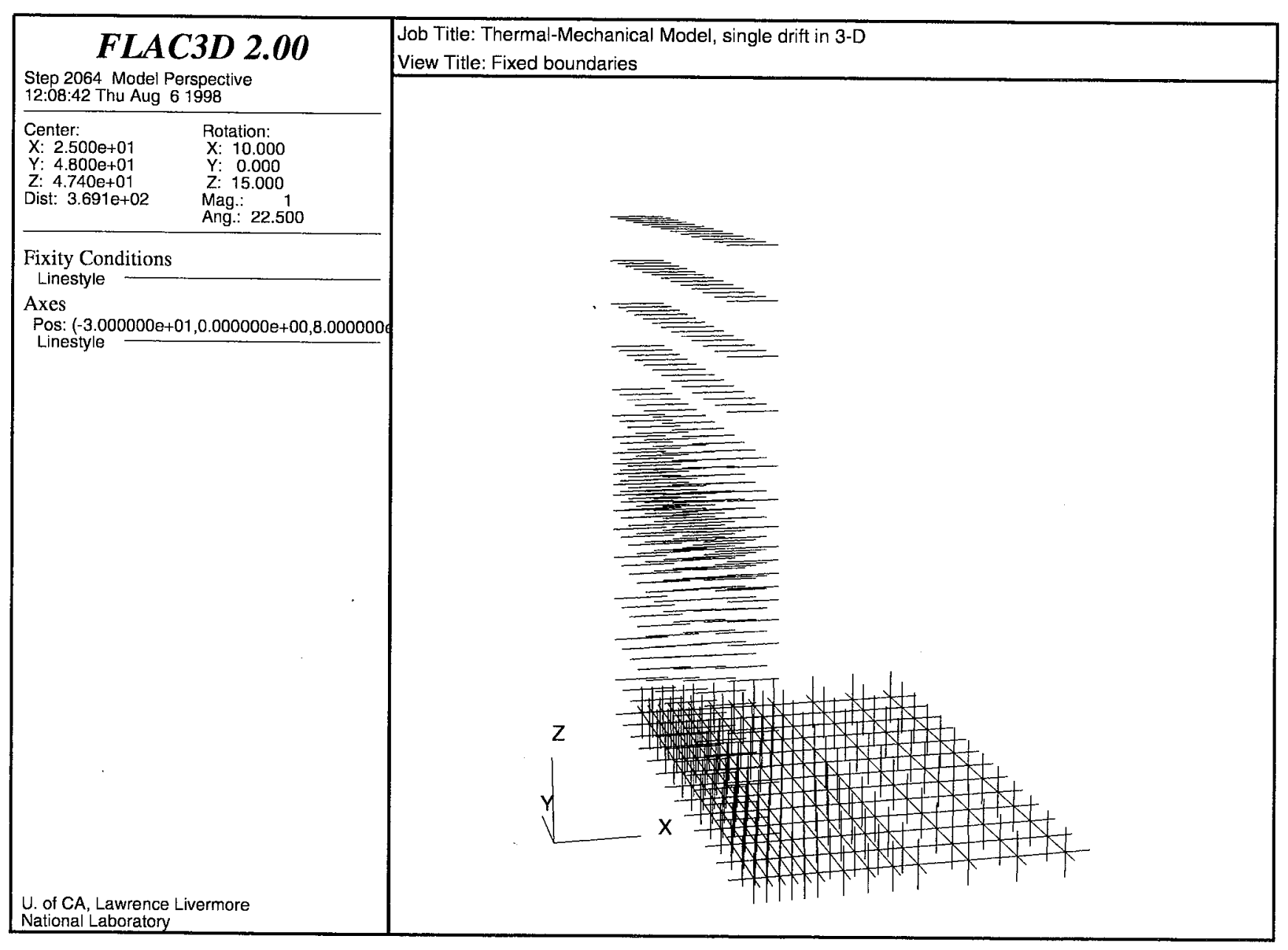

Figure B3. Fixed boundary condition locations for first case, using applied stresses at top and side boundaries (DTN LL980805604243.023) 


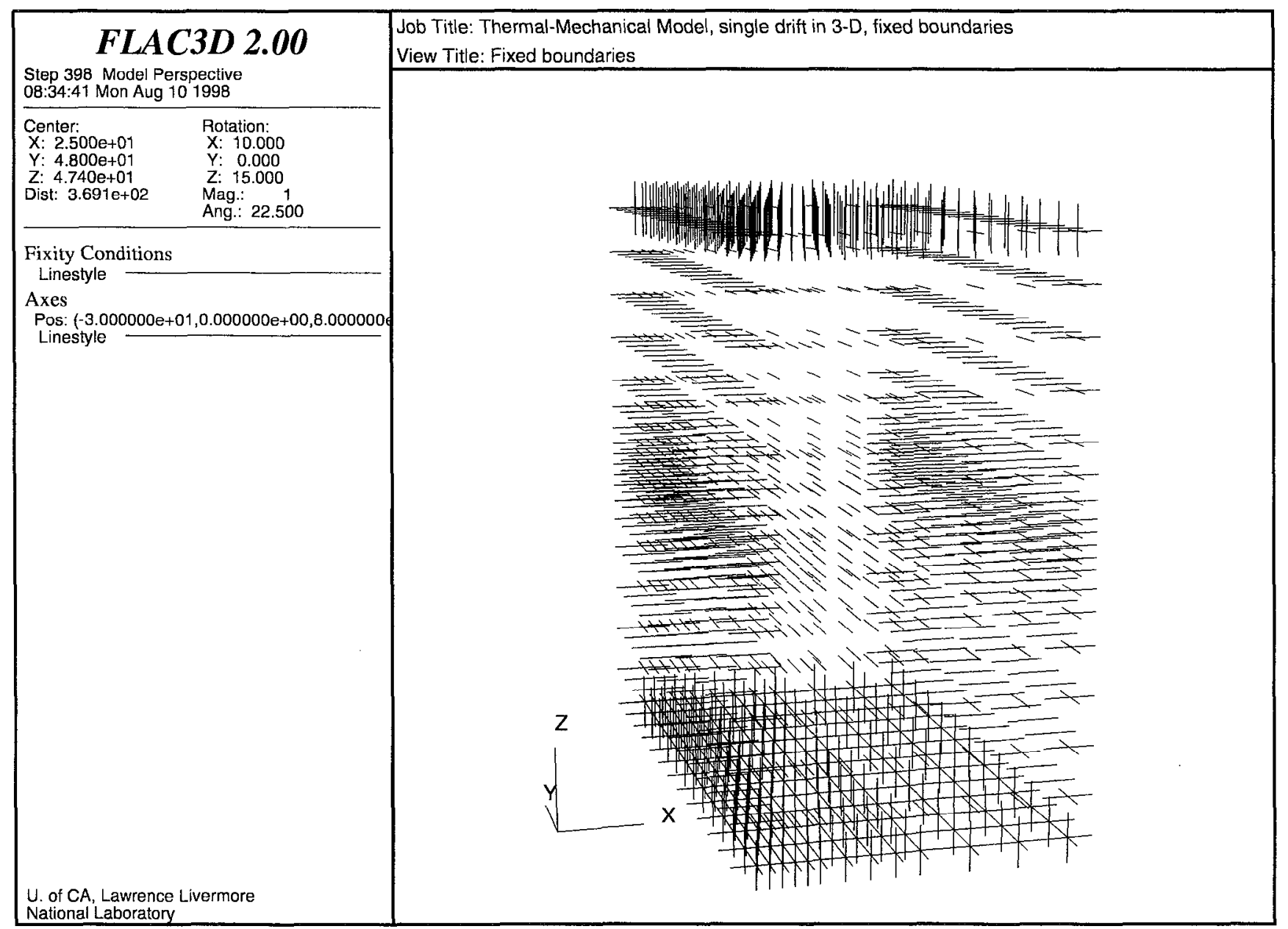

Figure B4. Fixed boundary condition locations for second case, no applied stresses at boundaries (DTN LL980805604243.023) 


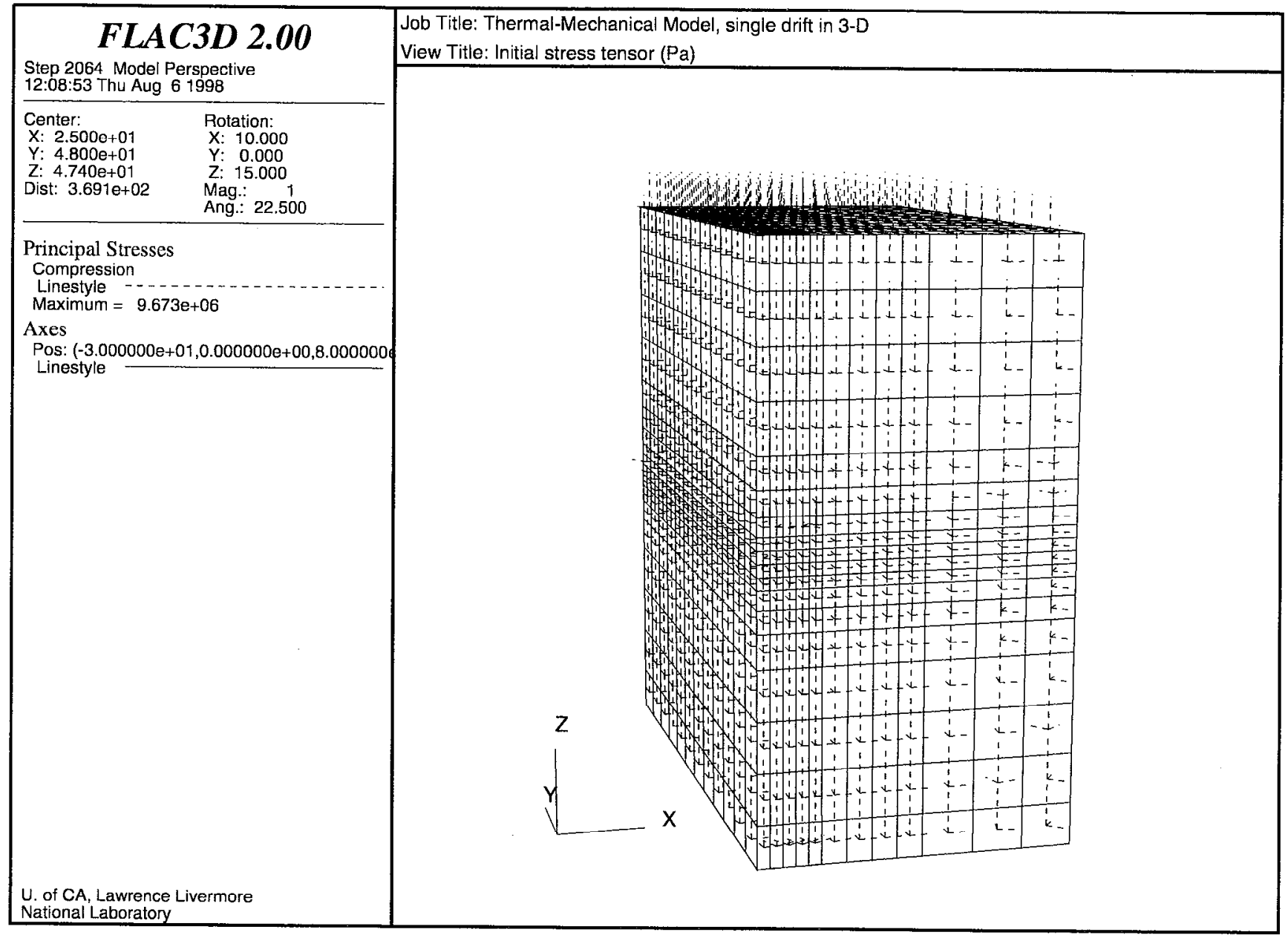

Figure B5. Initial stress tensor for first case having applied stresses at top and side boundaries, view for entire model (DTN LL980805604243.023) 


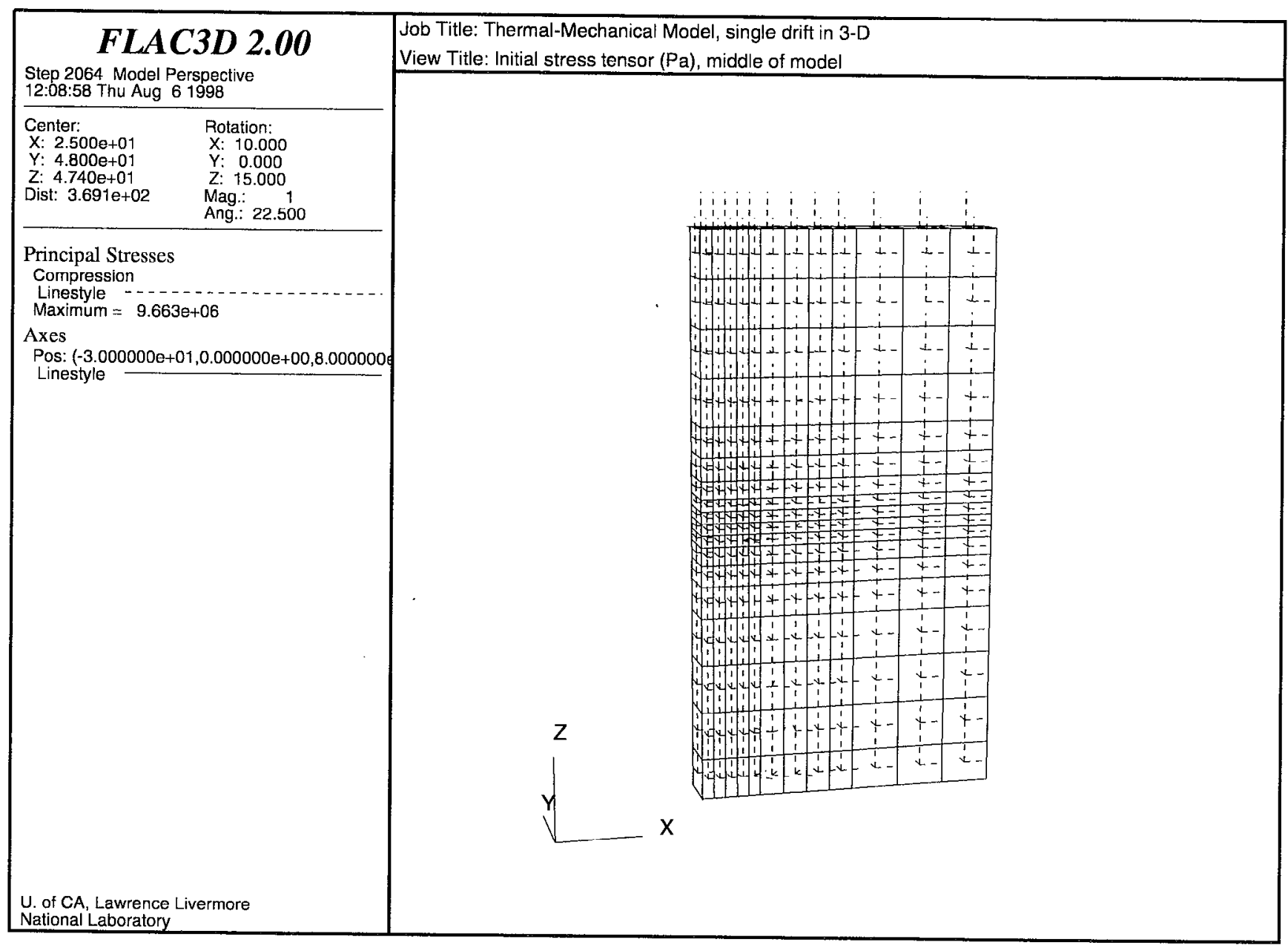

Figure B6. Initial stress tensor for first case having applied stresses at top and side boundaries, view for region near center of model (DTN LL980805604243.023) 


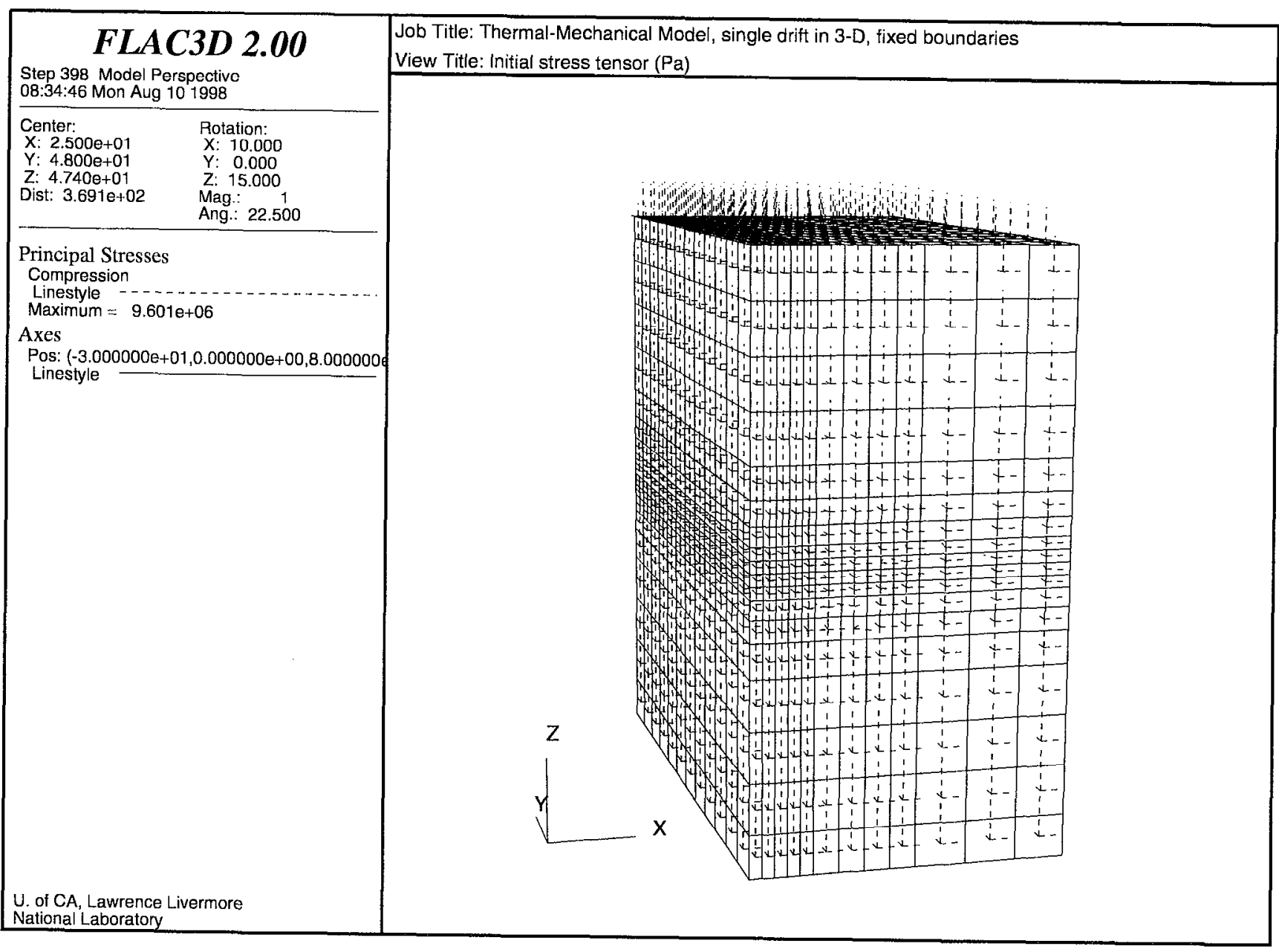

Figure B7. Initial stress tensor for second case having fixed boundaries, view for entire model (DTN LL980805604243.023) 


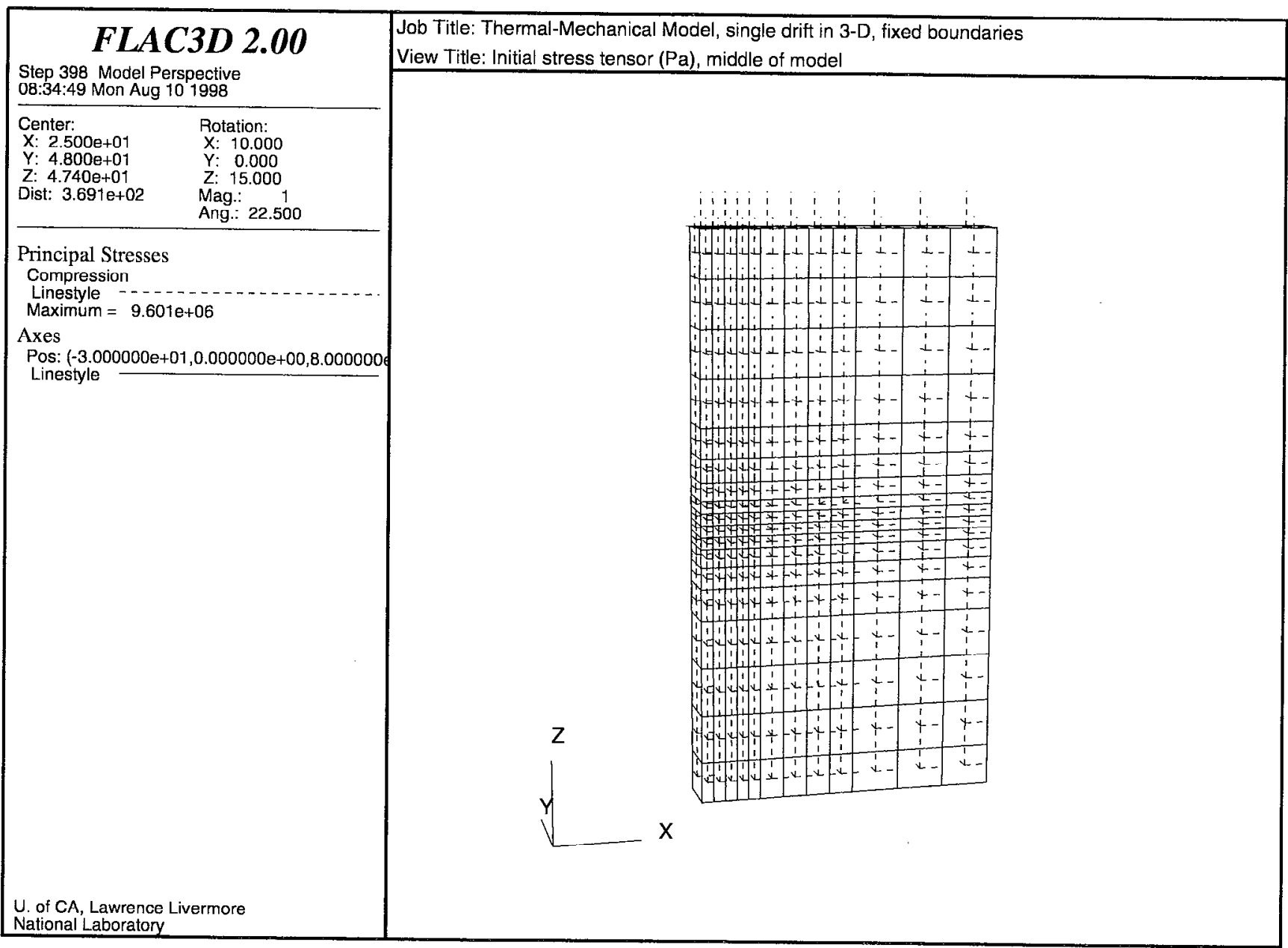

Figure B8. Initial stress tensor for second case having fixed boundaries, view for region near center of model (DTN LL980805604243.023) 


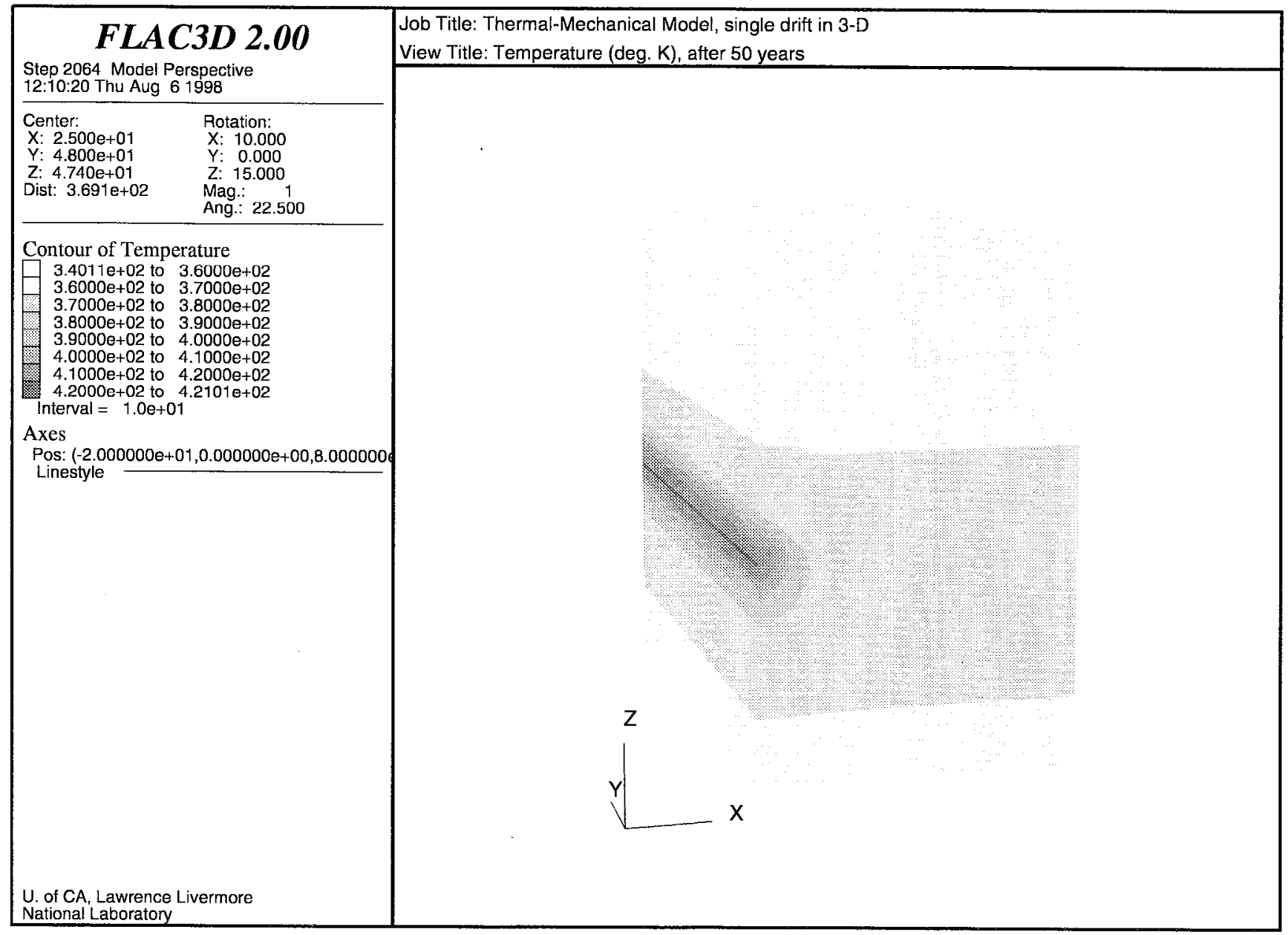

Figure B9. Model for .5 drift in 3-D, temperature field after $50 \mathrm{yr}$ of heating (DTN LL980805604243.023) 


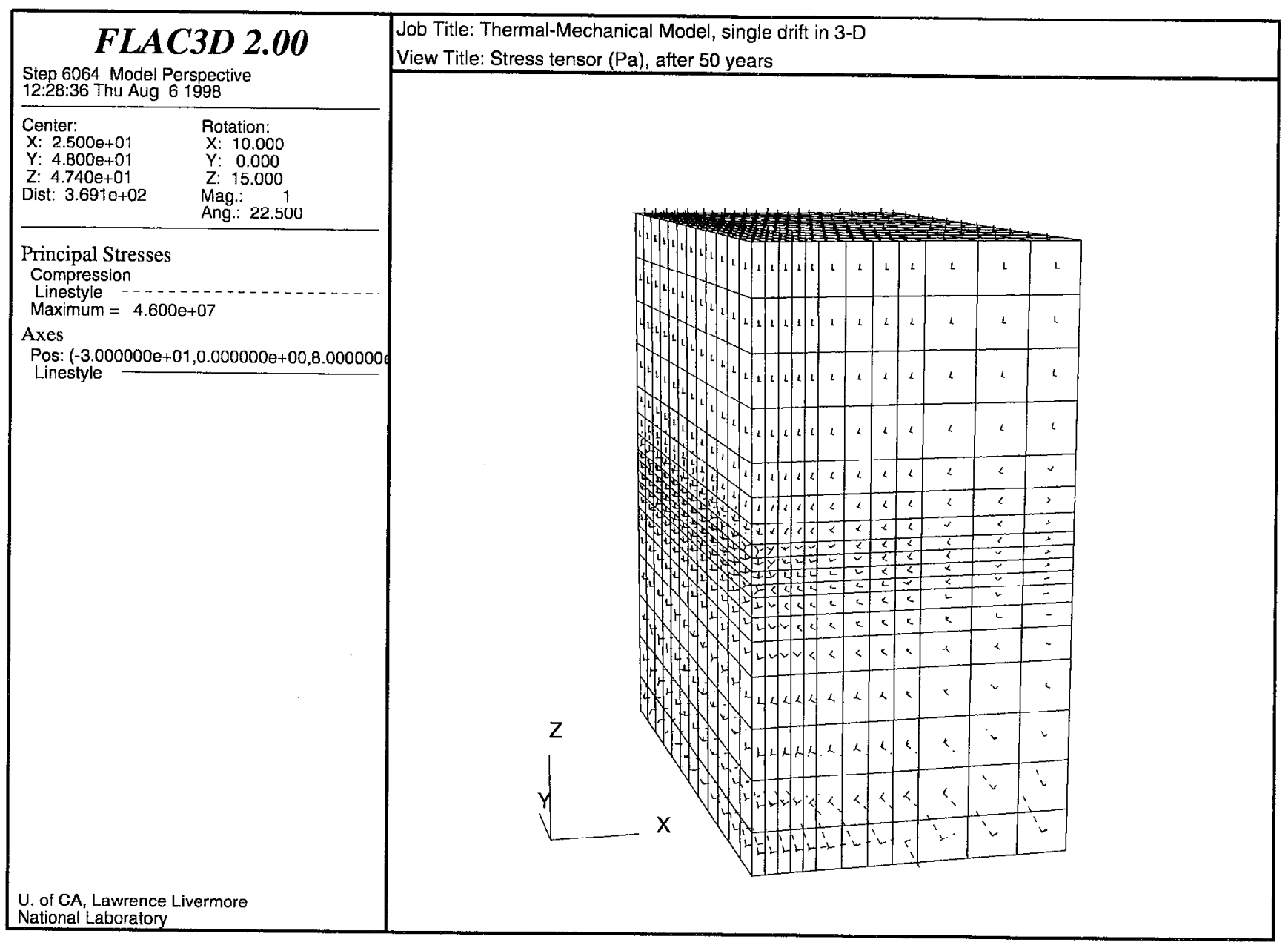

Figure B10. Stress tensor after $50 \mathrm{yr}$ of heating for first case having applied stresses at top and side boundaries, view for entire model (DTN LL980805604243.023) 


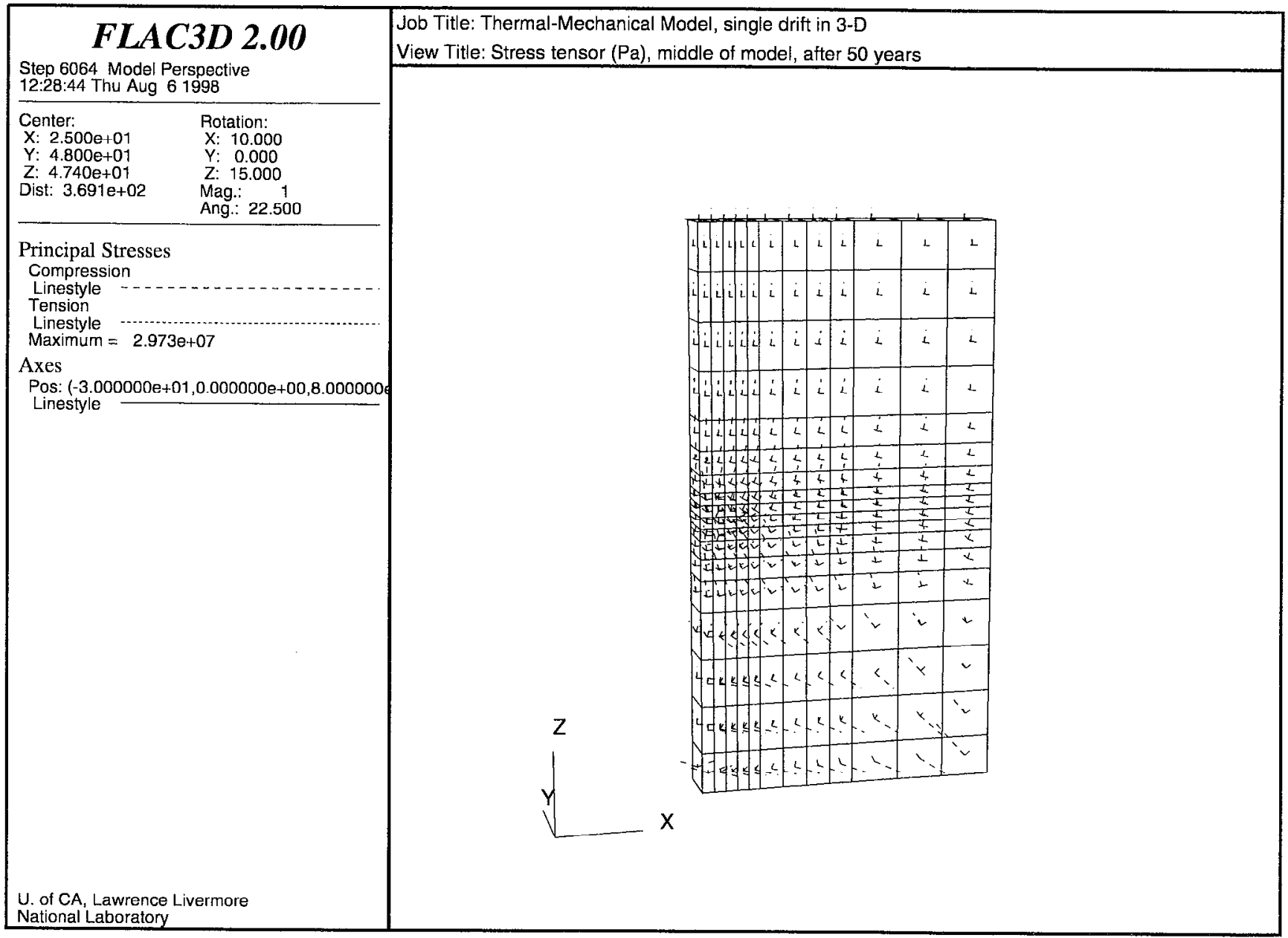

Figure B11. Stress tensor after 50 yr of heating for first case having applied stresses at top and side boundaries, view for region near center of model (DTN LL980805604243.023) 


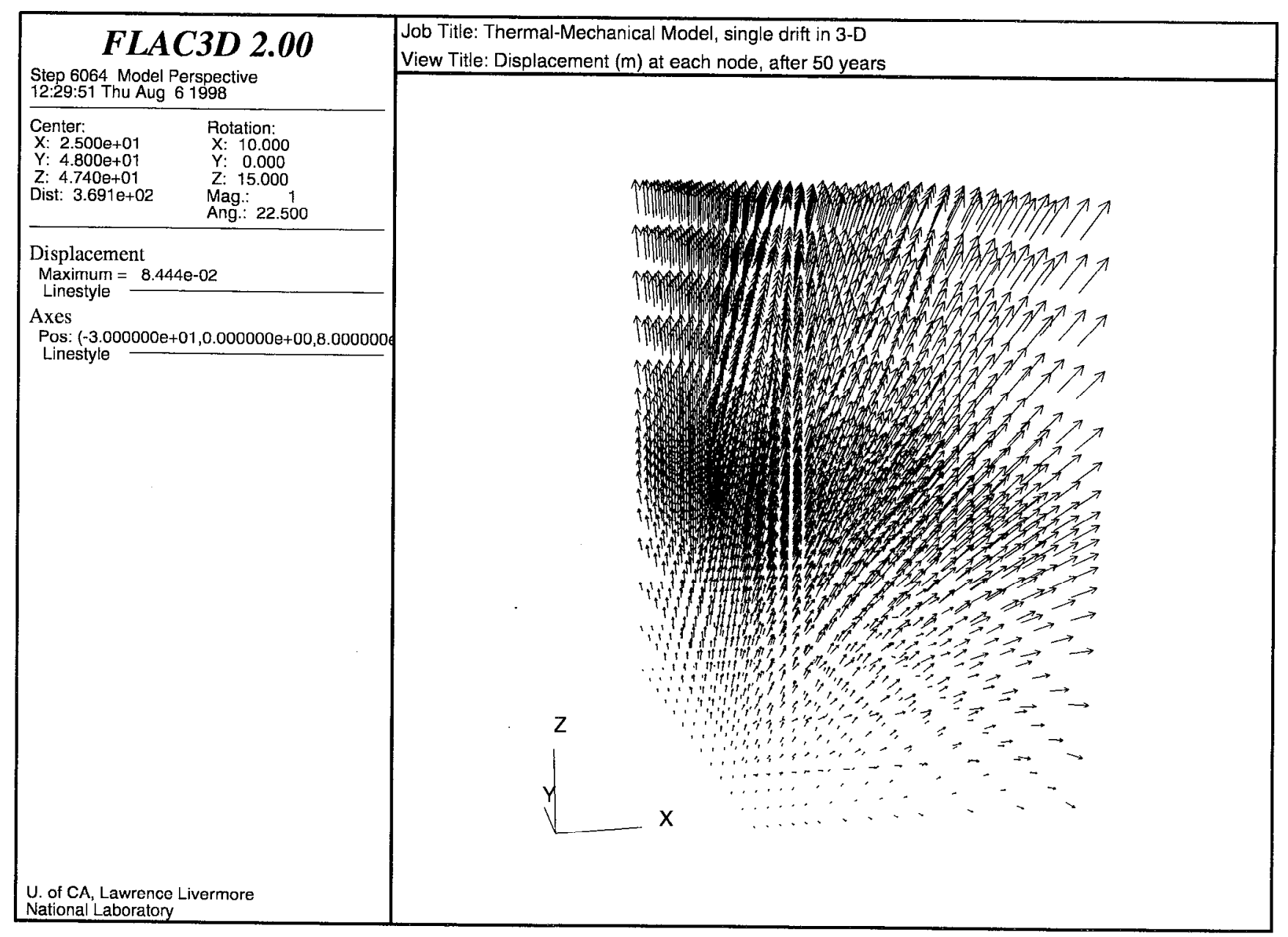

Figure B12. Displacement vectors at each node of model after $50 \mathrm{yr}$ of heating for first case having applied stresses at top and side boundaries (DTN LL980805604243.023) 


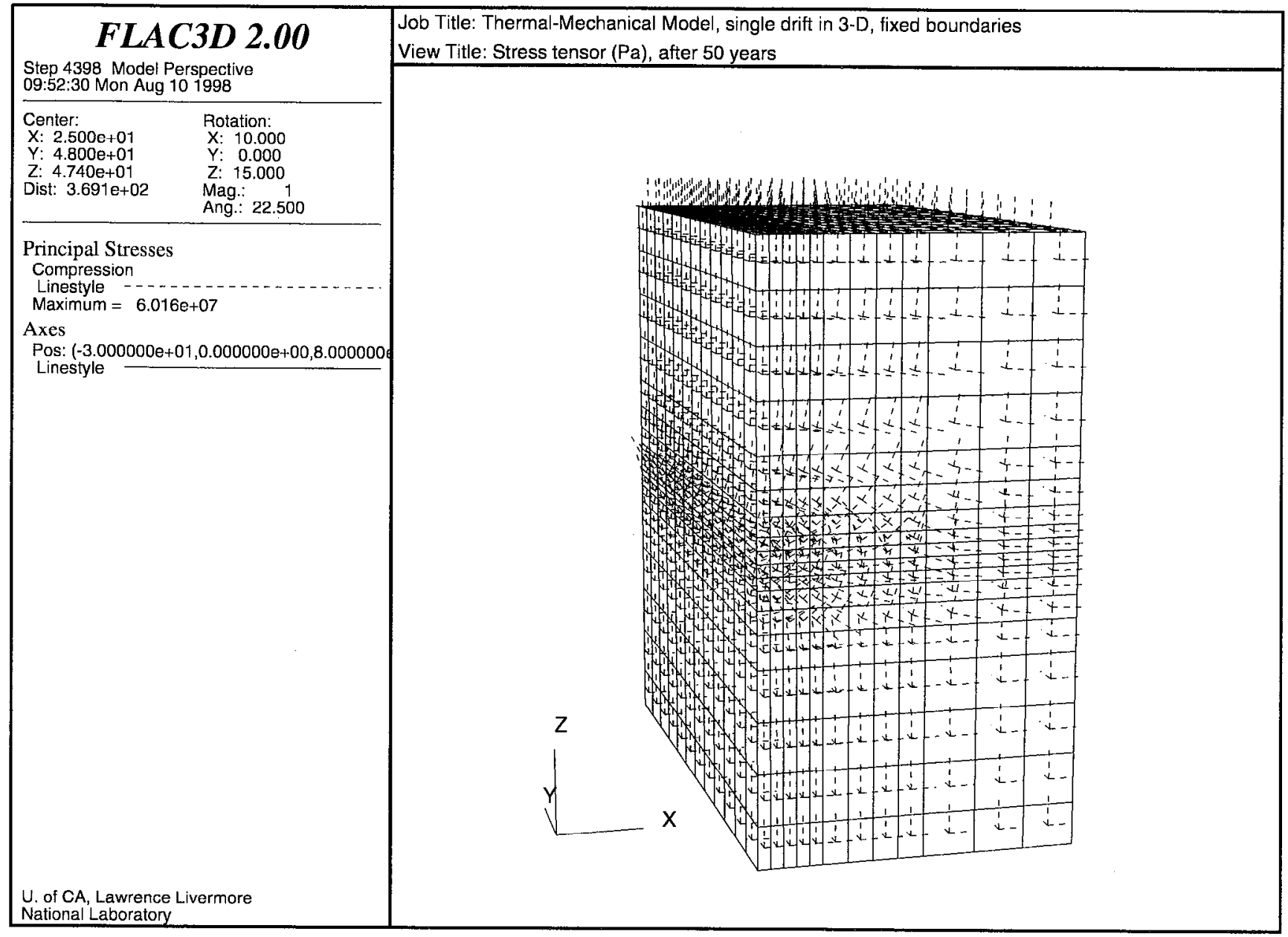

Figure B13. Stress tensor after 50 yr of heating for second case having fixed boundaries, view for entire model (DTN LL980805604243.023) 


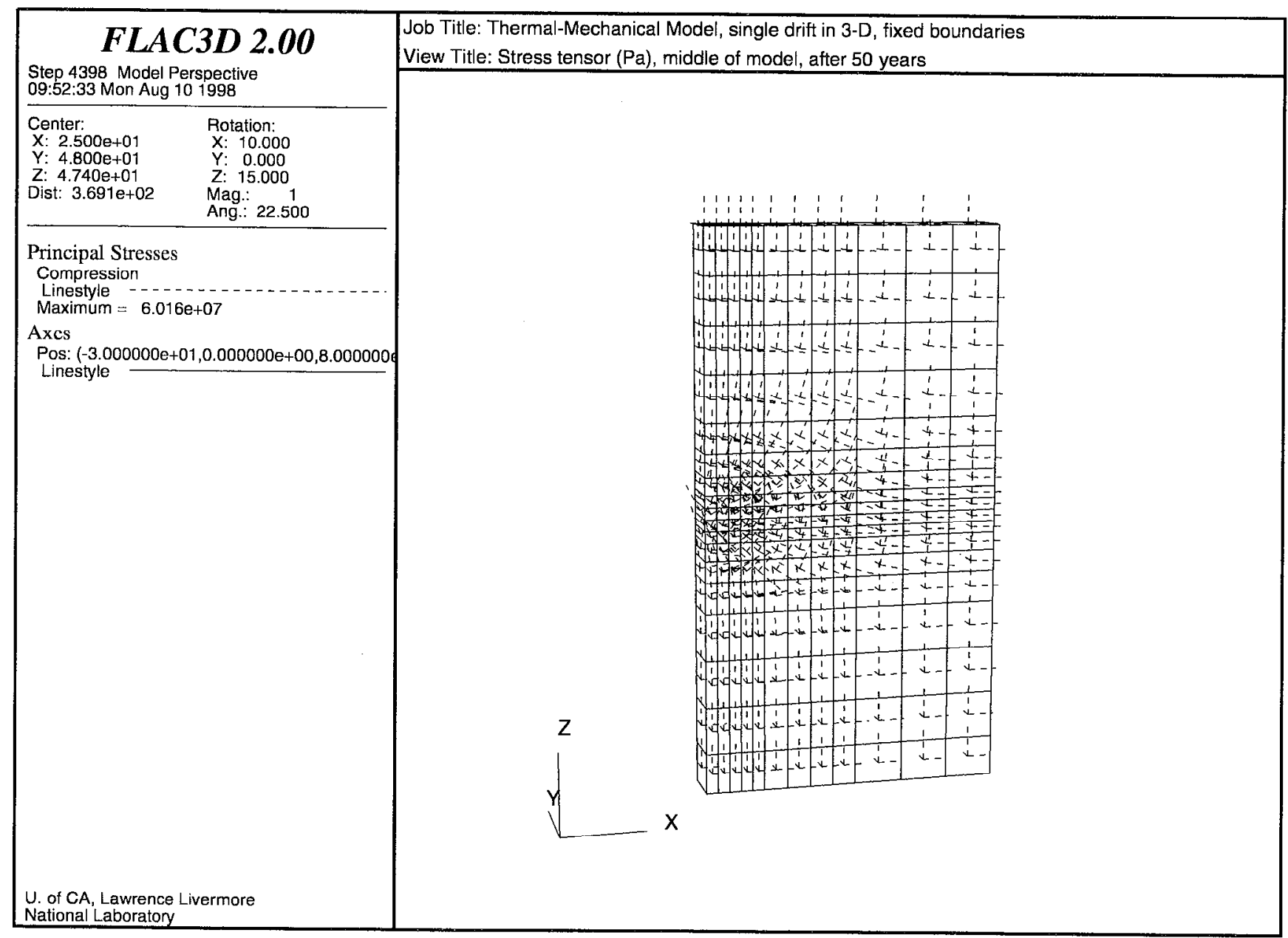

Figure B14. Stress tensor after 50 yr of heating for second case having fixed boundaries, view for region near center of model (DTN LL980805604243.023) 


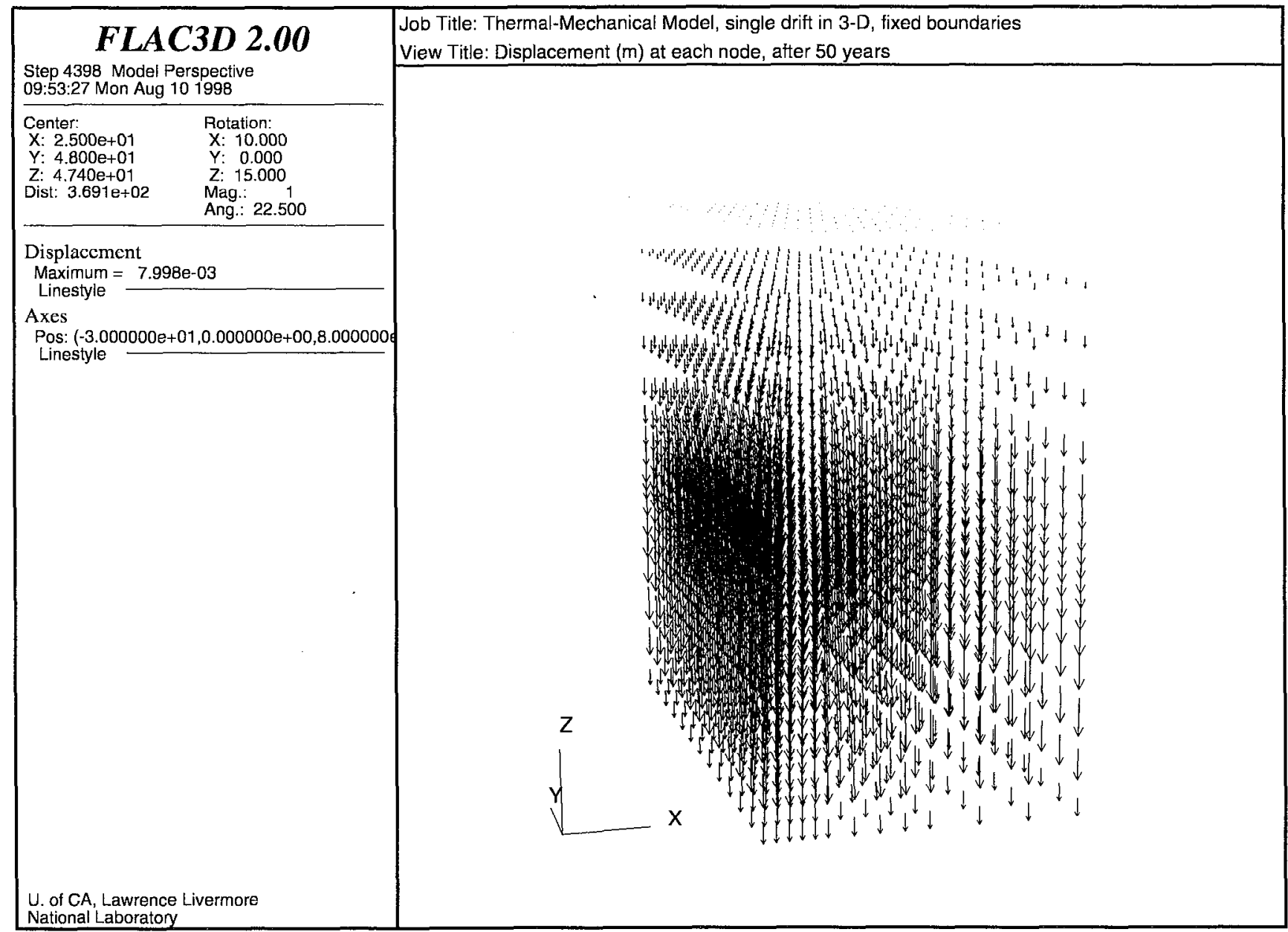

Figure B15. Displacement vectors at each node of model after $50 \mathrm{yr}$ of heating for second case having fixed boundaries (DTN LL980805604243.023) 


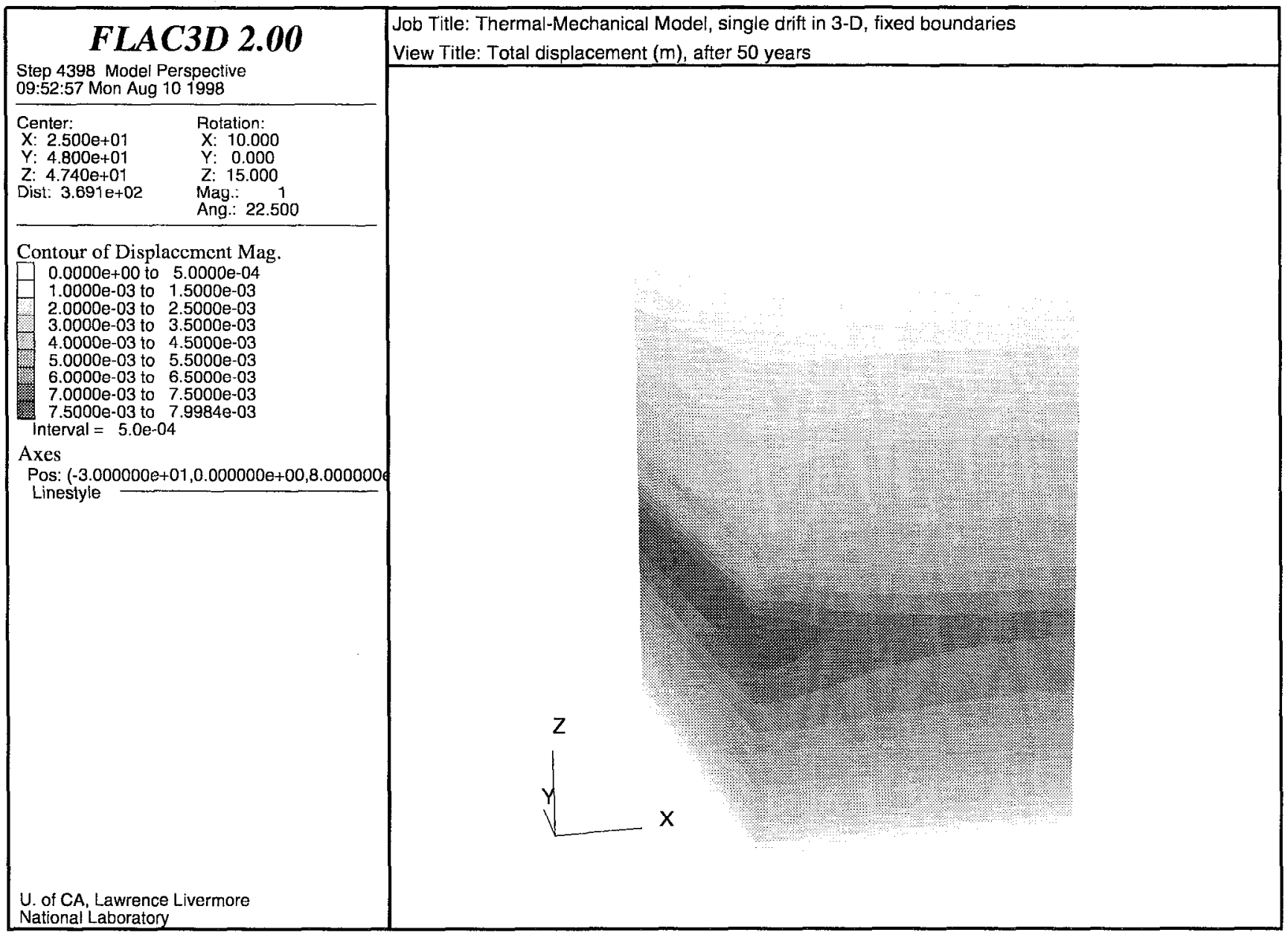

Figure B16. Model for .5 drift in 3-D, total displacement after 50 yr of heating for second case having fixed boundaries (DTN LL980805604243.023) 